NBER WORKING PAPER SERIES

\title{
PRODUCT AND LABOR MARKET IMPERFECTIONS AND SCALE ECONOMIES: MICRO-EVIDENCE ON FRANCE, JAPAN AND THE NETHERLANDS
}

\author{
Sabien Dobbelaere \\ Kozo Kiyota \\ Jacques Mairesse \\ Working Paper 19059 \\ http://www.nber.org/papers/w19059
NATIONAL BUREAU OF ECONOMIC RESEARCH
1050 Massachusetts Avenue
Cambridge, MA 02138
May 2013

We are grateful to Christopher Baum, Björn Brügemann, Masahisa Fujita, Kyoji Fukao, Michihiro Kandori, Bas van der Klaauw, José Luis Moraga-González, Masayuki Morikawa, Mark Schaffer, Ayumu Tanaka and other participants at various conferences and seminars for helpful comments and suggestions. The analysis using the French firm-level data was conducted at "Centre de Recherche en Économie et Statistique" (CREST) and the one using the Japanese firm-level data at the Research Institute of Economy, Trade and Industry (RIETI). The authors would like to thank Statistics Netherlands for providing the Dutch data. Kiyota acknowledges financial support from the Japan Society for the Promotion of Science (Grant-in-aid A-22243023). The views expressed herein are those of the authors and do not necessarily reflect the views of the National Bureau of Economic Research.

NBER working papers are circulated for discussion and comment purposes. They have not been peerreviewed or been subject to the review by the NBER Board of Directors that accompanies official NBER publications.

(C) 2013 by Sabien Dobbelaere, Kozo Kiyota, and Jacques Mairesse. All rights reserved. Short sections of text, not to exceed two paragraphs, may be quoted without explicit permission provided that full credit, including $\odot$ notice, is given to the source. 
Product and labor market imperfections and scale economies: Micro-evidence on France, Japan and the Netherlands

Sabien Dobbelaere, Kozo Kiyota, and Jacques Mairesse

NBER Working Paper No. 19059

May 2013, Revised June 2015

JEL No. C23,D21,J50,L13

\section{ABSTRACT}

Allowing for three labor market settings (perfect competition or right-to-manage bargaining, efficient bargaining and monopsony), this paper relies on two extensions of Halls econometric framework for estimating simultaneously price-cost margins and scale economies. Using an unbalanced panel of 17,653 firms over the period 1986-2001 in France, 8,728 firms over the period 1994-2006 in Japan and 7,828 firms over the period 1993-2008 in the Netherlands, we first apply two procedures to classify 30 comparable manufacturing industries in 6 distinct regimes that differ in terms of the type of competition prevailing in product and labor markets. For each of the predominant regimes in each country, we then investigate industry differences in the estimated product and labor market imperfections and scale economies. Consistent with differences in institutions and in the industrial relations system in the three countries, we find important regime differences across the three countries and also observe differences in the levels of product market imperfections and scale economies within regimes.

Sabien Dobbelaere

Faculty of Economics and

Business Administration

VU University Amsterdam

De Boelelaan 1105

1081 HV AMSTERDAM

THE NETHERLANDS

and Tinbergen Institute (TI) and IZA

sabien.dobbelaere@vu.nl

Kozo Kiyota

Keio University

Keio Economic Observatory

2-15-45, Mita, Minato-ku

108-8345 TOKYO

JAPAN

and RIETI

kiyota@sanken.keio.ac.jp
Jacques Mairesse

CREST (ParisTech-ENSAE)

15, Boulevard Gabriel PERI

92245 MALAKOFF CEDEX

FRANCE

and UNU-MERIT (Maastricht University)

and also NBER

mairesse@ensae.fr 


\section{Introduction}

A well-established result from welfare economic theory is that absent market failures, the unfettered market outcome is economically efficient. In reality, few if any markets are perfect in the sense that they satisfy the assumptions underlying textbook models of perfect competition or yield the performance of hypothetical perfectly competitive markets. The pervasiveness of deviations from economically efficient choices is often used as a rationale for public policy. The decision to (de)regulate or change regulatory policies must -among other things- be based on a careful identification of market failures. Indeed, identifying market failures and choosing appropriate policy instruments to mitigate them have been at the core of policy analysis for decades (Weimer and Vining, 2005; Kleiman and Teles, 2008; Koske et al., 2014). This paper focuses on the identification and quantification of one potential type of market failure, namely market power in product and labor markets. This allows us to evaluate how actual product and labor markets deviate from their perfectly competitive or economically efficient counterparts.

More specifically, combining firm, industry and country-level perspectives for three countries, our analysis serves the purpose of quantifying industry differences in product and labor market imperfections and scale economies using firm-level data in France, Japan and the Netherlands. The cross-country (cross-industry) comparison is motivated by the fact that resource allocative efficiency differs across countries. The selection of countries is driven by the following two reasons. First, there exist inherent institutional, organizational and cultural differences between France, Japan and the Netherlands, making our comparative study particularly relevant. Second, highly comparable microdata sets are available in these countries, allowing us to conduct a reliable international comparative study. ${ }^{1}$ Do manufacturing industries in the three countries under consideration belong to different regimes characterizing the type of competition prevailing in product and labor markets? To what extent do manufacturing industries within a particular regime differ in the degree of imperfections in the product and labor markets in which they operate? These are the main questions that we address.

In this paper, we rely on two extensions of Hall's (1988) econometric framework for estimating simultaneously price-cost margins and scale economies using firm panel data that take into account imperfections in the labor market. Instead of imposing a particular labor market setting on the data -a common practice in empirical studies estimating labor market imperfections- we follow Dobbelaere and Mairesse (2013) and use econometric production functions as a tool for testing the competitiveness of product and labor markets and evaluating their degree of imperfection. We consider two product market settings (perfect competition $(P C)$ and imperfect competition $(I C)$ ) and three labor market settings (perfect competition or right-tomanage bargaining $(P R)$, efficient bargaining $(E B)$ and monopsony $(M O))$. We thus distinguish six regimes. This tractable econometric method only requires data on production values, factor inputs and factor costs to classify economic entities in the six different regimes. Therefore, it proves particularly useful in our comparative setting.

Our empirical analysis is based on three large unbalanced panels of manufacturing firms: 17,653 firms over the period 1986-2001 in France, 8,728 firms over the period 1994-2006 in Japan and 7,828 firms over the

\footnotetext{
${ }^{1}$ For example, Bellone et al. (2014) use the same firm-level data for France and Japan to investigate productivity gaps between French and Japanese manufacturing industries.
} 
period 1993-2008 in the Netherlands. It consists of two parts. In the first part, we apply two procedures to classify 30 comparable manufacturing industries in distinct regimes that differ in terms of the type of competition prevailing in product and labor markets in each country. The first classification procedure is based on point estimates of our parameters of interest and enables a complete classification whilst the second is based on confidence intervals around estimated parameters which entails a more statistically correct -but incomplete- characterization of industries. Consistent with differences in the industrial relations system in the three countries, we observe important differences in the prevalent product and labor market settings, and hence in the prevalent regimes across the three countries. Irrespective of the classification procedure, we find that ( $i$ ) the proportion of industries (and firms) that is characterized by imperfect competition in the product market is much higher in France and the Netherlands than in Japan and (ii) the most prevalent labor market setting is efficient bargaining in France and perfect competition or right-to-manage bargaining in Japan and the Netherlands. As such, the dominant regime is one of imperfect competition in the product market and efficient bargaining in the labor market in France, one of perfect competition in the product market and perfect competition or right-to-manage bargaining in the labor market in Japan and one of imperfect competition in the product market and perfect competition or right-to-manage bargaining in the labor market in the Netherlands. In the second part, we investigate industry differences in the estimated product and labor market imperfection parameters within the predominant regimes in each country. In addition to the important cross-country regime differences that our analysis reveals, we also find differences in the levels of product market imperfections and scale economies within regimes.

From a methodological point of view, our analysis is most closely related to Dobbelaere and Mairesse (2013) and to some extent to Petrin and Sivadasan (2013). Both studies are based on the gap methodology, which is motivated by the observation that several phenomena move an economic entity away from the neoclassical setup where a variable input factor's estimated marginal product is equal to its measured payment. Paramount among these are economic factors like mark-ups, hiring, firing and search costs, variable factor utilization, factor adjustment costs and nonoptimal managerial behavior, and measurement errors. Using a sample of 10,646 manufacturing firms in France over the period 1978-2001, Dobbelaere and Mairesse (2013) provide a detailed industry- and firm-level analysis of product and labor market imperfections as two sources of discrepancies between the output contribution of individual production factors and their respective revenue shares. Using a sample of 5,000 manufacturing plants in Chile over the period 1982-1994, Petrin and Sivadasan (2013) estimate the gaps between an input's marginal product and its cost to infer the value of lost output arising from allocative inefficiency.

Our contribution to the econometric literature on estimating microeconomic production functions and the one on estimating simultaneously market imperfections in product and labor markets is threefold. First, given that we infer the type and the degree of market imperfections from consistent estimation of firm-level production functions, we discuss the methodological issues that arise when estimating microeconomic production functions (most notably simultaneity bias, selection bias and omitted price bias) and the direction of these possible biases. Second, we carefully check the sensitivity of our revealed product and labor market settings to the choice of estimator. Third, given that market imperfections are the norm but that misallocations in product and labor markets vary greatly across countries and across industries, our study is the first to investigate in what respects real-world product and labor markets deviate from perfectly-functioning markets 
in a comparative setting. By unraveling potential cross-country cross-industry differences, our analysis might deepen our understanding of sizeable variation in total factor productivity (TFP) across countries. ${ }^{2}$

We proceed as follows. Section 2 highlights some institutional characteristics in the three countries, thereby motivating the comparative nature of our study. Section 3 discusses the theoretical framework. Section 4 presents the firm panel data for France, Japan and the Netherlands. Section 5 discusses the estimation method. Section 6 elucidates the econometric implementation, applies two classification procedures to characterize the type of competition in the product and labor markets of our selected manufacturing industries and investigates the sensitivity of both classification procedures to four widely adopted estimators. Section 7 analyses industry differences in the degree of market imperfections within predominant regimes. Section 8 concludes.

\section{Institutional background}

Institutional and social norms vary greatly by country. Pursuing a highly comparable cross-country industry analysis is therefore valuable for understanding different patterns of economic phenomena across countries. This section briefly discusses some institutional characteristics of our selected countries which serve as background information for our econometric analysis.

During the last decade, OECD countries have extensively liberalized product markets and -as a consequencea convergence of regulation across OECD countries can be discerned. However, differences remain in the regulatory settings in France, Japan and the Netherlands that our comparative study may confirm. For example, the OECD overall indicator of product market anti-competitive regulations shows that the Netherlands is characterized by a level of anti-competitive restrictions that is significantly lower than the OECD average, while regulations in France and Japan are close to the OECD average. This is particularly true for domestic economic regulation which is related to public ownership, involvement in business operation and barriers to competition. In contrast, administrative regulation which is related to regulatory and administrative opacity and administrative burdens on startups appears to be less stricter in Japan (Wölfl et al., 2009, 2010).

On the labor market side, industrial relations differ considerably between France, Japan and the Netherlands. In all OECD countries, employees are represented in trade unions -which embody the traditional form of employee representation- and works councils which are organized at the company or establishment level. In Japan, trade union representation dominates while employee representation at the workplace occurs only through works councils in the Netherlands. France is characterized by a complex system of employee representation where both trade unions and elected representatives coexist. A unique feature of Japanese industrial relations is that unions are organized along enterprise lines. They are mainly concerned with the preservation of long-term employment contracts for regular employees, which is conducive to cooperative behavior (Verret, 2006; Noda and Hirano, 2013). In contrast, France and the Netherlands are characterized by industry-based unionism. In terms of union membership, trade union density is around the OECD average in Japan and the Netherlands (about 20\%), while the French trade union movement is among the weakest in the OECD

\footnotetext{
${ }^{2} \mathrm{~A}$ recent literature emphasizes resource misallocation across heterogeneous production units as an important source of large cross-country differences in measured TFP (Restuccia and Rogerson, 2008, 2013; Hsieh and Klenow, 2009).
} 
countries with only about $8 \%$ of employees in unions. French trade unions are divided into a number of rival confederations, competing for membership. However, union membership is not the only indicator of strength. Despite low membership and apparent division, French trade unions have repeatedly shown that they are able to mobilize workers in mass strikes and demonstrations to great effect. In France, negotiations are mostly held at the industry level which can be supplemented with bargaining agreements at the firm level. Since the government often extends the terms of industry-level agreements to all employers, collective bargaining coverage is very high (95\%). In the Netherlands, the proportion of employees covered by collective bargaining is also quite high and amounts to $85 \%$ (Venn, 2009). The fact that enterprise-based unions aim at defending the interests of unions members through collective bargaining and at concluding collective agreements that only cover their members explains the very low collective bargaining coverage in Japan (only 16\%). These institutional and organizational differences might shape firms' operational environment in general and the type of competition in product and labor markets in particular.

\section{Theoretical framework}

This section extends the framework of Hall (1988) for estimating price-cost margins and scale economies. To this end, we follow Dobbelaere and Mairesse (2013) by considering three labor market settings: perfect competition or right-to-manage bargaining (Nickell and Andrews, 1983), efficient bargaining (McDonald and Solow, 1981) and monopsony (Manning, 2003). ${ }^{3}$ This section contains the main ingredients of the theoretical framework. For technical details, we refer to Appendix A.

We start from a production function $Q_{i t}=\Theta_{i t} F\left(N_{i t}, M_{i t}, K_{i t}\right)$, where $i$ is a firm index, $t$ a time index, $N$ is labor, $M$ is material input and $K$ is capital. $\Theta_{i t}=A e^{\eta_{i}+u_{t}+v_{i t}}$, with $\eta_{i}$ an unobserved firm-specific effect, $u_{t}$ a year-specific intercept and $v_{i t}$ a random component, is an index of technical change or "true" total factor productivity. Denoting the logarithm of $Q_{i t}, N_{i t}, M_{i t}, K_{i t}$ and $\Theta_{i t}$ by $q_{i t}, n_{i t}, m_{i t}, k_{i t}$ and $\theta_{i t}$ respectively, the logarithmic specification of the production function gives:

$$
q_{i t}=\left(\varepsilon_{N}^{Q}\right)_{i t} n_{i t}+\left(\varepsilon_{M}^{Q}\right)_{i t} m_{i t}+\left(\varepsilon_{K}^{Q}\right)_{i t} k_{i t}+\theta_{i t}
$$

where $\left(\varepsilon_{J}^{Q}\right)_{i t}(J=N, M, K)$ is the elasticity of output with respect to input factor $J$.

Firms operate under imperfect competition in the product market $(I C)$. We allow for three labor market settings $(L M S)$ : perfect competition or right-to-manage bargaining $(P R)^{4}$, efficient bargaining $(E B)$ and monopsony $(M O)$. We assume that material input and labor are variable factors. Short-run profit maximization implies the following first-order condition with respect to material input:

$$
\left(\varepsilon_{M}^{Q}\right)_{i t}=\mu_{i t}\left(\alpha_{M}\right)_{i t}
$$

\footnotetext{
${ }^{3}$ As noted in Booth (2014), these imperfectly competitive labor market models can be viewed as polar extremes and are both intuitively appealing and tractable.

${ }^{4}$ Our framework does not allow to disentangle perfect competition in the labor market from right-to-manage bargaining. In both settings, labor is unilaterally determined by the firm from profit maximization, i.e. the wage rate equals the marginal revenue of labor (see Section A.1 in Appendix A).
} 
where $\left(\alpha_{M}\right)_{i t}=\frac{j_{i t} M_{i t}}{P_{i t} Q_{i t}}$ is the share of material costs in total revenue and $\mu_{i t}=\frac{P_{i t}}{\left(C_{Q}\right)_{i t}}$ refers to the mark-up of output price $P_{i t}$ over marginal cost $\left(C_{Q}\right)_{i t}$. Depending on the prevalent $L M S$, short-run profit maximization implies the following first-order condition with respect to labor:

$$
\begin{array}{rlr}
\left(\varepsilon_{N}^{Q}\right)_{i t} & =\mu_{i t}\left(\alpha_{N}\right)_{i t} \quad \text { if } L M S=P R & \\
& =\mu_{i t}\left(\alpha_{N}\right)_{i t}-\mu_{i t} \gamma_{i t}\left[1-\left(\alpha_{N}\right)_{i t}-\left(\alpha_{M}\right)_{i t}\right] \quad \text { if } L M S=E B \\
& =\frac{\mu_{i t}\left(\alpha_{N}\right)_{i t}}{\beta_{i t}} \quad \text { if } L M S=M O &
\end{array}
$$

where $\left(\alpha_{N}\right)_{i t}=\frac{w_{i t} N_{i t}}{P_{i t} Q_{i t}}$ is the share of labor costs in total revenue. $\gamma_{i t}=\frac{\phi_{i t}}{1-\phi_{i t}}$ represents the relative extent of rent sharing, $\phi_{i t} \in[0,1]$ the absolute extent of rent sharing, $\beta_{i t}=\frac{\left(\varepsilon_{w}^{N}\right)_{i t}}{1+\left(\varepsilon_{w}^{N}\right)_{i t}}$ and $\left(\varepsilon_{w}^{N}\right)_{i t} \in \Re_{+}$the wage elasticity of the labor supply. From the first-order conditions with respect to material input and labor, it follows that the parameter of joint market imperfections $\left(\psi_{i t}\right)$ :

$$
\begin{aligned}
\psi_{i t} & =\frac{\left(\varepsilon_{M}^{Q}\right)_{i t}}{\left(\alpha_{M}\right)_{i t}}-\frac{\left(\varepsilon_{N}^{Q}\right)_{i t}}{\left(\alpha_{N}\right)_{i t}} \\
& =0 \quad \text { if } L M S=P R \\
& =\mu_{i t} \gamma_{i t}\left[\frac{1-\left(\alpha_{N}\right)_{i t}-\left(\alpha_{M}\right)_{i t}}{\left(\alpha_{N}\right)_{i t}}\right]>0 \quad \text { if } L M S=E B \\
& =-\mu_{i t} \frac{1}{\left(\varepsilon_{w}^{N}\right)_{i t}}<0 \quad \text { if } L M S=M O
\end{aligned}
$$

Assuming that the elasticity of scale, $\lambda_{i t}=\left(\varepsilon_{N}^{Q}\right)_{i t}+\left(\varepsilon_{M}^{Q}\right)_{i t}+\left(\varepsilon_{K}^{Q}\right)_{i t}$, is known, the capital elasticity can be expressed as:

$$
\left(\varepsilon_{K}^{Q}\right)_{i t}=\lambda_{i t}-\left(\varepsilon_{N}^{Q}\right)_{i t}-\left(\varepsilon_{M}^{Q}\right)_{i t}
$$

Inserting Eqs. (2), (6) and (10) in Eq. (1) and rearranging terms gives:

$$
q_{i t}=\mu_{i t}\left[\left(\alpha_{N}\right)_{i t}\left(n_{i t}-k_{i t}\right)+\left(\alpha_{M}\right)_{i t}\left(m_{i t}-k_{i t}\right)\right]+\psi_{i t}\left(\alpha_{N}\right)_{i t}\left(k_{i t}-n_{i t}\right)+\lambda_{i t} k_{i t}+\theta_{i t}
$$

\section{Data description}

Our modified production function framework only requires data on production values, factor inputs and factor costs. This section presents the micro data in the three countries.

The French data are based on firm accounting information from EAE ("Enquête Annuelle d'Entreprise", "Service des Etudes et Statistiques Industrielles" (SESSI)). The Japanese data are sourced from the confidential micro database of the "Kigyou Katsudou Kihon Chousa Houkokusho" (Basic Survey of Japanese Business Structure and Activities (BSJBSA)) collected annually by the Research and Statistics Department (METI). ${ }^{5}$ The survey is compulsory for firms with more than 50 employees and with capital of more than 30 million yen. The Dutch data are sourced from the Production Surveys (PS) at Statistics Netherlands which are collected annually by the "Centraal Bureau voor de Statistiek" (CBS). A combination of census and stratified random sampling is used for each wave of the PS. A census is used for the population of enterprises

\footnotetext{
${ }^{5}$ For details on the Japanese data, we refer to Kiyota et al. (2009).
} 
with at least fifty employees and a stratified random sampling is used for enterprises with fewer than fifty employees. The stratum variables are the economic activity and the number of employees of an enterprise. For each country, our estimation sample is restricted to firms having at least four consecutive observations. After some trimming on input shares in total revenue and input growth rates to eliminate outliers and anomalies, we end up with an unbalanced panel of 17,653 firms covering the period 1986-2001 in France $(F R)$, 8,728 firms spanning the period 1994-2006 in Japan $(J P)$ and 7,828 firms over the period 1993-2008 in the Netherlands $(N L)$. Table B.1 in Appendix B gives the panel structure of the estimation sample by country.

Output $(Q)$ is defined as current production deflated by the two-digit producer price index in $F R$ and real gross output measured by nominal sales divided by the industry-level gross output price index in $J P$ and $N L{ }^{6}$ Labor $(N)$ refers to the average number of employees in $F R$ and $J P$, and the number of employees in September of a given year in $N L$. Material input is defined as intermediate consumption deflated by the industry-level intermediate consumption price index in the three countries. The capital stock $(K)$ is measured by the gross bookvalue of fixed assets in $F R$, computed from tangible assets and investment based on the perpetual inventory method in $J P^{7}$ and proxied by depreciation of fixed assets deflated by the industry-level gross fixed capital formation price index for all assets in $N L$. The price deflators for $J P$ are obtained from the Japan Industrial Productivity (JIP) 2009 database, which was compiled by RIETI and Hitotsubashi University. ${ }^{8}$ The price deflators for $N L$ are obtained from the EUKLEMS database (November 2009 release, March 2011 update). The shares of labor $\left(\alpha_{N}\right)$ and material input $\left(\alpha_{M}\right)$ are constructed by dividing respectively the firm total labor cost and undeflated intermediate consumption by the firm undeflated production and by taking the average of these ratios over adjacent years.

Table 1 reports the means, standard deviations and quartile values of our main variables by country. The average growth rate of real firm output is $3.3 \%$ per year in $F R, 2.0 \%$ in $J P$ and $2.5 \%$ in $N L$. In $F R$, labor, materials and capital have increased at an average annual growth rate of $1.4 \%, 4.9 \%$ and $0.8 \%$ respectively. In $J P$, labor and capital have decreased at an average annual growth rate of $0.3 \%$, while materials has increased at an average annual growth rate of $1.3 \%$. In $N L$, labor, materials and capital have increased at an average annual growth rate of $0.4 \%, 2.6 \%$ and $1.6 \%$ respectively. The Solow residual or the conventional measure of TFP is stable over the considered period in each country. As expected for firm-level data, the dispersion of all these variables is considerably large. For example, TFP growth is lower than $-5.2 \%(-2.2 \%)[-4.3 \%]$ for the first quartile of firms and higher than $5.9 \%(4.2 \%)[5.9 \%]$ for the upper quartile in $F R(J P)[N L]$.

\section{$<$ Insert Table 1 about here $>$}

\footnotetext{
${ }^{6}$ As in many firm-level datasets, we observe firm-level revenues and not prices and quantities separately. The productivity literature is dominated by two approaches to deal with this issue. One approach deflates firm-level revenues by an industrylevel price index and thus estimates a revenue production function rather than an output production function. The other approach follows Klette and Griliches (1996) which amounts to adding the growth in industry output as an additional regressor. Theoretically, this approach relies on the assumption that the market power of firms originates from product differentiation. Intuitively, in the case of product differentiation, the demand for an individual firm's products is a function of its relative price within the industry. Relative price differences can then be expressed in terms of relative output growth differences in the industry. We follow the predominant approach in the literature and use the former.

${ }^{7}$ Details on the measurement of the user cost of capital can be found in Section B.1 in Appendix B.

${ }^{8}$ For more details on the JIP database, see Fukao et al. (2007).
} 


\section{$5 \quad$ Estimation method}

We use econometric production functions as a tool for testing the competitiveness of product and labor markets and for assessing their degree of imperfection, not only for estimating factor elasticities and total factor productivity as has been common practice in the econometric literature on estimating microeconomic production functions.

Consistent estimation of the output contribution of individual production factors is non trivial because firms choose inputs knowing their own productivity level, which is unobservable to the econometrician. First discussed by Marschak and Andrews (1944), this endogeneity problem -known in the literature as the simultaneity/transmission bias- has fuelled formidable advances in econometric methods and practices. This section aims at investigating the sensitivity of production function coefficient, scale elasticity and product and labor market imperfection estimates to four widely adopted estimators: (i) the ordinary least squares (OLS) estimator, (ii) the within-group fixed-effects (FE) estimator, (iii) the system generalized method of moments (SYS-GMM) estimator and (iv) the Wooldridge-Levinsohn-Petrin estimator. ${ }^{9}$ To this end, we follow most of the literature by estimating average parameters:

$$
q_{i t}=\varepsilon_{N}^{Q} n_{i t}+\varepsilon_{M}^{Q} m_{i t}+\varepsilon_{K}^{Q} k_{i t}+u_{t}+\zeta_{i t}
$$

with $\zeta_{i t}=\omega_{i t}+\epsilon_{i t}$. Of the error components, $\omega_{i t}$ represents unobserved productivity to the econometrician but possible observed by the firm at $t$ when input decisions are made (transmitted productivity shock), while $\epsilon_{i t}$ captures all other sources of error or productivity that is not observed by the firm before making input choices at $t . u_{t}$ is a year-specific intercept.

Because of the potential correlation between $\omega_{i t}$ and the inputs chosen at $t$, the $O L S$ estimator (which assumes that the moments of the regressors with the disturbances are zero) produces inconsistent estimates.

If one is willing to assume that the productivity shock is constant over time $\left(\omega_{i t}=\omega_{i}\right)$, the endogeneity problem can be solved by exploiting the panel structure of the data and using the $F E$ estimator, which is a method of moments estimator based on the data after subtracting off time averages. However, this solution has produced unsatisfactory results. Typically, the coefficient on capital and returns to scale are estimated implausibly low (see e.g. Griliches and Mairesse, 1998). ${ }^{10}$

A general approach to estimating error components models designed for panels with few time periods and many individuals, covariates that are not strictly exogenous, unobserved heterogeneity, heteroskedasticity and autocorrelation within individuals was developed by Arellano and Bover (1995) and Blundell and Bond (1998) (SYS-GMM estimator). This approach extends the standard (first-differenced) GMM estimator of

\footnotetext{
${ }^{9}$ The purpose of this section is to provide some intuition behind the selected estimators. We refer the reader to the original papers mentioned in this section or textbooks for details on the econometric methods and to Section A.2 in Appendix A for a discussion of the semiparametric structural control function approach as an alternative to the parametric GMM approach to deal with endogeneity of inputs and unobserved productivity.

${ }^{10}$ First-differencing -another common method of eliminating the unobserved individual effects- usually produces even smaller production function coefficients due to the presence of measurement error. See also Mairesse (1990) and Griliches and Hausman (1986).
} 
Arellano and Bond (1991) -which eliminates unobserved firm-specific effects by taking first differences- by relying on a richer set of orthogonal conditions. ${ }^{11}$ The error components are an unobserved fixed effect $\left(\eta_{i}\right)$, a possibly autoregressive productivity shock $\left(\omega_{i t}=\rho \omega_{i t-1}+\xi_{i t}\right.$ with $\left.|\rho|<1\right)$ and serially uncorrelated measurement errors $\left(\epsilon_{i t}\right)$, with $\xi_{i t}, \epsilon_{i t} \sim i . i . d$. Consistent with our static theoretical framework, we estimate the restricted version of the Blundell-Bond model and only consider idiosyncratic productivity shocks (imposing $\rho=0) .{ }^{12}$ We apply the two-step $G M M$ estimator which is asymptotically more efficient than the one-step $G M M$ estimator and which is robust to whatever patterns of heteroskedasticity and cross-correlation. We use a finite-sample correction to the two-step covariance matrix developed by Windmeijer (2005). The validity of $G M M$ crucially hinges on the assumption that the instruments are exogenous. We report both the Sargan and Hansen test statistics for the joint validity of the overidentifying restrictions. ${ }^{13,14}$ In addition, we provide difference-in-Hansen statistics to test the validity of subsets of instruments.

Fundamental to the control function $(C F)$ approach is to use firm decisions to find proxy variables for the transmitted productivity shock $\left(\omega_{i t}\right)$ and use information in these proxy variables to invert out unobserved productivity $\omega_{i t}$ from the residual. Olley and Pakes (1996) (OP for short) use the investment decision to proxy for $\omega_{i t}$ whereas Levinsohn and Petrin (2003) ( $L P$ for short) use an intermediate input demand function to invert out $\omega_{i t}$. As noted by Ackerberg et al. (2006) (ACF for short) and Bond and Söderbom (2005), collinearity between labor and the non-parametric inverse of $\omega_{i t}$ (i.e. the control function) causes the production coefficient of labor to be nonparametrically unidentified in the first stage. $A C F$ propose a hybrid of the $O P$ and $L P$ approaches. They implement a two-stage estimator that resolves the firststage collinearity problem by only separating the untransmitted productivity shock $\left(\epsilon_{i t}\right)$ from the production function in the first stage and consistently estimating all production function coefficients in the second stage. Wooldridge (2009) modifies the $L P$ approach ( $W$-LP for short) by writing the moment restrictions used by $L P$ in terms of two equations with the same dependent variable but different instrument sets and applying generalized method of moments. The main advantages of this one-step approach compared to the $A C F$ two-step estimation procedure are $(i)$ obtaining robust standard errors in the standard GMM framework,

\footnotetext{
${ }^{11}$ The Arellano-Bover/Blundell-Bond estimator assumes that the first differences of the instrumental variables are uncorrelated with the fixed effects, which allows the introduction of more instruments which might improve efficiency dramatically. It was successfully applied within a production function framework by Blundell and Bond (2000).

${ }^{12}$ Considering only labor as a variable input factor, Blundell and Bond (2000) estimate a dynamic common factor respresentation of a Cobb-Douglas production function: $q_{i t}=\varepsilon_{N}^{Q} n_{i t}-\rho \varepsilon_{N}^{Q} n_{i t-1}+\varepsilon_{M}^{Q} m_{i t}-\rho \varepsilon_{M}^{Q} m_{i t-1}+\varepsilon_{K}^{Q} k_{i t}-\rho \varepsilon_{K}^{Q} k_{i t}+\left(u_{t}-\rho u_{t-1}\right)+$ $\left(\eta_{i}(1-\rho)+\xi_{i t}+\epsilon_{i t}-\rho \epsilon_{i t-1}\right)$. Table 2 in Dobbelaere and Mairesse (2013) presents estimates of a dynamic specification of our modified production function.

${ }^{13}$ We build sets of instruments following the Holtz-Eakin et al. (1988)-approach which avoids the standard two-stage least squares trade-off between instrument lag depth and sample depth by including separate instruments for each time period and substituting zeros for missing observations. However, the $S Y S-G M M$ estimator might generate moment conditions prolifically with the instrument count quadratic in the time dimension of the panel. To avoid instrument proliferation, we only use 2- and 3 -year lags of the instrumented variables as instruments in the first-differenced equation and the 1-year lag of the first-differenced instrumented variables as instruments in the original equation. The use of past levels and differences of inputs as instruments for current inputs can be theoretically justified through adjustment costs generating dependence of current input levels on past realizations of productivity shocks (see Bond and Söderbom, 2005).

${ }^{14}$ We opt to report both the Sargan and the Hansen statistics after the two-step estimations since the Sargan tests do not depend on an estimate of the optimal weighting matrix and are hence not so vulnerable to instrument proliferation. On the other hand, they require homoskedastic errors for consistency which is not likely to be the case. As documented by Andersen and Sørensen (1996) and Bowsher (2002), instrument proliferation might weaken the Hansen test of instrument validity to the point where it generates implausibly good $p$-values (see Roodman, 2009 for a discussion).
} 
(ii) generating more efficient estimates by using the cross-equation correlation and an optimal weighting matrix accounting for serial correlation and heteroskedasticity and (iii) allowing for straightforward testing of overidentification restrictions. As usually done, we approximate the unobserved productivity shock by a third-order polynomial in material costs and capital.

Besides the simultaneity bias, other methodological issues emerge when estimating microeconomic production functions, most notably omitted price bias, selection bias/endogeneity of attrition and measurement error. To deal with these methodological issues, several estimators have been proposed. ${ }^{15}$ Like most researchers, we do not observe firm-level price indices. As noted in the previous section, we deflate firm-level nominal sales and input expenditures by an industry price index. If firms face downward-sloping demands, a negative correlation might arise between firm-level price deviations (from the average price index) and input choices. As a result, the production function estimates of the variable inputs could be biased downward. De Loecker (2011) implements the correction for the omitted output price bias developed by Klette and Griliches (1996) ( $K G$ for short) in the $O P$ estimation algorithm. ${ }^{16,17}$ Relaxing the $K G$ assumption of equal demand elasticities across firms within industries and allowing for differentiated products in both output and inputs markets, Katayama et al. (2009) propose a -more flexible but less straightforward in terms of practical implementationnonparametric Bayesian approach to resolve the omitted (output and input) price bias. ${ }^{18}$ The omitted price bias might work in the opposite direction than the simultaneity bias, making any prior on the net direction of the bias difficult.

Intuitively, the selection bias arises because a firm decides on the allocation of inputs in a particular period conditional on its survival. A firm's knowledge about its productivity level $\left(\omega_{i t}\right)$ prior to making exit decisions generates a negative correlation between $\omega_{i t}$ and $k_{i t}$ conditional on continuing since a firm with a higher capital level will ceteris paribus be able to withstand a lower $\omega_{i t}$ without exiting (Ackerberg et al., 2007). As a result, our capital coefficient could be biased downward. We argue, however, that this bias is mitigated by using unbalanced panels which take entry and exit implicitly into account. The $O P$ estimation algorithm takes explicitly both the endogeneity and the selection problem into account.

The presence of measurement error (errors-in-variables or errors-in-regressors) causes biased and inconsistent parameter estimates. As shown by Griliches and Hausman (1986) and Wansbeek (2001), panel data allow correction for measurement error without assuming a known measurement error covariance matrix or using

\footnotetext{
${ }^{15}$ We opt to give some intuition on the possible direction of these biases rather than discussing these estimators at length or evaluating the sensitivity of microeconomic production function estimates to these estimators. For a descriptive overview of these issues, we refer to Van Beveren (2012).

${ }^{16}$ In the case of imperfectly competitive output markets, controlling for firm-level unobserved output prices controls at least partly for firm-level unobserved input prices since higher input prices will be passed through a higher output price (De Loecker, 2011).

${ }^{17}$ Crépon et al. (2005) implement the Klette and Griliches (1996) solution in a simplified version of our framework. Other studies related to the omitted price bias include Dunne and Roberts (1992), Griliches and Mairesse (1998), Melitz (2001), Mairesse and Jaumandreu (2005), Jaumandreu and Mairesse (2006), Levinsohn and Melitz (2006), Foster et al. (2008) and Syverson (2011).

${ }^{18}$ Other studies resolving the omitted input and output price bias by exploiting firm-level variation in output and input prices are Eslava et al. (2004) and Ornaghi (2006, 2008).
} 
additional validation/replication data to estimate the measurement error covariance matrix. ${ }^{19}$

Finally, our production function estimates could be biased by the presence of adjustment costs in inputs. In particular, assuming that labor and materials are variable input factors free of adjustment costs (i.e. decided at production time when $\omega_{i t}$ is observed by the firm) could generate an upward bias in the respective production function coefficients. ${ }^{20}$ However, by estimating average production function coefficients, we argue that this effect should be limited. Note that although our estimation method might wash out firm-level differences in adjustment costs which are temporary in nature, country- and industry-level differences in adjustment costs which are permanent/structural in nature might still remain. ${ }^{21}$

It is clear that the methodologies discussed above are based on different statistical and economic assumptions. Since we are primarily interested in retrieving consistent production function coefficients based on three different micro datasets rather than an accurate measure of productivity, we judge the $S Y S$-GMM estimator to be the most appropriate one among the four selected estimators. We put forward the following arguments. First, the $S Y S-G M M$ estimator generates consistent estimates incorporating firm fixed effects $\left(\eta_{i}\right)$. Second, following the structural estimation approach building on an inverse productivity function, the $W$ - $L P$ estimator relies on a larger set of assumptions regarding input demand equations, such as strict monotonicity and scalar unobservable assumptions. Third, there is an efficiency gain from using the $S Y S-G M M$ estimator rather than an instrumental variables $(I V)$ estimation using $G M M$. The $S Y S-G M M$ estimator allows the projection on the instruments to be different for every year whereas the $W$-LP estimator constrains it to be the same. This different method for constructing instruments drives the difference in number of observations between the $S Y S-G M M$ and $W$-LP estimation samples. Applying the $W$-LP estimator results in a loss of $36 \%-50 \%$ of our observations. ${ }^{22}$

For illustrative purposes, we assume homogeneity of the production technology across all firms. Table B.2 in Appendix B presents the estimates of production function coefficients, scale elasticity and product and labor market imperfection parameters at the manufacturing level for the four selected estimators. Focusing first on the technology parameter estimates $\left(\widehat{\varepsilon}_{N}^{Q}, \widehat{\varepsilon}_{M}^{Q}\right.$ and $\left.\widehat{\varepsilon}_{K}^{Q}\right)$, we observe the following systematic patterns across countries which are in line with prior expectations. The $O L S$ estimate of the labor coefficient is the highest

\footnotetext{
${ }^{19}$ Xiao et al. (2010) unify Griliches and Hausman's and Wansbeek's methods by showing that both methods are asymptotically equivalent and computationally similar.

${ }^{20}$ Investigating the direction of this bias on all production function coefficients would require resorting to a dynamic specification of firm productivity changes (which is beyond the scope of our analysis) or data on capacity utilization or working hours (which are not available in our datasets). Bond and Van Reenen (2007) survey recent microeconometric studies on investment and employment using firm-level or plant-level data, thereby focusing on the adjustment processes for both capital and labor.

${ }^{21}$ Cahuc and Zylberberg (2004) point out that high firing costs tend to raise wages (if the workers are already employed) because firms will face the costs when the workers separate from firms. As firing costs are higher in $F R$ than in $J P(O E C D$, $2004)$, the reservation wage -for workers who have already been employed- will be systematically higher in $F R$ than in $J P$, which could raise the elasticity of output with respect to labor in $F R$ compared to $J P$. We consider investigating this issue as an interesting avenue for future research but beyond the scope of this paper.

${ }^{22}$ More specifically, to obtain the SYS-GMM estimates, we follow the literature and use the "xtabond 2"-routine in Stata, which performs two-step efficient GMM estimation using Holtz-Eakin et al. (1988)-type of instruments. The $W$ - $L P$ estimator is programmed with a single line of code in Stata (made available on Amil Petrin's website) and implements an $I V$ using textbook two-step efficient GMM. In contrast to the xtabond2-routine, there is no building of Holtz-Eakin et al. (1988)-instruments as such.
} 
among all estimators. This is consistent with an upward bias in $O L S$ estimates due to the transmission problem. The $S Y S-G M M$ estimator yields the highest estimate for the material input coefficient while the largest capital coefficient estimate is found using the $W-L P$ estimator. Note that the capital coefficient estimates using the $W-L P$ estimator are far too large, especially for $J P$ and $N L$. One potential reason could be that this estimator is based on a set of assumptions regarding input demand equations that do not fit the data very well in these countries. For $J P$ and $N L$, we find the lowest capital coefficient estimate when accounting for firm-level fixed effects while ignoring any further impact of heterogeneous productivity shocks ( $F E$ estimator). This downward bias in the capital coefficient might reflect that measurement error in the capital variable affects the capital coefficient more severely in the within transformation where a large share of variability is taken out of the data. Consequently, decreasing returns to scale are found when applying the $F E$ estimator.

How do variation in technology parameter estimates affect the joint market imperfection parameter estimate $(\widehat{\psi})$ which determines the prevalent regime? Irrespective of the selected estimator, we infer from $\widehat{\psi}$ that the $I C$-EB-regime applies at the manufacturing level in $F R$ and $J P$. This regime stability is not confirmed for $N L$, which is due to a combination of relatively narrowly dispersed labor coefficient estimates and relatively widely dispersed material input coefficient estimates across estimators.

Focusing on our preferred estimator $(S Y S-G M M)$, we find that the three countries are characterized by $I C-E B$ at the manufacturing level. The price-cost mark-up is estimated at 1.229 in $F R, 1.184$ in $J P$ and 1.277 in $N L$. The absolute extent rent of rent-sharing is estimated at 0.598 in $F R, 0.672$ in $J P$ and 0.693 in $N L$. We find decreasing returns to scale in $F R$ while no evidence against constant returns to scale in $J P$ and $N L$. A crucial assumption of the validity of $G M M$ is that the instruments are exogenous. The Sargan and Hansen statistics test the joint validity of the moment conditions (identifying restrictions). For the three countries, both tests indicate that the null of exogeneity is rejected, thus rendering our instrumentation strategy invalid. As the Hansen test evaluates the entire set of overidentifying restrictions/instruments, it is particularly important to test the validity of subsets of instruments (levels and differenced) via the difference-in-Hansen tests. For $J P$, the difference-in-Hansen tests suggest that the 2- and 3-year lags of the inputs as instruments in the first-differenced equation may be to blame (exogeneity rejected) ${ }^{23}$ while the use of 1-year lagged first-differenced inputs as instruments in the levels equation does not prove informative for $N L$. While the Hansen test is usually considered as a test of instrument validity, it can also be thought of as a test of structural specification (Baum, 2006; Roodman, 2009). When the functional form of a model does not match the phenomenon it aims to describe or when important explanatory variables are missing, components of variation could be moved into the error term and make them correlated with the instruments. As our manufacturing samples contain heterogeneous firms from different industries, this problem might arise by imposing common slopes for the industries. If input choice is correlated with unobserved firmlevel production technology differences, this unaccounted heterogeneity might further introduce a bias in the production function coefficients. Following the tradition in the empirical industrial organization literature, these arguments greatly motivate our analysis at the industry level.

\footnotetext{
${ }^{23}$ Note however the implausibly perfect $p$-value of 1.000 of Dif-Hansen (lev).
} 


\section{Classification procedure}

This section focuses on the cornerstone of our analysis, i.e. the classification of comparable manufacturing industries in distinct regimes that differ in terms of the type of competition prevailing in product and labor markets in each country. First, we elucidate the econometric implementation and perform two classification procedures - one based on point estimates of our parameters only and the other based on confidence intervals around estimated parameters- using our preferred SYS-GMM estimator. Second, we evaluate the sensitivity of both classification procedures to the four widely adopted estimators that we discussed in the previous section.

\subsection{Econometric implementation}

Eq. (6) shows that the differences between the estimated output elasticities of labor and materials and their revenue shares are key to empirical identification of the product and labor market imperfection parameters.

Essential is that the test for the prevalent $L M S$ assumes that firms take the price of materials as given. In a perfectly competitive labor market or in a right-to-manage bargaining setting, the only source of discrepancy between the estimated output elasticity of labor and the share of labor costs in revenue is the firm price-cost mark-up, just like in the materials market [Eq. (3)]. Therefore, the difference in the two factors' outputelasticity-to-revenue-share ratios, i.e. the parameter of joint market imperfections, equals zero [Eq. (7)].

In an efficient bargaining setting, the marginal employee receives a wage that exceeds his/her marginal revenue since efficient bargaining allocates inframarginal gains across employees. As such, the output-elasticity-torevenue-share ratio for labor becomes smaller, and smaller than the respective ratio for materials in particular. Hence, there is a positive difference between the materials and labor ratios, i.e. the parameter of joint market imperfections is positive [Eq. (8)].

In a monopsony setting, on the other hand, the marginal employee obtains a wage that is less than his/her marginal revenue. As such, the output-elasticity-to-revenue-share ratio for labor exceeds the respective ratio for materials, yielding the negative parameter of joint market imperfections [Eq. (9)].

Depending on the $L M S$, it follows from the parameter of joint market imperfections that the differences between the estimated output elasticities of labor and materials and their revenue shares can be mapped into either the firm price-cost mark-up and the extent of rent sharing [Eq. (8)] or the firm price-cost mark-up and the firm labor supply elasticity [Eq. (9)].

Since our study aims at $(i)$ comparing regime differences in terms of the type of competition prevailing in product and labor markets across $F R, J P$ and $N L$ and (ii) assessing within-regime industry differences in the estimated product and labor market imperfection parameters and the scale elasticity parameters in each of the countries, we estimate average parameters. There are many sources of variation in input shares. Some of them are related to variation in labor adjustment costs, machinery and capacity utilization, i.e. variation over the business cycle. When deriving our parameters of interest, we want to abstract from such sources of 
variation. Therefore, we assume average input shares. The empirical specification that acts as the bedrock for the regressions at the industry level is hence given by:

$$
q_{i t}=\mu\left[\alpha_{N}\left(n_{i t}-k_{i t}\right)+\alpha_{M}\left(m_{i t}-k_{i t}\right)\right]+\psi \alpha_{N}\left(k_{i t}-n_{i t}\right)+\lambda k_{i t}+\zeta_{i t}
$$

The estimated industry-specific joint market imperfections parameter $\left(\widehat{\psi}_{j}\right)$ determines the regime characterizing the type of competition prevailing in the product and the labor market. A priori, 6 distinct regimes are possible: (1) perfect competition in the product market and perfect competition or right-to-manage bargaining in the labor market, (2) imperfect competition in the product market and perfect competition or right-to-manage bargaining in the labor market, (3) perfect competition in the product market and efficient bargaining in the labor market, (4) imperfect competition in the product market and efficient bargaining in the labor market, (5) perfect competition in the product market and monopsony in the labor market and (6) imperfect competition in the product market and monopsony in the labor market. We denote the 6 possible regimes by $R \in \Re=\{P C-P R, I C-P R, P C-E B, I C-E B, P C-M O, I C-M O\}$, where the first part reflects the type of competition in the product market and the second part reflects the type of competition in the labor market. Once the regime is determined, we derive the product and labor market imperfection parameters from the estimated joint market imperfections parameter.

In each country, we consider 30 comparable manufacturing industries, making up our estimation sample. This decomposition is detailed enough for our purpose and ensures that each industry contains a sufficient number of observations (minimum: 342 observations). Table B.3 in Appendix B presents the industry repartition of the estimation sample and the number of firms and the number of observations by industry and country. For each industry $j \in\{1, \ldots, 30\}$, we estimate a standard Cobb-Douglas production function [Eq. (13)] using the $S Y S-G M M$ estimator.

On pragmatic grounds, we consider that defining perfect competition in both product and labor markets as respectively implying $\mu_{j}=1$ and $\psi_{j}=0$ is unrealistic. We prefer to distinguish between nearly perfectly (or weakly imperfectly) competitive product markets as $H_{10}: \mu_{j} \leq \mu_{j 0}$ against imperfectly competitive product markets as $H_{1 a}: \mu_{j}>\mu_{j 0}$, and similarly nearly perfectly (or weakly imperfectly) competitive labor markets as $H_{20}:\left|\psi_{j}\right| \leq\left|\psi_{j 0}\right|$ against imperfectly competitive labor markets as $H_{2 a}:\left|\psi_{j}\right|>\left|\psi_{j 0}\right|$. The difficult problem is to find sensible values for both threshold values $\mu_{j 0}$ and $\psi_{j 0}$ that are the same for the three countries. Note that we could have chosen to make such distinction between perfectly and imperfectly competitive labor markets in terms of $\widehat{\phi}_{j}$ and $\left(\widehat{\varepsilon}_{w}^{N}\right)_{j}$-instead of in terms of $\widehat{\psi}_{j}$ - which makes more direct economic sense but would have added a number of complications. In particular, $\widehat{\phi}_{j}$ and $\left(\widehat{\varepsilon}_{w}^{N}\right)_{j}$ do not only depend on $\mu_{j}$ and $\psi_{j}$ but also on the input shares $\left(\alpha_{N}\right)_{j}$ and $\left(\alpha_{M}\right)_{j}$ and the output elasticities $\left(\varepsilon_{N}^{Q}\right)_{j}$ and $\left(\varepsilon_{M}^{Q}\right)_{j}$. Then, they would have to be different across countries and across industries as well as different for efficient bargaining and monopsony. After some considerations, we have chosen $\mu_{j 0}=1.10$ and $\left|\psi_{j 0}\right|=|0.30|$ as reasonable values for our comparison. Table B.4 in Appendix B motivates the "data-dependent" choice of $|0.30|$ for $\left|\psi_{j 0}\right|$. It shows that when we choose a common threshold of $|0.30|$ for $\left|\psi_{j 0}\right|$, the average and median values of industryspecific labor market imperfection parameters are economically meaningful for the three countries. Remark that if we apply the classification procedure of Dobbelaere and Mairesse (2013), which has the advantage of 
not relying on data-dependent threshold values ${ }^{24}$ but does not consider a comparison across countries, we find that-consistent with our results- the dominant labor market setting is $E B$ in $F R$ and $P R$ in $J P$ and $N L$.

We apply two classification procedures. Classification procedure 1 is based on point estimates of our parameters only and classification 2 is based on confidence intervals around estimated parameters.

1) Classification procedure 1, on which we comment below, is summarized as follows:

\begin{tabular}{ll}
\hline \hline $\begin{array}{l}\text { Classification procedure 1: } \\
\text { Hypothesis test }\end{array}$ & $\begin{array}{c}\text { Null hypothesis } \\
\text { not rejected }\end{array}$ \\
\hline \hline$H_{10}:\left(\mu_{j}-1=\frac{\left(\varepsilon_{M}^{Q}\right)_{j}}{\left(\alpha_{M}\right)_{j}}-1\right) \leq 0.10$ and & $R=P C-P R$ \\
$H_{20}:\left(\psi_{j}=\frac{\left(\varepsilon_{M}^{Q}\right)_{j}}{\left(\alpha_{M}\right)_{j}}-\frac{\left(\varepsilon_{N}^{Q}\right)_{j}}{\left(\alpha_{N}\right)_{j}}\right) \leq \mid 0.30$ & \\
\hline$H_{10}:\left(\mu_{j}-1=\frac{\left(\varepsilon_{M}^{Q}\right)_{j}}{\left(\alpha_{M}\right)_{j}}-1\right)>0.10$ and & $R=I C-P R$ \\
$H_{20}:\left(\psi_{j}=\frac{\left(\varepsilon_{M}^{Q}\right)_{j}}{\left(\alpha_{M}\right)_{j}}-\frac{\left(\varepsilon_{N}^{Q}\right)_{j}}{\left(\alpha_{N}\right)_{j}}\right) \leq|0.30|$ & \\
\hline$H_{10}:\left(\mu_{j}-1=\frac{\left(\varepsilon_{M}^{Q}\right)_{j}}{\left(\alpha_{M}\right)_{j}}-1\right) \leq 0.10$ and & $R=P C-E B$ \\
$H_{20}:\left(\psi_{j}=\frac{\left(\varepsilon_{M}^{Q}\right)_{j}}{\left(\alpha_{M}\right)_{j}}-\frac{\left(\varepsilon_{N}^{Q}\right)_{j}}{\left(\alpha_{N}\right)_{j}}\right)>0.30$ & $R=I C-E B$ \\
\hline$H_{10}:\left(\mu_{j}-1=\frac{\left(\varepsilon_{M}^{Q}\right)_{j}}{\left(\alpha_{M}\right)_{j}}-1\right)>0.10$ and & \\
$H_{20}:\left(\psi_{j}=\frac{\left(\varepsilon_{M}^{Q}\right)_{j}}{\left(\alpha_{M}\right)_{j}}-\frac{\left(\varepsilon_{N}^{Q}\right)_{j}}{\left(\alpha_{N}\right)_{j}}\right)>0.30$ & $R=P C-M O$ \\
\hline$H_{10}:\left(\mu_{j}-1=\frac{\left(\varepsilon_{M}^{Q}\right)_{j}}{\left(\alpha_{M}\right)_{j}}-1\right) \leq 0.10$ and & \\
$H_{20}:\left(\psi_{j}=\frac{\left(\varepsilon_{M}^{Q}\right)_{j}}{\left(\alpha_{M}\right)_{j}}-\frac{\left(\varepsilon_{N}^{Q}\right)_{j}}{\left(\alpha_{N}\right)_{j}}\right)<-0.30$ & $R=I C-M O$ \\
\hline$H_{10}:\left(\mu_{j}-1=\frac{\left(\varepsilon_{M}^{Q}\right)_{j}}{\left(\alpha_{M}\right)_{j}}-1\right)>0.10$ and & \\
$H_{20}:\left(\psi_{j}=\frac{\left(\varepsilon_{M}^{Q}\right)_{j}}{\left(\alpha_{M}\right)_{j}}-\frac{\left(\varepsilon_{N}^{Q}\right)_{j}}{\left(\alpha_{N}\right)_{j}}\right)<-0.30$ & \\
\hline \hline
\end{tabular}

Classification 1 is entirely based on the point estimates of the price-cost mark-up $\mu_{j}$ and the joint market imperfections parameter $\psi_{j}$. For example, if our null hypothesis is that imperfect competition in the product market and efficient bargaining in the labor market feature the industry, we perform the following test: $H_{10}:\left(\mu_{j}-1\right)>0.10$ and $H_{20}: \psi_{j}>0.30$. The test rejects that the $I C$-EB-regime applies if either $H_{10}$ or $H_{20}$ is rejected. By construction, this procedure does not take into account the precision of the estimates but has the advantage of entailing a complete classification.

\footnotetext{
${ }^{24}$ This classification proceduree consists of two parts. In the first part, we perform an $F$-test of the joint hypothesis $H_{0}$ : $\left(\mu_{j}-1\right)=\psi_{j}=0$, where the alternative is that at least one of the parameters does not equal zero. The first part allows to select industries belonging to the $P C$ - $P R$-regime. In the second part, we test a 2-dimensional hypothesis by conducting two separate $t$-tests to classify the remaining industries in one of the 5 other regimes.
} 
Table 2 summarizes the resulting industry classification. Columns 3-5 in Table B.5 in Appendix B provide details on the specific industries belonging to each regime according to classification 1 . Focusing on the product market side, more than $86 \%$ of the industries comprising more than $95 \%$ of the firms are typified by imperfect competition in $F R$ and $N L$ whilst this does only hold for $47 \%$ of the industries comprising $44 \%$ of the firms in $J P$. On the labor market side, $43 \%$ of the industries comprising $68 \%$ of the firms are characterized by efficient bargaining, $43 \%$ of the industries comprising $27 \%$ of the firms by perfect competition or right-to-manage bargaining and monopsony features only $13 \%$ of the industries comprising $5 \%$ of the firms in $F R$. In $J P, 70 \%$ of the industries comprising $67 \%$ of the firms are characterized by perfect competition or right-to-manage bargaining and $30 \%$ of the industries comprising $33 \%$ of the firms efficient bargaining. Strikingly, none of the industries is characterized by monopsony. In $N L$, the three labor market settings are evenly distributed: $33 \%$ of the industries comprising $38 \%$ of the firms are characterized by perfect competition or right-to-manage bargaining, $33 \%$ of the industries comprising $36 \%$ of the firms by efficient bargaining and $33 \%$ of the industries comprising $26 \%$ of the firms by monopsony.

Taken together, the predominant regimes in $F R$ are $I C-E B, I C-P R, P C-P R$ and $I C-M O$ :

- $I C$-EB-regime: $43 \%$ of the industries comprising $68 \%$ of the firms,

- IC-PR-regime: $33 \%$ of the industries comprising $22 \%$ of the firms,

- $P C$ - $P R$-regime: $10 \%$ of the industries comprising $5 \%$ of the firms and

- IC-MO-regime: $10 \%$ of the industries comprising $4 \%$ of the firms.

In $J P$, the predominant regimes are $P C-P R, I C-P R, P C-E B$ and $I C-E B$ :

- $P C$-PR-regime: $37 \%$ of the industries comprising $42 \%$ of the firms,

- $I C$ - $P R$-regime: $33 \%$ of the industries comprising $25 \%$ of the firms,

- PC-EB-regime: $17 \%$ of the industries comprising $14 \%$ of the firms and

- $I C$-EB-regime: $13 \%$ of the industries comprising $19 \%$ of the firms.

In $N L$, the predominant regimes are $I C-P R, I C-E B$ and $I C-M O$ :

- IC-PR-regime: $30 \%$ of the industries comprising $37 \%$ of the firms,

- $I C$-EB-regime: $33 \%$ of the industries comprising $36 \%$ of the firms and

- IC-MO-regime: $27 \%$ of the industries comprising $22 \%$ of the firms.

$<$ Insert Table 2 about here $>$ 
2) Classification procedure 2, on which we comment below, is summarized as follows:

\begin{tabular}{|c|c|c|}
\hline Classification procedure 2: & $\begin{array}{l}\text { Statistical } \\
\text { significance level }\end{array}$ & Null hypothesis not rejected \\
\hline \multicolumn{3}{|l|}{ Hypothesis test for product market setting $(P M S)$} \\
\hline$P C$ is null: $H_{10}: \mu_{j}-1 \leq 0.10$ against $H_{1 a}: \mu_{j}-1>0.10$ & $5 \%$ & $P M S=P C$ \\
\hline$I C$ is null: $H_{10}: \mu_{j}-1>0.10$ against $H_{1 a}: \mu_{j}-1 \leq 0.10$ & $5 \%$ & $P M S=I C$ \\
\hline \multicolumn{3}{|l|}{ Hypothesis test for $E B$-labor market setting $(L M S)$} \\
\hline$P R$ is null: $H_{10}: \psi_{j} \leq 0.30$ against $H_{1 a}: \psi_{j}>0.30$ & $5 \%$ & $L M S=P R$ \\
\hline$E B$ is null: $H_{10}: \psi_{j}>0.30$ against $H_{1 a}: \psi_{j} \leq 0.30$ & $5 \%$ & $L M S=E B$ \\
\hline \multicolumn{3}{|l|}{ Hypothesis test for $M O$-labor market setting $(L M S)$} \\
\hline$P R$ is null: $H_{10}: \psi_{j} \geq-0.30$ against $H_{1 a}: \psi_{j}<-0.30$ & $5 \%$ & $L M S=P R$ \\
\hline$M O$ is null: $H_{10}: \psi_{j}<-0.30$ against $H_{1 a}: \psi_{j} \geq-0.30$ & $5 \%$ & $L M S=M O$ \\
\hline
\end{tabular}

Classification procedure 2 is based on confidence intervals around estimated parameters. To determine the relevant product/labor market setting, we consider two a priori null hypotheses. Focusing on the product market side, choosing $I C$ as the null hypothesis can be interpreted as believing more strongly in (some degree of) imperfect competition, whilst the opposite is true when choosing $P C$ as the null hypothesis. The choice of two a priori null hypotheses allows the characterization of three types of industries. In particular, industry j

- is characterized to be highly imperfectly competitive or far from perfectly competitive, denoted by $I C^{*}$, if $P M S=I C$ under both null hypotheses.

- is characterized to be weakly imperfectly competitive or nearly perfectly competitive, denoted by $P C^{*}$, if $P M S=P C$ under both null hypotheses.

- belongs to the overlapping category, denoted by mover, if the $P M S$-type is different under both null hypotheses.

Focusing on the labor market side, choosing $E B / M O$ as the null hypothesis can be interpreted as believing more strongly that the marginal employee receives a wage that differs from his/her marginal revenue, whilst choosing $P R$ as the null hypothesis supports more the belief that the marginal employee receives a wage equal to his/her marginal revenue. The choice of two a priori null hypotheses allows the characterization of four types of industries. In particular, industry $j$

- is most likely to be characterized by efficient bargaining, denoted by $E B^{*}$, if $L M S=E B$ under both null hypotheses.

- is most likely to be characterized by monopsony, denoted by $M O^{*}$, if $L M S=M O$ under both null hypotheses.

- is most likely to be characterized by perfect competition/right-to-manage bargaining, denoted by $P R^{*}$, if $L M S=P R$ under both null hypotheses. 
- belongs to the overlapping category, denoted by mover, if the $L M S$-type is different under both null hypotheses.

Table 3a reports the three types of industries on the product market side and the four types of industries on the labor market side. Table 3b summarizes the resulting -incomplete- industry classification. Table B.5 in Appendix B provides details on $(i)$ the characterization of the specific industries (columns 6-8 on the product market side, columns 9-11 on the labor market side) and (ii) the specific industries belonging to a particular regime (columns 12-14).

Let us first focus the discussion on the product market side. A large proportion of industries is characterized to be highly imperfectly competitive in $F R$ and $N L: 67 \%$ of the industries comprising $84 \%$ of the firms in the former and $73 \%$ of the industries comprising $89 \%$ of the firms in the latter. In contrast, $20 \%$ of the industries comprising $18 \%$ of the firms are typified to be nearly perfectly competitive in $J P$. In $N L$ and $F R$, only about one fourth of the industries making up about one tenth of the firms are typified as movers whereas $57 \%$ of the industries comprising $57 \%$ of the firms belong to the overlapping category in $J P$.

On the labor market side, the majority of industries comprising the majority of firms are typified as movers in $J P$ and $N L$. In $F R$, this holds for $47 \%$ of the industries making up $44 \%$ of the firms. In $F R, 30 \%$ of the industries comprising $57 \%$ of the firms are most likely to be characterized by efficient bargaining whereas the remaining $23 \%$ of industries comprising $9 \%$ of the firms are most likely to be characterized by perfect competition/right-to-manage bargaining. In $N L$ and $J P$, about $30 \%$ of the industries making up more than $34 \%$ of the firms are typified as $P R^{*}$-industries whereas only a relatively small proportion $-13 \%(3 \%)$ of the industries comprising $14 \%(8 \%)$ of the firms in $J P(N L)$ - are characterized as $E B^{*}$-industries.

\section{$<$ Insert Table 3 a about here $>$}

Whereas classification procedure 2 provides a more statistically correct characterization of industries, it entails an incomplete classification. From Table 3b, it follows that $43 \%(20 \%)$ of the industries comprising $63 \%(40 \%)$ of the firms can be classified in one of the six regimes in $F R(N L)$ whereas this is only true for $17 \%$ of the industries making up $20 \%$ of the firms in $J P$. The dominant regime is

- $I C^{*}-E B^{*}$ in $F R$, covering $30 \%$ of the industries comprising $57 \%$ of the firms,

- $P C^{*}-P R^{*}$ in $J P$, covering $10 \%$ of the industries comprising $10 \%$ of the firms and

- $I C^{*}-P R^{*}$ in $N L$, covering $13 \%$ of the industries comprising $31 \%$ of the firms.

\section{$<$ Insert Table $3 b$ about here $>$}

Summing up, irrespective of the classification procedure, we observe considerable differences in the prevalent product and labor market settings and hence in the prevalent regimes across countries. The proportion of industries (and firms) that is characterized by imperfect competition in the product market is much higher in $F R$ and $N L$ than in $J P$. The most prevalent labor market setting is efficient bargaining in $F R$ and perfect competition or right-to-manage bargaining in $J P$ and $N L$. As such, the dominant regime is one of imperfect competition in the product market and efficient bargaining in the labor market in $F R$, one 
of perfect competition in the product market and perfect competition or right-to-manage bargaining in the labor market in $J P$ and one of imperfect competition in the product market and perfect competition or right-to-manage bargaining in the labor market in $N L$. These differences in labor market settings are largely consistent with differences in the industrial relations system and in institutions in the three countries (see Section 2). The predominant $E B$-labor market setting in $F R$ is compatible with industry-based unionism and high collective bargaining coverage in $F R$ and with the fact that French trade unions have proven to be quite powerful. The predominant $P R$-labor market setting in $J P$ matches with the prevalence of enterprise-based unionism which stimulates cooperative behavior..$^{25,26}$

Does the finding of important regime differences across the three countries imply that manufacturing industries in the three countries differ considerably in the type of competition prevailing in product and labor markets? To answer that question, we compare the relevant regime of each industry $j \in\{1, \ldots, 30\}$ across the three countries. To ensure a complete classification, we base the comparison on classification procedure 1. From columns 3-5 in Table B.5 in Appendix B, it follows that ten industries are characterized by the same product market setting in each of the three countries. Industries manufacturing textiles, furniture, chemicals, pharmaceuticals, metals, other metal products, electronic parts and components, other transport equipment, precision instruments and miscellaneous manufacturing products are characterized by imperfect competition. Six industries are typified by the same labor market setting in each of the three countries. Industries manufacturing miscellaneous chemical products, plastics, general industrial machinery and other electrical machinery are characterized by perfect competition or right-to-manage bargaining whilst industries manufacturing miscellaneous food and related products and wooden products are characterized by efficient bargaining. As discussed in Section 2, several studies -including OECD studies- report the degree of product and labor market regulation at the country level. Our finding that the same manufacturing industry is mostly characterized by different product and labor market settings in the three countries, however, calls for an approach to construct such a regulation index at the country-industry level rather than at the country level.

\subsection{Sensitivity of classification to estimation methods}

How sensitive are the revealed product and labor market settings and regimes to the choice of estimator? As a sensitivity check, we take our preferred estimator ( $S Y S-G M M)$ as the benchmark and compare systematically each of the three other estimators $(O L S, F E$ and $W-L P)$ to this benchmark. Tables 4 and 5 summarize this sensitivity check by reporting the proportion of industries belonging to the same product market setting/labor market setting/regime according to each pair of estimators for classification 1 and classification 2 respectively.

\footnotetext{
${ }^{25}$ Applying the classification procedure of Dobbelaere and Mairesse (2013), we find that -consistent with classification procedures 1 and 2 - the dominant regime is $I C-E B$ in $F R$ and $I C-P R$ in $N L$. In $J P$, the dominant regime is found to be $I C-P R$. Details on this classification procedure are not reported but available upon request.

${ }^{26} \mathrm{~A}$ more rigorous analysis of the relationship between regime differences and differences in terms of (legal) institutions and industrial relations across the three countries would necessitate firm-level information on e.g. the skill composition of the workforce, the degree of unionization, the nature of innovation activities, the export/import status and sales or even plant-level information on prices and product characteristics. Besides lacking this type of information in our current datasets, we consider addressing/testing empirically these relationships as a worthy subject for future research but beyond the scope of this paper.
} 
From Table 4, it follows that for the three countries, the lowest match in terms of $P M S$ results from comparing the $S Y S-G M M$ and $W$-LP estimators whilst the highest match is obtained by comparing the $S Y S-G M M$ and $O L S$ estimators. The proportion of industries belonging to the same $P M S$ lies in the [67\%-83\%]-range for $F R$, the [50\%-63\%]-range for $J P$ and the [37\%-90\%]-range for $N L$. The match in terms of $L M S$ across estimators is driven by the matched $P R$-industries. Consistent with the product market side, we observe the lowest match in terms of $L M S$ by comparing the $S Y S-G M M$ and $W-L P$ estimators in the three countries whilst the highest match by comparing the $S Y S-G M M$ and $F E$ estimators in $F R$ and by comparing the $S Y S-G M M$ and $O L S$ estimators in $J P$ and $N L$. The proportion of industries belonging to the same $L M S$ lies in the [27\%-77\%]-range for $F R$, the [57\%-70\%]-range for $J P$ and the [37\%-73\%]-range for $N L$. For the three countries, the lowest match in terms of regime (requiring a match in terms of the product market as well as the labor market setting) results from comparing the $S Y S-G M M$ and $W-L P$ estimators whilst the highest match is obtained by comparing the $S Y S-G M M$ and $O L S$ estimators for $F R$ and $N L$ and the $S Y S-G M M$ and $F E$ estimators for $J P$. The proportion of industries belonging to the same regime lies in the [20\%-37\%]-range for $F R$, the [27\%-43\%]-range for $J P$ and the [23\%-67\%]-range for $N L$.

\section{$<$ Insert Table 4 about here $>$}

To design Table 5, we select the industries that $(i)$ do not belong to the overlapping categories of either the product or the labor market side using the $S Y S-G M M$ estimator (see Table 3a) and determine the proportion of industries belonging to either the same product market setting $\left(P C^{*}\right.$ or $\left.I C^{*}\right)$ or the same labor market setting $\left(P R^{*}, E B^{*}\right.$ or $\left.M O^{*}\right)$ according to each pair of estimators and (ii) can be classified in one of the six regimes (see Table $3 \mathrm{~b}$ ) and determine the proportion of industries belonging to the same regime according to each pair of estimators. ${ }^{27}$ Focusing on the product market side, the match in terms of $P M S$ is qualitatively the same as for classification 1 . In quantitative terms, the match between $S Y S-G M M$ and $W$-LP is much lower for the three countries compared to classification 1. Focusing on the labor market side, we observe the lowest match in terms of $L M S$ by comparing the $S Y S-G M M$ and $W$ - LP estimators in the three countries (which is consistent with classification 1) whilst the highest match by comparing the $S Y S-G M M$ and $O L S$ estimators for $F R$ and $N L$ and the $S Y S-G M M$ and $F E$ estimators for $J P$. In quantitative terms, the match between $S Y S-G M M$ and $W-L P$ is much lower for $J P$ but higher for $F R$ and $N L$ compared to classification 1. The proportion of industries belonging to the same $L M S$ lies in the [44\%-56\%]-range for $F R$, the [8\%-77\%]range for $J P$ and the [60\%-90\%]-range for $N L$. The match in terms of regime is quantitatively close to the one for classification 1 in FR. The lowest match results from comparing the $S Y S-G M M$ and FE results and the highest match from comparing the $S Y S-G M M$ and $O L S$ results. Consistent with classification 1, the lowest match in terms of regime is obtained by comparing the $S Y S-G M M$ and $W$-LP estimators for $J P$ and $N L .^{28}$ For these two countries, the highest match results from comparing the $S Y S-G M M$ and FE results. The latter match is significantly higher than the one for classification 1 . The proportion of industries belonging to the same regime lies in the [31\%-46\%]-range for $F R$, the [0\%-60\%]-range for $J P$ and the [0\%-83\%]-range for $N L$.

\footnotetext{
${ }^{27}$ For example, focusing on the product market side in $F R$, we determine the proportion of $P C^{*}$ - and $I C^{*}$-industries $(22$ in total, see Table 3a) belonging to the same PMS. Comparing the $S Y S-G M M$ with the $O L S$ results, about $73 \%$ of these 22 industries match in terms of product market setting: $68 \%$ are characterized as $I C^{*}$-industries according to both estimators whilst $5 \%$ are characterized as $P C^{*}$-industries.

${ }^{28}$ Note, however, that in contrast to classification 1 , none of the industries is characterized by the same regime in these two countries.
} 
$<$ Insert Table 5 about here $>$

\section{Within-regime industry differences in parameters of interest}

To what extent do manufacturing industries within a particular regime differ in the degree of imperfections in the product and labor markets in which they operate? To address that question, we condition our answer on classification 1 and investigate industry differences in the estimated industry-specific scale elasticity parameter $\widehat{\lambda}_{j}$, joint market imperfections parameter $\widehat{\psi}_{j}$, and corresponding price-cost mark-up $\widehat{\mu}_{j}$ and absolute extent of rent-sharing $\widehat{\phi}_{j}$ or labor supply elasticity $\left(\widehat{\varepsilon}_{w}^{N}\right)_{j}$ parameters within each of the predominant regimes in $F R, J P$ and $N L$.

Table 6 presents the industry mean and the industry quartile values of the $S Y S$-GMM results within the predominant regimes in each country. The left part of Table 6 reports the estimated scale elasticity parameter, the middle part the estimated joint market imperfections parameter and the right part the relevant product and labor market imperfection parameters, i.e. the price-cost mark-up within $P C$ - $P R$ and $I C$ - $P R$, the pricecost mark-up and the extent of rent sharing within $P C-E B$ and $I C-E B$, and the price-cost mark-up and the labor supply elasticity within $I C-M O$. We also present the industry-specific profit ratio parameter, which can be expressed as the estimated industry-specific price-cost mark-up divided by the estimated industryspecific scale elasticity $\left(\frac{\widehat{\mu}}{\widehat{\lambda}}\right)_{j}$. This ratio shows that the source of profit lies either in imperfect competition or decreasing returns to scale. The standard errors $(\sigma)$ of $\widehat{\mu}_{j}, \widehat{\gamma}_{j}, \widehat{\phi}_{j}, \widehat{\beta}_{j}$ and $\left(\widehat{\varepsilon}_{w}^{N}\right)_{j}$ are computed using the Delta method (Wooldridge, 2002). ${ }^{29}$ All industry-specific estimates are presented in Table B.6 in Appendix B. ${ }^{30,31}$ In addition to the parameters reported in Table 6, Table B.6 also reports the computed factor shares

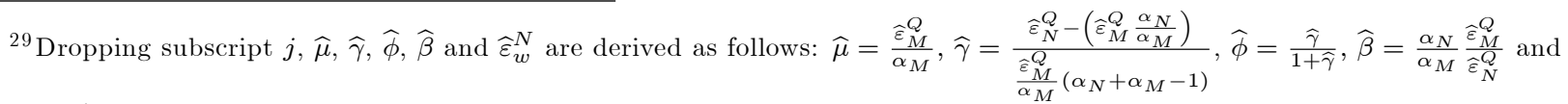
$\widehat{\varepsilon}_{w}^{N}=\frac{\widehat{\beta}}{1-\widehat{\beta}}$. Their respective standard errors are computed as:

$$
\begin{aligned}
& \left(\sigma_{\widehat{\mu}}\right)^{2}=\frac{1}{\left(\alpha_{M}\right)^{2}}\left(\sigma_{\widehat{\varepsilon}_{M}^{Q}}\right)^{2},\left(\sigma_{\widehat{\gamma}}\right)^{2}=\left(\frac{\alpha_{M}}{\alpha_{N}+\alpha_{M}-1}\right)^{2} \frac{\left(\widehat{\varepsilon}_{M}^{Q}\right)^{2}\left(\sigma_{\widehat{\varepsilon}_{N}^{Q}}\right)^{2}-2 \widehat{\varepsilon}_{N}^{Q} \widehat{\varepsilon}_{M}^{Q}\left(\sigma_{\widehat{\varepsilon}_{N}^{Q,} \widehat{\varepsilon}_{M}^{Q}}\right)+\left(\widehat{\varepsilon}_{N}^{Q}\right)^{2}\left(\sigma_{\widehat{\varepsilon}_{N}^{Q}}\right)^{2}}{\left(\widehat{\varepsilon}_{M}^{Q}\right)^{4}},\left(\sigma_{\widehat{\phi}}\right)^{2}=\frac{\left(\sigma_{\widehat{\gamma}}\right)^{2}}{(1+\widehat{\gamma})^{4}}, \\
& \left(\sigma_{\widehat{\beta}}\right)^{2}=\left(\frac{\alpha_{N}}{\alpha_{M}}\right)^{2} \frac{\left(\widehat{\varepsilon}_{M}^{Q}\right)^{2}\left(\sigma_{\widehat{\varepsilon}_{N}^{Q}}\right)^{2}-2 \widehat{\varepsilon}_{N}^{Q} \widehat{\varepsilon}_{M}^{Q}\left(\sigma_{\widehat{\varepsilon}_{N}^{Q}, \widehat{\varepsilon}_{M}^{Q}}\right)+\left(\widehat{\varepsilon}_{N}^{Q}\right)^{2}\left(\sigma_{\widehat{\varepsilon}_{M}^{Q}}\right)^{2}}{\left(\widehat{\varepsilon}_{N}^{Q}\right)^{4}} \text { and }\left(\sigma_{\widehat{\varepsilon}_{w}^{N}}\right)^{2}=\frac{\left(\sigma_{\widehat{\beta}}\right)^{2}}{(1-\widehat{\beta})^{4}} .
\end{aligned}
$$

${ }^{30}$ For reasons of completeness, Table B.6 also provides detailed information on the $S Y S$-GMM estimates of the industries which are classified in the non-predominant regimes in the three countries, i.e. the $P C$ - $P R$ - and $P C$ - $M O$-regimes in $F R$ and the $P C$ - $M O$ - and $P C$ - $P R$-regimes in $N L$.

${ }^{31} \mathrm{As}$ mentioned above, the Hansen statistic tests the joint validity of the moment conditions (identifying restrictions). In 20 out of the 30 industries in $F R$, in 15 out of the 30 industries in $J P$ and in 2 out of the 30 industries in $N L$, the null hypothesis of joint validity of instruments is rejected. For 15 out of these 20 industries in $F R$ (more specifically ind. $j=1,2,4,5,6,7,9,14,15,17,19,20,21,22,26)$, the difference-in-Hansen tests reject the exogeneity of the 1 -year lagged first-differenced inputs as instruments in the levels equation whereas the validity of the 2- and 3-year lags of the inputs as instruments in the first-differenced equation is not rejected. Looking in detail at the difference-in-Hansen tests for these 15 industries in $J P$ reveals a more complex pattern: For 6 industries (ind. $j=2,9,15,19,25,26$ ) the difference-in-Hansen tests reject the exogeneity of both the 1-year lagged first-differenced inputs as instruments in the levels equation and the 2-year lags of the inputs as instruments in the first-differenced equation, for 5 industries (ind. $j=13,14,16,22,27$ ) the validity of the 1-year lagged first-differenced inputs as instruments in the levels equation is rejected and for industry 8 the use of 3-year lags of the 
and the output elasticity estimates. In Table B.6, industries within the $P C$ - $P R$ - and $I C$ - $P R$-regimes are ranked according to $\widehat{\mu}_{j}$. Within the $P C$-EB- and $I C$-EB-regimes, we rank industries in increasing order of $\widehat{\phi}_{j}$. Within the $P C$ - $M O$ - and $I C$ - $M O$-regimes, industries are ranked according to $\widehat{\beta}_{j}$.

Let us focus the discussion on the primary parameters within the predominant regimes in $F R, J P$ and $N L$ respectively. The predominant regimes in $F R$ are $I C-E B$ (43\% of industries/68\% of firms), IC-PR (33\% of industries $/ 22 \%$ of firms), $P C-P R$ ( $10 \%$ of industries/5\% of firms) and $I C-M O$ ( $10 \%$ of industries/4\% of firms).

- Within regime $R=I C-E B$ in $F R, \widehat{\lambda}_{j}$ is lower than 0.944 for industries in the first quartile and higher than 0.993 for industries in the third quartile. $\widehat{\psi}_{j}$ is lower than 0.539 for industries in the first quartile and higher than 0.642 for industries in the third quartile. The corresponding $\widehat{\mu}_{j}$ is lower than 1.308 for the first quartile of industries and higher than 1.390 for the top quartile. The corresponding $\widehat{\phi}_{j}$ is lower than 0.373 for the first quartile of industries and higher than 0.466 for the top quartile. The median values of $\widehat{\lambda}_{j}, \widehat{\psi}_{j}, \widehat{\mu}_{j}$ and $\widehat{\phi}_{j}$ are estimated at $0.955,0.555,1.339$ and 0.428 respectively.

- Within regime $R=I C-P R$ in $F R, \widehat{\lambda}_{j}$ is lower than 0.981 for industries in the first quartile and higher than 1.016 for industries in the third quartile. $\widehat{\mu}_{j}$ is lower than 1.171 for industries in the first quartile and higher than 1.272 for industries in the upper quartile. The median values of $\widehat{\lambda}_{j}$ and $\widehat{\mu}_{j}$ are estimated at 1.006 and 1.225 respectively.

- Within regime $R=P C-P R$ in $F R, \widehat{\lambda}_{j}$ is lower than 0.939 for industries in the first quartile and higher than 0.981 for industries in the third quartile. $\widehat{\mu}_{j}$ is lower than 0.892 for industries in the first quartile and higher than 1.092 for industries in the upper quartile. The median values of $\widehat{\lambda}_{j}$ and $\widehat{\mu}_{j}$ are estimated at 0.953 and 1.034 respectively.

- Within regime $R=I C-M O$ in $F R, \widehat{\lambda}_{j}$ is lower than 1.015 for industries in the first quartile and higher than 1.059 for industries in the third quartile. $\widehat{\psi}_{j}$ is lower than -0.624 for industries in the first quartile and higher than -0.418 for industries in the third quartile. The corresponding $\widehat{\mu}_{j}$ is lower than 1.130 for the first quartile of industries and higher than 1.207 for the top quartile. The corresponding $\left(\widehat{\varepsilon}_{w}^{N}\right)_{j}$ is estimated to be lower than 1.883 for industries in the first quartile and higher than 2.700 for industries in the upper quartile. The median values of $\widehat{\lambda}_{j}, \widehat{\psi}_{j}, \widehat{\mu}_{j}$ and $\left(\widehat{\varepsilon}_{w}^{N}\right)_{j}$ are estimated at 1.045, $-0.542,1.176$ and 2.226 respectively.

The predominant regimes in $J P$ are $P C-P R$ ( $37 \%$ of industries $/ 42 \%$ of firms), $I C-P R$ ( $33 \%$ of industries $/ 25 \%$ of firms), $P C-E B$ ( $17 \%$ of industries/14\% of firms) and $I C-E B$ (13\% of industries/19\% of firms).

- Within regime $R=P C-P R$ in $J P, \widehat{\lambda}_{j}$ is lower than 1.031 for industries in the first quartile and higher than 1.069 for industries in the third quartile. $\widehat{\mu}_{j}$ is lower than 1.037 for industries in the first quartile and higher than 1.092 for industries in the upper quartile. The median values of $\widehat{\lambda}_{j}$ and $\widehat{\mu}_{j}$ are estimated at 1.037 and 1.066 respectively.

inputs as instruments in the first-differenced equation does not prove informative. As for $N L$, the difference-in-Hansen tests reject the null of the subset of instruments in the levels equation for industry 2 whereas the validity of 2-year lags of the inputs as instruments in the first-differenced equation is rejected for industry 18 . 
- Within regime $R=I C-P R$ in $J P, \widehat{\lambda}_{j}$ is lower than 1.025 for industries in the first quartile and higher than 1.056 for industries in the third quartile. $\widehat{\mu}_{j}$ is lower than 1.127 for industries in the first quartile and higher than 1.182 for industries in the upper quartile. The median values of $\widehat{\lambda}_{j}$ and $\widehat{\mu}_{j}$ are estimated at 1.029 and 1.135 respectively.

- Within regime $R=P C$-EB in $J P, \widehat{\lambda}_{j}$ is lower than 1.003 for industries in the first quartile and higher than 1.014 for industries in the third quartile. $\widehat{\psi}_{j}$ is lower than 0.347 for industries in the first quartile and higher than 0.438 for industries in the third quartile. The corresponding $\widehat{\mu}_{j}$ is lower than 1.067 for the first quartile of industries and higher than 1.087 for the top quartile. The corresponding $\widehat{\phi}_{j}$ is estimated to be lower than 0.449 for industries in the first quartile and higher than 0.499 for industries in the upper quartile. The median values of $\widehat{\lambda}_{j}, \widehat{\psi}_{j}, \widehat{\mu}_{j}$ and $\widehat{\phi}_{j}$ are estimated at $1.007,0.357,1.080$ and 0.458 respectively.

- Within $R=I C-E B$ in $J P, \widehat{\lambda}_{j}$ is lower than 1.014 for industries in the first quartile and higher than 1.028 for industries in the third quartile. $\widehat{\psi}_{j}$ is lower than 0.437 for industries in the first quartile and higher than 0.474 for industries in the third quartile. The corresponding $\widehat{\mu}_{j}$ is lower than 1.162 for the first quartile of industries and higher than 1.193 for the top quartile. The corresponding $\widehat{\phi}_{j}$ is estimated to be lower than 0.405 for industries in the first quartile and higher than 0.513 for industries in the upper quartile. The median values of $\widehat{\lambda}_{j}, \widehat{\psi}_{j}, \widehat{\mu}_{j}$ and $\widehat{\phi}_{j}$ are estimated at 1.024, 0.446, 1.177 and 0.450 respectively.

The predominant regimes in $N L$ are $I C-P R$ (30\% of industries/37\% of firms), $I C-E B$ (33\% of industries $/ 36 \%$ of firms) and $I C-M O$ ( $27 \%$ of industries $/ 22 \%$ of firms).

- Within regime $R=I C-P R$ in $N L, \widehat{\lambda}_{j}$ is lower than 1.014 for industries in the first quartile and higher than 1.033 for industries in the third quartile. $\widehat{\mu}_{j}$ is lower than 1.309 for industries in the first quartile and higher than 1.368 for industries in the upper quartile. The median values of $\widehat{\lambda}_{j}$ and $\widehat{\mu}_{j}$ are estimated at 1.024 and 1.339 respectively.

- Within $R=I C-E B$ in $N L, \widehat{\lambda}_{j}$ is lower than 0.983 for industries in the first quartile and higher than 1.046 for industries in the third quartile. $\widehat{\psi}_{j}$ is lower than 0.422 for industries in the first quartile and higher than 0.571 for industries in the third quartile. The corresponding $\widehat{\mu}_{j}$ is lower than 1.364 for the first quartile of industries and higher than 1.506 for the top quartile. The corresponding $\widehat{\phi}_{j}$ is estimated to be lower than 0.389 for industries in the first quartile and higher than 0.480 for industries in the upper quartile. The median values of $\widehat{\lambda}_{j}, \widehat{\psi}_{j}, \widehat{\mu}_{j}$ and $\widehat{\phi}_{j}$ are estimated at $1.011,0.498,1.400$ and 0.436 respectively.

- Within $R=I C-M O$ in $N L, \widehat{\lambda}_{j}$ is lower than 1.020 for industries in the first quartile and higher than 1.130 for industries in the third quartile. $\widehat{\psi}_{j}$ is lower than -0.819 for industries in the first quartile and higher than -0.415 for industries in the third quartile. The corresponding $\widehat{\mu}_{j}$ is lower than 1.159 for the first quartile of industries and higher than 1.336 for the top quartile. The corresponding $\left(\widehat{\varepsilon}_{w}^{N}\right)_{j}$ is estimated to be lower than 1.556 for industries in the first quartile and higher than 3.115 for industries in the upper quartile. The median values of $\widehat{\lambda}_{j}, \widehat{\psi}_{j}, \widehat{\mu}_{j}$ and $\left(\widehat{\varepsilon}_{w}^{N}\right)_{j}$ are estimated at 1.047, $-0.574,1.229$ and 2.220 respectively. 


\section{$<$ Insert Table 6 about here $>$}

Summing up, we observe important regime differences across the three countries and also find differences in the levels of scale elasticities and product market imperfections within a regime. The levels of labor market imperfections appear to be quite similar across countries within a regime. Within the $I C$ - $P R$-regime in $F R$, $J P$ and $N L$, the median scale elasticity estimates are comparable across $J P$ and $N L$ and higher than in $F R$. The median price-cost mark-up is estimated to be the lowest in $J P$ and the highest in $N L$. The same pattern can be observed within the $I C$-EB-regime in $F R, J P$ and $N L$ whilst the median absolute extent of rent sharing is estimated to be fairly similar across the three countries. Within the $I C$ - $M O$-regime in $F R$ and $N L$, the median scale elasticity and the median labor supply elasticity estimates are quite similar whilst the median price-cost mark-up is estimated to be the highest in $N L$.

How do our estimates of product and labor market imperfections match up with other studies focusing on the same countries? Our industry classification 1 and the order of magnitudes of our joint market imperfections parameter and corresponding product and labor market imperfection parameters within each regime are consistent with the classification and parameter estimates of Dobbelaere and Mairesse (2013). The latter study uses an unbalanced panel of 10,646 French firms in 30 manufacturing industries over the period 19782001 extracted from EAE and assumes constant returns to scale. Using an unbalanced panel of more than 8,000 Japanese firms in 26 manufacturing industries over the period 1994-2006 extracted from the BSJBSA and imposing $L M S=P R$ on the data, Kiyota (2010) estimates the scale elasticity parameter to be lower than 0.868 for the bottom quartile of industries and higher than 0.930 for the top quartile. The price-cost mark-up is estimated to be lower than 0.940 for the first quartile of industries and higher than 0.993 for the upper quartile. Using an unbalanced panel of 2,471 Dutch firms in 11 manufacturing industries over the period 1992-1997 extracted from the Amadeus database, assuming constant returns to scale and imposing $L M S=P R$ on the data, Konings et al. (2001) find that the price-cost mark-up is lower than 1.460 for the first quartile of industries and higher than 1.790 for the upper quartile.

As mentioned above, other studies focusing on the same kind of analysis include Dobbelaere (2004) and Boulhol et al. (2011). Using an unbalanced panel of 7,086 Belgian firms in 18 manufacturing industries over the period 1988-1995 extracted from the annual company accounts collected by the National Bank of Belgium and imposing $L M S=E B$ on the data, the former estimates the scale elasticity parameter to be lower than 1.000 for the first quartile of industries and higher than 1.171 for the upper quartile. The pricecost mark-up is estimated to be lower than 1.347 for the bottom quartile of industries and higher than 1.629 for the top quartile. The corresponding absolute extent of rent-sharing estimate is lower than 0.134 for the first quartile of industries and higher than 0.221 for the third quartile. Using a panel of 11,799 British firms in 20 manufacturing industries over the period 1988-2003 extracted from OneSource and Financial Analysis Made Easy, assuming constant returns to scale and imposing $L M S=E B$ on the data, Boulhol et al. (2011) estimate the price-cost mark-up to be lower than 1.212 for the bottom quartile of industries and higher than 1.292 for the top quartile. The corresponding absolute extent of rent sharing is estimated to be lower than 0.189 for the first quartile of industries and higher than 0.544 for the upper quartile. Whereas there is an abundant literature on estimating the extent of product market power (see Bresnahan, 1989 for a survey and De Loecker and Warzynski, 2012 for references), there is less direct evidence of employer market power over its 
workers. For studies estimating the wage elasticity of the labor supply curve facing an individual employer, we refer to Reynolds (1946), Nelson (1973), Sullivan (1989), Boal (1995), Falch (2001), Manning (2003), Staiger et al. (2010) and Booth and Katic (2011). These studies point to an elasticity in the [0.7-5]-range.

\section{Conclusion}

It is generally believed that market imperfections are the norm, not the exception. The theory of market failures is widely used as an analytical tool for making policy choices. In practice, the case for public policy interventions must start with the identification and quantification of market imperfections, which is at the core of our study. In particular, this paper examines how actual product and labor markets deviate from their perfectly competitive or economically efficient counterparts and focuses on manufacturing industries in France, Japan and the Netherlands. How different are manufacturing industries in their factor shares, in their marginal products, in their scale economies and in their imperfections in the product and labor markets in which they operate? How does their behavior deviate across countries? In order to analyze these non-trivial questions, we rely on two extensions of Hall's (1988) econometric framework for estimating price-cost margins and scale economies by nesting three distinct labor market settings (perfect competition or right-to-manage bargaining, efficient bargaining and monopsony).

Using an unbalanced panel of 17,653 firms over the period 1986-2001 in France, 8,728 firms over the period 1994-2006 in Japan and 7,828 firms over the period 1993-2008 in the Netherlands, we first apply two procedures to determine the prevalent product market and labor market settings, and hence the prevalent regime, in 30 comparable manufacturing industries. We then investigate industry differences in the estimated product and labor market imperfection parameters within the predominant regimes in each country.

Institutions, social norms and the nature of industrial relations vary significantly between our selected countries. Along with lifetime employment, seniority wages and bonuses, enterprise-based unionism is at the core of Japanese industrial relations. Being concerned with ensuring job security for regular employees, the system is conducive to cooperative behavior. Contrary to Japan, industry-based unionism is prevalent in France and the Netherlands. In France, there are rival trade union confederations competing for membership, causing the French trade union movement to be among the weakest in the OECD countries (only about $8 \%$ of employees in unions) while trade union density is close to the OECD average in Japan and the Netherlands (20\%). Collective bargaining coverage is very high in France and the Netherlands ( $95 \%$ and $85 \%$ respectively) while very low in Japan (16\%).

These differences in the industrial relations system in the three countries are reflected in our results. Indeed, irrespective of the classification procedure, our analysis provides evidence of pronounced regime differences across France, Japan and the Netherlands. The dominant regime in France is one of imperfect competition in the product market and efficient bargaining in the labor market $(I C-E B)$. The median profit ratio - defined as the price-cost mark-up divided by the scale elasticity- and absolute extent of rent-sharing parameters in the

$I C$-EB-industries are of 1.40 and 0.43 respectively. In Japan, the dominant regime is perfect competition in the product market and perfect competition or right-to-manage bargaining in the labor market $(P C$ $P R$ ), with a median profit ratio of about 1.00. The dominant regime in the Netherlands is one of imperfect 
competition in the product market and perfect competition or right-to-manage bargaining in the labor market $(I C-P R)$, with a median profit ratio of about 1.31. Our study does not only highlight cross-country regime differences, it also reveals cross-country differences in the levels of product market imperfections and scale economies within a particular regime.

Our analysis can be pursued in several directions, either to explain some of our findings or to examine some new developments. First, given that our study reveals important cross-country regime differences and crosscountry differences in terms of product and labor market settings for given manufacturing industries, one obvious research avenue is to examine the potential relationship between regime differences and differences in terms of (legal) institutions and industrial relations across the three countries using firm-level information on e.g. the skill composition of the workforce, the nature of innovation activities, and export and import transactions. Second, our gap methodology identifies regimes by comparing differences between the estimated average output elasticities of labor and materials and their average revenue shares. A more rigorous identification strategy could be based on bootstrap hypothesis testing. Third, a natural extension of our production function framework is to take into account worker heterogeneity by building on the method of Hellerstein et al. (1999) and to investigate whether our product and labor market imperfection parameters vary by skill type. Finally, extending our analysis from a static to a dynamic framework might enable us to investigate the impact of country- and industry-level adjustment costs which are structural/permanent in nature on the prevalence of different product and labor market settings.

\section{References}

[1] Ackerberg D, Caves K, Frazer G. 2006. Structural identification of production functions. Unpublished manuscript.

[2] Ackerberg D, Benkard L, Berry S, Pakes A. 2007. Econometric tools for analyzing market outcomes. In Handbook of Econometrics, vol. 6, Heckman JJ. (ed). Amsterdam: Elsevier.

[3] Arellano M, Bond SR. 1991. Some tests of specification for panel data: Monte Carlo evidence and an application to employment equations. Review of Economic studies. 58(2): 277-297.

[4] Arellano M, Bover O. 1995. Another look at the instrumental variable estimation of error-components models. Journal of Econometric 68(1): 29-51.

[5] Baum FC. 2006. An introduction to modern econometrics using Stata. Texas: Stata Press.

[6] Bellone F, Kiyota K, Matsuura T, Musso P, Nesta L. 2014. 70: 56-74.

[7] Bhaskar V, Manning A, To T. 2002. Oligopsony and monopsonistic competition in labor markets. Journal of Economic Perspectives 16(2): 155-174.

[8] Bhaskar V, To T. 1999. Minimum wages for Ronald McDonald monopsonies: A theory of monopsonistic competition. Economic Journal 109(455): 190-203.

[9] Blundell RW, Bond SR. 1998. Initial conditions and moment restrictions in dynamic panel data models. Journal of Econometrics 87(1): 115-143. 
[10] Blundell RW, Bond SR. 2000. GMM estimation with persistent panel data: An application to production functions. Econometric Reviews 19(3): 321-340.

[11] Boal WM. 1995. Testing for employer monopsony in turn-of-the-century coal mining. RAND Journal of Economics 26(3): 519-536.

[12] Boal WM, Ransom MR. 1997. Monopsony in the labor market. Journal of Economic Literature 35(1): $86-112$.

[13] Bond SR, Söderbom M. 2005. Adjustment costs and the identification of Cobb-Douglas production functions. Nuffield College Economics Working Paper 2005-04.

[14] Bond SR, Van Reenen J. 2007. Microeconometric models of investment and employment. In Handbook of Econometrics, vol. 6A, Heckman JJ, Leamer EE (eds). North-Holland: Amsterdam.

[15] Booth AL, Katic P. 2011. Estimating the wage elasticity of labour supply to a firm: What evidence is there for monopsony? Economic Record 87(278): 359-369.

[16] Booth A. 2014. Wage determination and imperfect competition. Labour Economics, Special Issue European Association of Labour Economists 25th Annual Conference, forthcoming.

[17] Boulhol H, Dobbelaere S, Maioli S. 2011. Imports as product and labour market discipline. British Journal of Industrial Relations 49(2): 331-361.

[18] Bowsher CG. 2002. On testing overidentifying restrictions in dynamic panel data models. Economics Letters 77(2): 211-220.

[19] Bresnahan T. 1989. Empirical studies of industries with market power. In Handbook of Industrial Organization, vol. 2, Schmalensee R, Willig R (eds). North-Holland: Amsterdam.

[20] Burdett K, Mortensen D. 1998. Wage differentials, employer size and unemployment. International Economic Review 39(2): 257-273.

[21] Cahuc P, Zylberberg A. 2004. Labor Economics, Cambridge, MA: MIT Press.

[22] Crépon B, Desplatz R, Mairesse J. 2005. Price-cost margins and rent sharing: Evidence from a panel of French manufacturing firms. Annales d'Economie et de Statistique, Special issue in memory of Zvi Griliches 79/80: 585-611.

[23] Del Gatto M, Di Liberto A, Petraglia C. 2011. Measuring productivity. Journal of Economic Surveys 25(5): 952-1008.

[24] De Loecker J. 2011. Product differentiation, multi-product firms and estimating the impact of trade liberalization on productivity. Econometrica 79(5): 1407-1451.

[25] De Loecker J, Warzynski F. 2012. Markups and firm-level export status. American Economic Review 102(6): 2437-2471. 
[26] Dobbelaere S. 2004. Estimation of price-cost margins and union bargaining power for Belgian manufacturing. International Journal of Industrial Organization 22(10): 1381-1398.

[27] Dobbelaere S, Mairesse J. 2013. Panel data estimates of the production function and product and labor market imperfections. Journal of Applied Econometrics 28(1): 1-46.

[28] Doraszelski U, Jaumandreu J. 2013. R\&D and productivity: Estimating endogenous productivity. Review of Economic Studies 80(4): 1338-1383.

[29] Dunne T, Roberts MJ. 1992. Costs, demand and imperfect competition as determinants of plant level output prices. In Empirical studies in industrial organization: Essays in honor of Leonard W. Weiss, Audretsch DB, Siegfried JJ. (eds). Kluwer Aacademic Publishers: Boston

[30] Eberhardt M, Helmer C. 2010. Untested assumptions and data slicing: A critical review of firm-level production function estimators. Department of Economics Discussion Paper 513. University of Oxford.

[31] Eslava M, Haltiwanger J, Kugler A, Kugler M. 2004. The effects of structural reforms on productivity and profitability enhancing reallocation: Evidence from Colombia. Journal of Development Economics 75(2): 333-371.

[32] Falch T. 2001. Decentralized public sector wage determination: Wage curve and wage comparison for Norwegian teachers in the pre-WW2 period. Labour 15(3): 343-369.

[33] Foster L, Haltiwanger J, Syverson C. 2008. Reallocation, firm turnover, and efficiency: Selection on productivity or profitability? American Economic Review 98(1): 394-425.

[34] Fukao K, Hamagata S, Inui T, Ito K, Kwon HU, Makino T, Miyagawa T, Nakanishi Y, Tokui J. 2007. Estimation procedures and TFP analysis of the JIP database 2006. RIETI Discussion Paper 07-E-003. Research Institute of Economy, Trade and Industry.

[35] Fukao K, Kwon HU. 2006. Why did Japan's TFP growth slow down in the lost decade? An empirical analysis based on firm-level data of manufacturing. Japanese Economic Review 57(2): 195-228.

[36] Griliches Z, Hausman JA. 1986. Errors in variables in panel data. Journal of Econometrics 31(1): 93-118.

[37] Griliches Z, Mairesse J. 1998. Production functions: The search for identification. In Essays in honour of Ragnar Frisch, Econometric Society Monograph Series. Strom S (ed). Cambridge University Press: Cambridge.

[38] Hall RE. 1988. The relationship between price and marginal cost in US industry. Journal of Political Economy 96(5): 921-947.

[39] Hellerstein JK, David N, Troske KR. 1999. Wages, productivity and worker characteristics: Evidence from plant-level production function and wage equations. Journal of Labor Economics 17(3): 409-446.

[40] Holtz-Eakin D, Newey W, Rosen HS. 1988. Estimating Vector Autoregressions with panel data. Econometrica 56(6): 1371-1395. 
[41] Hsieh CT, Klenow P. 2009. Misallocation and manufacturing TFP in China and India. Quarterly Journal of Economics 124(4): 1403-1448.

[42] Jaumandreu J, Mairesse J. 2006. Using price and demand information to identify production functions. MPRA Discussion Paper 124\%.

[43] Katayama H, Lu S, Tybout JR. 2009. Firm-level productivity studies: Illusions and a solution. International Journal of Industrial Organization 27(3): 403-413.

[44] Kiyota K. 2010. Productivity, markup, scale economies, and the business cycle: Estimates from firmlevel panel data in Japan. RIETI Discussion Paper 10-E-040. Research Institute of Economy, Trade and Industry.

[45] Kioyta K, Nakajima T, Nishimura KG. 2009. Measurement of the market power of firms: the Japanese case in the 1990s, Industrial and Corporate Change 18(3): 381-414.

[46] Kleiman MAR, Teles SM. 2008. Market and non-market failures. In Oxford handbook of public policy, Moran M, Rein M, Goodin RE (eds). Oxford University Press: Oxford.

[47] Klette TJ, Griliches Z. 1996. The inconsistency of common scale estimators when output prices are unobserved and endogenous. Journal of Applied Econometrics 11(4): 343-361.

[48] Konings J, Van Cayseele P, Warzynski F. 2001. The dynamics of industrial mark-ups in two small open economies: Does national competition policy matter? International Journal of Industrial Organization 19(5): 841-859.

[49] Koske I, Wanner I, Bitetti R, Barbiero O. 2014. The 2013 update of the OECD product market regulation indicators: Policy insights for OECD and non-OECD countries, OECD Economics Department Working Papers, forthcoming.

[50] Levinsohn J, Melitz MJ. 2006. Productivity in a differentiated products market equilibrium. Unpublished manuscript. Princeton University.

[51] Levinsohn J, Petrin A. 2003. Estimating production functions using inputs to control for unobservables. Review of Economic Studies 70(2): 317-341.

[52] Mairesse J. 1990. Time-series and cross-sectional estimates on panel data: Why are they different and why should they be equal? In Panel data and labor market studies. Hartog J, Ridder G, Theeuwes J (eds). North-Holland: Amsterdam.

[53] Mairesse J, Jaumandreu J. 2005. Panel-data estimates of the production function and the revenue function: What difference does it make? Scandinavian Journal of Economics 107(4): 651-672.

[54] Manning A. 2003. Monopsony in motion: Imperfect competition in labor markets. Princeton University Press: Princeton.

[55] Marschak J, Andrews WH. 1944. Random simultaneous equations and the theory of production. Econometrica 12(3-4): 143-205. 
[56] McDonald IM, Solow RM. 1981. Wage bargaining and employment. American Economic Review 71(5): 896-908.

[57] Melitz M. 2001. Estimating firm-level productivity in differentiated product industries. Unpublished manuscript. Harvard University.

[58] Nelson P. 1973. The elasticity of labor supply to the individual firm. Econometrica 41(5): 853-866.

[59] Nickell SJ, Andrews M. 1983. Unions, real wages and employment in Britain 1951-79. Oxford Economic Papers 35(supplement): 183-205.

[60] Noda T, Hirano D. 2013. Enterprise unions and downsizing in Japan before and after 1997. Journal of the Japanese and International Economies 28(C): 91-118.

[61] OECD. 2004. OECD Employment Outlook. Organisation for Economic Cooperation and Development.

[62] Olley S, Pakes A. 1996. The dynamics of productivity in the telecommunications equipment industry. Econometrica 64(6): 1263-1295.

[63] Ornaghi C. 2006. Assessing the effects of measurement errors on the estimation of production functions. Journal of Applied Econometrics 21(6): 879-891.

[64] Ornaghi C. 2008. Price deflators and the estimation of the production function. Economics Letters 99(1): 168-171.

[65] Petrin A, Sivadasan J. 2013. Estimating lost output from allocative efficiency, with an application to Chile and firing costs. Review of Economics and Statistics 95(1): 286-301.

[66] Research and Statistics Department, Ministry of Economy, Trade and Industry (METI). 1994-2006. Kigyou Katsudou Kihon Chousa Houkokusho (Basic Survey of Japanese Business Structure and Activities). METI: Tokyo.

[67] Restuccia D, Rogerson R. 2008. Policy distortions and aggregate productivity within heterogeneous establishments. Review of Economic Dynamics 11(4): 707-720.

[68] Restuccia D, Rogerson R. 2013. Misallocation and productivity. Review of Economic Dynamics 16(1): $1-10$.

[69] Reynolds L. 1946. The supply of labor to the firm. Quarterly Journal of Economics 60(2): 390-411.

[70] Roodman DM. 2009. A note on the theme of too many instruments. Oxford Bulletin of Economics and Statistics 71(1): 135-158.

[71] Shea J. 1993. The input-output approach to instrument selection. Journal of Business and Economic Statistics 11(2): 145-155.

[72] Staiger D, Spetz J, Phibbs C. 2010. Is there monopsony in the labor market? Evidence from a natural experiment. Journal of Labor Economics 28(2): 211-236. 
[73] Sullivan D. 1989. Monopsony power in the market for nurses. Journal of Law and Economics 32(2): S135-S178.

[74] Syverson C. 2004. Market structure and productivity: A concrete example. Journal of Political Economy 112(6): 1181-1222.

[75] Syverson C. 2011. What determines productivity? Journal of Economic Literature 49(2): 326-65.

[76] Tokui J, Inui T, Kim YG. 2008. Embodied technological progress and productivity slowdown in Japan. RIETI Discussion Paper 08-E-01\%. Research Institute of Economy, Trade and Industry.

[77] Van Beveren I. 2012. Total factor productivity: A practical review.Journal of Economic Surveys 26(1): 98-128.

[78] Van Biesebroeck J. 2007. Robustness of productivity estimates. Journal of Industrial Economics 55(3): 529-569.

[79] Venn D. 2009. Legislation, collective bargaining and enforcement: Updating the OECD employment protection indicators. OECD Social, Employment and Migration Working Paper 89. Organisation for Economic Cooperation and Development.

[80] Verret I. 2006. Collective employee representation systems in Japan and France. Unpublished manuscript.

[81] Wansbeek TJ. 2001. GMM estimation in panel data models with measurement error. Journal of Econometrics 104(2), 259-268.

[82] Weimer DL, Vining AR. 2005. Policy analysis: Concepts and practice. Prentice Hall: Upper Saddle River, New Jersey.

[83] Windmeijer F. 2005. A finite sample correction for the variance of linear efficient two-step GMM estimators. Journal of Econometrics 126(1): 25-51.

[84] Wölfl A, Wanner I, Kozluk T, Nicoletti G. 2009. Ten years of product market reform in OECD countries: Insights from a revised PMR indicator. OECD Economics Department Working Paper 695. Organisation for Economic Cooperation and Development.

[85] Wölf A, Wanner I, Röhn O, Nicoletti G. 2010. Product market regulation: Extending the analysis beyond OECD countries. OECD Economics Department Working Paper 799. Organisation for Economic Cooperation and Development.

[86] Wooldridge JM. 2002. Econometric analysis of cross sections and panel data. MIT Press: Cambridge, MA.

[87] Wooldridge JM. 2009. On estimating firm-level production functions using proxy variables to control for unobservables. Economics Letters 104(3): 112-114.

[88] Xiao Z, Shao J, Palta M. 2010. Instrumental variable and GMM estimation for panel data with measurement error. Statistica Sinica 20(4): 1725-1747. 
Table 1: Descriptive statistics by country

\begin{tabular}{|c|c|c|c|c|c|c|}
\hline \multicolumn{7}{|c|}{ FRANCE (1986-2001) } \\
\hline Variables & Mean & Sd. & $\overline{\mathrm{Q}_{1}}$ & $\overline{\mathrm{Q}_{2}}$ & $\overline{\mathrm{Q}_{3}}$ & $\overline{\mathrm{N}}$ \\
\hline Real firm output growth rate $\Delta q_{i t}$ & 0.033 & 0.152 & -0.050 & 0.030 & 0.115 & 156,947 \\
\hline Labor growth rate $\Delta n_{i t}$ & 0.014 & 0.128 & -0.040 & 0.000 & 0.066 & 156,947 \\
\hline Materials growth rate $\Delta m_{i t}$ & 0.049 & 0.192 & -0.054 & 0.044 & 0.148 & 156,947 \\
\hline Capital growth rate $\Delta k_{i t}$ & 0.008 & 0.156 & -0.070 & -0.013 & 0.074 & 156,947 \\
\hline$\left(\alpha_{N}\right)_{j}\left(\Delta n_{i t}-\Delta k_{i t}\right)+\left(\alpha_{M}\right)_{j}\left(\Delta m_{i t}-\Delta k_{i t}\right)$ & 0.022 & 0.148 & -0.058 & 0.024 & 0.102 & 156,947 \\
\hline$\left(\alpha_{N}\right)_{j}\left(\Delta k_{i t}-\Delta n_{i t}\right)$ & -0.002 & 0.055 & -0.028 & -0.004 & 0.024 & 156,947 \\
\hline$S R_{i t}$ & 0.003 & 0.098 & -0.052 & 0.004 & 0.059 & 156,947 \\
\hline Labor share in nominal output $\left(\alpha_{N}\right)_{i}$ & 0.309 & 0.130 & 0.217 & 0.296 & 0.386 & 156,947 \\
\hline Materials share in nominal output $\left(\alpha_{M}\right)_{i}$ & 0.502 & 0.143 & 0.413 & 0.511 & 0.602 & 156,947 \\
\hline $1-\left(\alpha_{N}\right)_{i}-\left(\alpha_{M}\right)_{i}$ & 0.188 & 0.087 & 0.130 & 0.165 & 0.219 & 156,947 \\
\hline Number of employees $N_{i t}$ & 144 & 722 & 30 & 46 & 99 & 156,947 \\
\hline \multicolumn{7}{|c|}{ JAPAN (1994-2006) } \\
\hline Variables & Mean & Sd. & $\overline{\mathrm{Q}_{1}}$ & 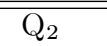 & $\overline{\mathrm{Q}_{3}}$ & $\overline{\mathrm{N}}$ \\
\hline Real firm output growth rate $\Delta q_{i t}$ & 0.020 & 0.140 & -0.050 & 0.015 & 0.085 & 75,067 \\
\hline Labor growth rate $\Delta n_{i t}$ & -0.003 & 0.096 & -0.042 & -0.005 & 0.034 & 75,067 \\
\hline Materials growth rate $\Delta m_{i t}$ & 0.013 & 0.161 & -0.065 & 0.009 & 0.088 & 75,067 \\
\hline Capital growth rate $\Delta k_{i t}$ & -0.003 & 0.108 & -0.071 & -0.032 & 0.028 & 75,067 \\
\hline$\left(\alpha_{N}\right)_{j}\left(\Delta n_{i t}-\Delta k_{i t}\right)+\left(\alpha_{M}\right)_{j}\left(\Delta m_{i t}-\Delta k_{i t}\right)$ & 0.011 & 0.144 & -0.058 & 0.021 & 0.089 & 75,067 \\
\hline$\left(\alpha_{N}\right)_{j}\left(\Delta k_{i t}-\Delta n_{i t}\right)$ & 0.000 & 0.027 & -0.015 & -0.003 & 0.010 & 75,067 \\
\hline$S R_{i t}$ & 0.011 & 0.067 & -0.022 & 0.009 & 0.042 & 75,067 \\
\hline Labor share in nominal output $\left(\alpha_{N}\right)_{i}$ & 0.199 & 0.088 & 0.139 & 0.187 & 0.245 & 83,322 \\
\hline Materials share in nominal output $\left(\alpha_{M}\right)_{i}$ & 0.714 & 0.105 & 0.657 & 0.728 & 0.786 & 83,322 \\
\hline $1-\left(\alpha_{N}\right)_{i}-\left(\alpha_{M}\right)_{i}$ & 0.087 & 0.048 & 0.054 & 0.074 & 0.105 & 83,322 \\
\hline Number of employees $N_{i t}$ & 531 & 2,255 & 94 & 160 & 340 & 83,322 \\
\hline \multicolumn{7}{|c|}{ THE NETHERLANDS (1993-2008) } \\
\hline Variables & Mean & Sd. & 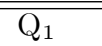 & 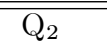 & 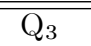 & $\overline{\mathrm{N}}$ \\
\hline Real firm output growth rate $\Delta q_{i t}$ & 0.025 & 0.186 & -0.063 & 0.022 & 0.115 & 65,321 \\
\hline Labor growth rate $\Delta n_{i t}$ & 0.004 & 0.127 & -0.026 & 0.000 & 0.034 & 65,321 \\
\hline Materials growth rate $\Delta m_{i t}$ & 0.026 & 0.251 & -0.088 & 0.020 & 0.142 & 65,321 \\
\hline Capital growth rate $\Delta k_{i t}$ & 0.016 & 0.227 & -0.076 & 0.000 & 0.114 & 65,321 \\
\hline$\left(\alpha_{N}\right)_{j}\left(\Delta n_{i t}-\Delta k_{i t}\right)+\left(\alpha_{M}\right)_{j}\left(\Delta m_{i t}-\Delta k_{i t}\right)$ & 0.001 & 0.175 & -0.077 & -0.003 & 0.078 & 65,321 \\
\hline$\left(\alpha_{N}\right)_{j}\left(\Delta k_{i t}-\Delta n_{i t}\right)$ & 0.003 & 0.061 & -0.023 & 0.000 & 0.032 & 65,321 \\
\hline$S R_{i t}$ & 0.008 & 0.107 & -0.043 & 0.004 & 0.059 & 65,321 \\
\hline Labor share in nominal output $\left(\alpha_{N}\right)_{i}$ & 0.275 & 0.109 & 0.200 & 0.273 & 0.344 & 73,149 \\
\hline Materials share in nominal output $\left(\alpha_{M}\right)_{i}$ & 0.447 & 0.147 & 0.349 & 0.439 & 0.539 & 73,149 \\
\hline $1-\left(\alpha_{N}\right)_{i}-\left(\alpha_{M}\right)_{i}$ & 0.278 & 0.092 & 0.215 & 0.272 & 0.332 & 73,149 \\
\hline Number of employees $N_{i t}$ & 105 & 472 & 27 & 45 & 93 & 73,149 \\
\hline
\end{tabular}

Note: $S R_{i t}=\Delta q_{i t}-\left(\alpha_{N}\right)_{j} \Delta n_{i t}-\left(\alpha_{M}\right)_{j} \Delta m_{i t}-\left[1-\left(\alpha_{N}\right)_{j}-\left(\alpha_{M}\right)_{j}\right] \Delta k_{i t}$. 
Table 2: Industry classification 1 by country

\begin{tabular}{|c|c|c|c|c|c|c|c|c|c|c|c|c|}
\hline $\begin{array}{l}\text { \# ind. } \\
\text { prop. of ind. }(\%)\end{array}$ & \multicolumn{9}{|c|}{ LABOR MARKET SETTING } & \multirow[b]{3}{*}{$F R$} & \multirow[b]{3}{*}{$J P$} & \multirow[b]{3}{*}{$N L$} \\
\hline PRODUCT MARKET & \multicolumn{3}{|c|}{ PR } & \multicolumn{3}{|c|}{ EB } & \multicolumn{3}{|c|}{ MO } & & & \\
\hline SETTING & $F R$ & $J P$ & $N L$ & $F R$ & $J P$ & $N L$ & $F R$ & $J P$ & $N L$ & & & \\
\hline \multirow{3}{*}{ PC } & 3 & 11 & 1 & 0 & 5 & 0 & 1 & 0 & 2 & 4 & 16 & 3 \\
\hline & 10.0 & 36.7 & 3.3 & 0 & 16.7 & 0 & 3.3 & 0 & 6.7 & 13.3 & 53.4 & 10.0 \\
\hline & 4.7 & 41.9 & 1.2 & 0 & 14.3 & 0 & 0.6 & 0 & 3.9 & 5.3 & 56.2 & 5.1 \\
\hline \multirow{6}{*}{ IC } & 10 & 10 & 9 & 13 & 4 & 10 & 3 & 0 & 8 & 26 & 14 & 27 \\
\hline & 33.3 & 33.3 & 30.0 & 43.3 & 13.3 & 33.3 & 10.0 & 0 & 26.7 & 86.6 & 46.6 & 90.0 \\
\hline & 22.2 & 24.8 & 37.1 & 68.3 & 18.9 & 36.0 & 4.1 & 0 & 21.8 & 94.6 & 43.7 & 94.9 \\
\hline & 13 & 21 & 10 & 13 & 9 & 10 & 4 & 0 & 10 & 30 & 30 & 30 \\
\hline & 43.3 & 70.0 & 33.3 & 43.3 & 30.0 & 33.3 & 13.3 & 0 & 33.4 & 100 & 100 & 100 \\
\hline & 26.9 & 66.7 & 38.3 & 68.3 & 33.2 & 36.0 & 4.7 & 0 & 25.7 & 100 & 100 & 100 \\
\hline
\end{tabular}


Table 3a: Product and labor market settings according to industry classification 2 by country

\begin{tabular}{|c|c|c|c|}
\hline PRODUCT MARKET SETTING & $F R$ & $J P$ & $N L$ \\
\hline \multicolumn{4}{|l|}{$P C^{*}$} \\
\hline \# ind. & 2 & 6 & 1 \\
\hline prop. of ind. (\%) & 6.7 & 20.0 & 3.3 \\
\hline prop. of firms (\%) & 3.4 & 18.1 & 1.0 \\
\hline \multicolumn{4}{|l|}{$I C^{*}$} \\
\hline \# ind. & 20 & 7 & 22 \\
\hline prop. of ind. (\%) & 66.7 & 23.3 & 73.3 \\
\hline prop. of firms (\%) & 84.3 & 24.7 & 88.6 \\
\hline \multicolumn{4}{|l|}{ mover } \\
\hline \# ind. & 8 & 17 & 7 \\
\hline prop. of ind. (\%) & 26.7 & 56.7 & 23.3 \\
\hline prop. of firms (\%) & 12.2 & 57.2 & 10.4 \\
\hline " LABOR MARKET SETTING & $F R$ & $J P$ & $\overline{N N L}$ \\
\hline \multicolumn{4}{|l|}{$P R^{*}$} \\
\hline \# ind. & 7 & 9 & 9 \\
\hline prop. of ind. (\%) & 23.3 & 30.0 & 30.0 \\
\hline prop. of firms (\%) & 9.3 & 34.7 & 39.8 \\
\hline \multicolumn{4}{|l|}{$E B^{*}$} \\
\hline \# ind. & 9 & 4 & 1 \\
\hline prop. of ind. (\%) & 30.0 & 13.3 & 3.3 \\
\hline prop. of firms (\%) & 56.9 & 14.4 & 7.9 \\
\hline \multicolumn{4}{|l|}{$M O^{*}$} \\
\hline \# ind. & 0 & 0 & 0 \\
\hline prop. of ind. (\%) & 0 & 0 & 0 \\
\hline prop. of firms (\%) & 0 & 0 & 0 \\
\hline \multicolumn{4}{|l|}{ mover } \\
\hline \# ind. & 14 & 17 & 20 \\
\hline prop. of ind. (\%) & 46.7 & 56.7 & 66.7 \\
\hline prop. of firms $(\%)$ & 33.8 & 50.8 & 52.3 \\
\hline
\end{tabular}

Table 3b: Industry classification 2 by country

\begin{tabular}{|c|c|c|c|c|c|c|c|c|c|c|c|c|}
\hline $\begin{array}{l}\text { \# ind. } \\
\text { prop. of ind. }(\%)\end{array}$ & \multicolumn{9}{|c|}{ LABOR MARKET SETTING } & \multirow[b]{2}{*}{$F R$} & \multirow[b]{2}{*}{$J P$} & \multirow[b]{2}{*}{$N L$} \\
\hline SETTING & $F R$ & $J P$ & $N L$ & $F R$ & $J P$ & $N L$ & $F R$ & $J P$ & $N L$ & & & \\
\hline $\mathbf{P C}^{*}$ & 2 & 3 & 1 & 0 & 1 & 0 & 0 & 0 & 0 & 2 & 4 & 1 \\
\hline \multirow{4}{*}{$\mathbf{I C}^{*}$} & 2 & 0 & 4 & 9 & 1 & 1 & 0 & 0 & 0 & 11 & 1 & 5 \\
\hline & 6.7 & 0 & 13.3 & 30.0 & 3.3 & 3.3 & 0 & 0 & 0 & 36.7 & 3.3 & 16.6 \\
\hline & 2.3 & 0 & 30.9 & 56.9 & 7.7 & 7.9 & 0 & 0 & 0 & 59.2 & 7.7 & 38.8 \\
\hline & 4 & 3 & 5 & 9 & 2 & 1 & 0 & 0 & 0 & 13 & 5 & 6 \\
\hline
\end{tabular}


Table 4: Sensitivity of classification 1 to estimation methods

\begin{tabular}{|c|c|c|c|c|c|c|c|c|c|}
\hline \multirow[b]{2}{*}{ PRODUCT MARKET SETTING } & \multicolumn{3}{|c|}{ SYS-GMM - OLS } & \multicolumn{3}{|c|}{$S Y S-G M M-F E$} & \multicolumn{3}{|c|}{$S Y S S-G M M-W-L P$} \\
\hline & $F R$ & $J P$ & $N L$ & $F R$ & $J P$ & $N L$ & $F R$ & $J P$ & $N L$ \\
\hline $\begin{array}{l}P C \\
\text { prop. of ind. }(\%)\end{array}$ & 6.7 & 43.3 & 6.7 & 16.7 & 40.0 & 3.3 & 10.0 & 36.4 & 10.0 \\
\hline $\begin{array}{l}I C \\
\text { prop. of ind. (\%) }\end{array}$ & 76.7 & 20.0 & 83.3 & 50.0 & 23.3 & 73.3 & 56.7 & 13.3 & 26.7 \\
\hline $\begin{array}{l}\text { TOTAL PMS } \\
\text { prop. of ind. }(\%)\end{array}$ & 83.4 & 63.3 & 90.0 & 66.7 & 63.3 & 76.6 & 66.7 & 49.7 & 36.7 \\
\hline LABOR MARKET SETTING & $F R$ & $J P$ & $N L$ & $F R$ & $J P$ & $N L$ & $F R$ & $J P$ & $N L$ \\
\hline $\begin{array}{l}P R \\
\text { prop. of ind. }(\%)\end{array}$ & 30.0 & 66.7 & 30.0 & 63.3 & 46.7 & 20.0 & 13.3 & 40.0 & 6.7 \\
\hline $\begin{array}{l}E B \\
\text { prop. of ind. (\%) }\end{array}$ & 10.0 & 3.3 & 13.3 & 6.7 & 16.7 & 10.0 & 10.0 & 16.7 & 10.0 \\
\hline $\begin{array}{l}M O \\
\text { prop. of ind. (\%) }\end{array}$ & 3.3 & 0.0 & 30.0 & 6.7 & 0.0 & 10.0 & 3.3 & 0.0 & 20.0 \\
\hline $\begin{array}{l}\text { TOTAL LMS } \\
\text { prop. of ind. }(\%)\end{array}$ & 43.3 & 70.0 & 73.3 & 76.7 & 63.4 & 40.0 & 26.6 & 56.7 & 36.7 \\
\hline REGIME & $F R$ & $J P$ & $N L$ & $F R$ & $J P$ & $N L$ & $F R$ & $J P$ & $N L$ \\
\hline prop. of ind. (\%) & 36.7 & 40.0 & 66.7 & 26.7 & 43.3 & 36.7 & 20.0 & 26.7 & 23.3 \\
\hline
\end{tabular}


Table 5: Sensitivity of classification 2 to estimation methods

\begin{tabular}{|c|c|c|c|c|c|c|c|c|c|}
\hline \multirow[b]{2}{*}{ PRODUCT MARKET SETTING } & \multicolumn{3}{|c|}{ SYS-GMM - OLS } & \multicolumn{3}{|c|}{$S Y S-G M M-F E$} & \multicolumn{3}{|c|}{$S Y S S-G M M-W-L P$} \\
\hline & $F R$ & $J P$ & $N L$ & $F R$ & $J P$ & $N L$ & $F R$ & $J P$ & $N L$ \\
\hline $\begin{array}{l}P C^{*} \\
\text { prop. of ind. }(\%)\end{array}$ & 4.6 & 38.5 & 4.4 & 9.1 & 38.5 & 0.0 & 9.1 & 15.4 & 4.3 \\
\hline $\begin{array}{l}I C^{*} \\
\text { prop. of ind. }(\%)\end{array}$ & 68.2 & 7.7 & 73.9 & 50.0 & 7.7 & 73.9 & 27.3 & 0.0 & 8.7 \\
\hline $\begin{array}{l}\left(P C^{*}+I C^{*}\right) \\
\text { prop. of ind. }(\%)\end{array}$ & 72.7 & 46.2 & 78.3 & 59.1 & 46.2 & 73.9 & 36.4 & 15.4 & 13.0 \\
\hline LABOR MARKET SETTING & $F R$ & $J P$ & $N L$ & $F R$ & $J P$ & $N L$ & $F R$ & $J P$ & $N L$ \\
\hline $\begin{array}{l}P R^{*} \\
\text { prop. of ind. }(\%)\end{array}$ & 37.5 & 30.8 & 90.0 & 37.5 & 46.2 & 80.0 & 18.8 & 7.7 & 60.0 \\
\hline $\begin{array}{l}E B^{*} \\
\text { prop. of ind. (\%) }\end{array}$ & 18.8 & 0.0 & 0.0 & 12.5 & 30.8 & 10.0 & 25.0 & 0.0 & 0.0 \\
\hline $\begin{array}{l}M O^{*} \\
\text { prop. of ind. }(\%)\end{array}$ & 0.0 & 0.0 & 0.0 & 0.0 & 0.0 & 0.0 & 0.0 & 0.0 & 0.0 \\
\hline $\begin{array}{l}\left(P R^{*}+E B^{*}+M O^{*}\right) \\
\text { prop. of ind. }(\%)\end{array}$ & 56.3 & 30.8 & 90.0 & 50.0 & 76.9 & 90.0 & 43.8 & 7.7 & 60.0 \\
\hline REGIME & $F R$ & $J P$ & $N L$ & $F R$ & $J P$ & $N \overline{N L}$ & 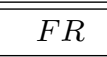 & $J P$ & $\overline{N L L}$ \\
\hline prop. of ind. (\%) & 46.2 & 20.0 & 66.7 & 30.8 & 60.0 & 83.3 & 38.5 & 0.0 & 0.0 \\
\hline
\end{tabular}


Table 6: Industry-specific scale elasticity parameter $\widehat{\lambda}_{j}$, joint market imperfections parameter $\widehat{\psi}_{j}$, and corresponding price-cost mark-up $\widehat{\mu}_{j}$ and absolute extent of rent sharing $\widehat{\phi}_{j}$ or labor supply elasticity $\left(\widehat{\varepsilon}_{w}^{N}\right)_{j}$ by country

\begin{tabular}{|c|c|c|c|c|c|c|}
\hline \multicolumn{7}{|c|}{ FRANCE } \\
\hline $\begin{array}{l}\text { Regime } R=I C-E B \\
{[43 \% \text { of industries, } 68 \% \text { of firms }]}\end{array}$ & $\widehat{\lambda}_{j}$ & $\widehat{\psi}_{j}$ & $\widehat{\mu}_{j}$ & $\left(\frac{\widehat{\mu}}{\widehat{\lambda}}\right)_{j}$ & $\widehat{\gamma}_{j}$ & $\widehat{\phi}_{j}$ \\
\hline Industry mean & $0.964(0.021)$ & $0.599(0.150)$ & $1.352(0.049)$ & $1.403(0.062)$ & $0.762(0.167)$ & $0.423(0.057)$ \\
\hline Industry $Q_{1}$ & $0.944(0.019)$ & $0.539(0.124)$ & $1.308(0.042)$ & $1.339(0.054)$ & $0.595(0.127)$ & $0.373(0.041)$ \\
\hline Industry $Q_{2}$ & $0.955(0.020)$ & $0.555(0.138)$ & $1.339(0.049)$ & $1.400(0.056)$ & $0.749(0.155)$ & $0.428(0.048)$ \\
\hline Industry $Q_{3}$ & $0.993(0.021)$ & $0.642(0.156)$ & $1.390(0.052)$ & $1.441(0.073)$ & $0.872(0.213)$ & $0.466(0.081)$ \\
\hline $\begin{array}{l}\text { Regime } R=I C-P R \\
{[33 \% \text { of industries, } 22 \% \text { of firms }]}\end{array}$ & $\widehat{\lambda}_{j}$ & $\widehat{\psi}_{j}$ & $\widehat{\mu}_{j}$ & $\left(\frac{\widehat{\mu}}{\widehat{\lambda}}\right)_{j}$ & & \\
\hline Industry mean & $0.995(0.030)$ & $0.082(0.234)$ & $1.233(0.079)$ & $1.239(0.089)$ & & \\
\hline Industry $Q_{1}$ & $0.981(0.026)$ & $-0.093(0.208)$ & $1.171(0.065)$ & $1.195(0.074)$ & & \\
\hline Industry $Q_{2}$ & $1.006(0.030)$ & $0.134(0.255)$ & $1.225(0.074)$ & $1.225(0.082)$ & & \\
\hline Industry $Q_{3}$ & $1.016(0.034)$ & $0.216(0.266)$ & $1.272(0.096)$ & $1.253(0.113)$ & & \\
\hline $\begin{array}{l}\text { Regime } R=P C-P R \\
{[\mathbf{1 0 \%} \text { of industries, } \mathbf{5 \%} \text { of firms }]}\end{array}$ & $\widehat{\lambda}_{j}$ & $\widehat{\psi}_{j}$ & $\widehat{\mu}_{j}$ & $\left(\frac{\widehat{\mu}}{\widehat{\lambda}}\right)_{j}$ & & \\
\hline Industry mean & $0.958(0.030)$ & $-0.229(0.294)$ & $1.006(0.075)$ & $1.050(0.094)$ & & \\
\hline Industry $Q_{1}$ & $0.939(0.023)$ & $-0.287(0.215)$ & $0.892(0.037)$ & $0.936(0.057)$ & & \\
\hline Industry $Q_{2}$ & $0.953(0.025)$ & $-0.202(0.326)$ & $1.034(0.070)$ & $1.101(0.085)$ & & \\
\hline Industry $Q_{3}$ & $0.981(0.042)$ & $-0.197(0.343)$ & $1.092(0.117)$ & $1.113(0.141)$ & & \\
\hline $\begin{array}{l}\text { Regime } R=I C-M O \\
{[\mathbf{1 0 \%} \text { of industries, } 4 \% \text { of firms }]}\end{array}$ & $\widehat{\lambda}_{j}$ & $\widehat{\psi}_{j}$ & $\widehat{\mu}_{j}$ & $\left(\frac{\widehat{\mu}}{\hat{\lambda}}\right)_{j}$ & $\widehat{\beta}_{j}$ & $\left(\widehat{\varepsilon}_{w}^{N}\right)_{j}$ \\
\hline Industry mean & $1.040(0.024)$ & $-0.528(0.326)$ & $1.171(0.083)$ & $1.127(0.088)$ & $0.691(0.146)$ & $2.270(1.630)$ \\
\hline Industry $Q_{1}$ & $1.015(0.021)$ & $-0.624(0.276)$ & $1.130(0.062)$ & $1.081(0.062)$ & $0.653(0.108)$ & $1.883(0.900)$ \\
\hline Industry $Q_{2}$ & $1.045(0.022)$ & $-0.542(0.321)$ & $1.176(0.083)$ & $1.110(0.094)$ & $0.690(0.162)$ & $2.226(1.690)$ \\
\hline Industry $Q_{3}$ & $1.059(0.028)$ & $-0.418(0.379)$ & $1.207(0.104)$ & $1.190(0.108)$ & $0.730(0.168)$ & $2.700(2.302)$ \\
\hline \multicolumn{7}{|c|}{ JAPAN } \\
\hline $\begin{array}{l}\text { Regime } R=P C-P R \\
{[37 \% \text { of industries, } 42 \% \text { of firms }]}\end{array}$ & $\widehat{\lambda}_{j}$ & $\widehat{\psi}_{j}$ & $\widehat{\mu}_{j}$ & $\left(\frac{\widehat{\mu}}{\hat{\lambda}}\right)_{j}$ & & \\
\hline Industry mean & $1.047(0.021)$ & $-0.109(0.248)$ & $1.058(0.047)$ & $1.011(0.054)$ & & \\
\hline Industry $Q_{1}$ & $1.031(0.016)$ & $-0.283(0.214)$ & $1.037(0.042)$ & $0.967(0.048)$ & & \\
\hline Industry $Q_{2}$ & $1.037(0.018)$ & $-0.136(0.256)$ & $1.066(0.044)$ & $0.995(0.053)$ & & \\
\hline Industry $Q_{3}$ & $1.069(0.027)$ & $0.003(0.278)$ & $1.092(0.055)$ & $1.052(0.064)$ & & \\
\hline $\begin{array}{l}\text { Regime } R=I C-P R \\
{[33 \% \text { of industries, } 25 \% \text { of firms }]}\end{array}$ & $\widehat{\lambda}_{j}$ & $\widehat{\psi}_{j}$ & $\widehat{\mu}_{j}$ & $\left(\frac{\widehat{\mu}}{\hat{\lambda}}\right)_{j}$ & & \\
\hline Industry mean & $1.034(0.018)$ & $0.134(0.206)$ & $1.148(0.036)$ & $1.111(0.043)$ & & \\
\hline Industry $Q_{1}$ & $1.025(0.016)$ & $0.040(0.159)$ & $1.127(0.029)$ & $1.079(0.037)$ & & \\
\hline Industry $Q_{2}$ & $1.029(0.017)$ & $0.113(0.199)$ & $1.135(0.036)$ & $1.107(0.043)$ & & \\
\hline Industry $Q_{3}$ & $1.056(0.021)$ & $0.204(0.238)$ & $1.182(0.041)$ & $1.119(0.049)$ & & \\
\hline $\begin{array}{l}\text { Regime } R=P C-E B \\
{[\mathbf{1 7 \%} \text { of industries, } \mathbf{1 4 \%} \text { of firms }]}\end{array}$ & $\widehat{\lambda}_{j}$ & $\widehat{\psi}_{j}$ & $\widehat{\mu}_{j}$ & $\left(\frac{\widehat{\mu}}{\widehat{\lambda}}\right)_{j}$ & $\widehat{\gamma}_{j}$ & $\widehat{\phi}_{j}$ \\
\hline Industry mean & $1.003(0.017)$ & $0.440(0.220)$ & $1.071(0.035)$ & $1.067(0.039)$ & $0.908(0.469)$ & $0.474(0.134)$ \\
\hline Industry $Q_{1}$ & $1.003(0.015)$ & $0.347(0.208)$ & $1.067(0.024)$ & $1.059(0.035)$ & $0.815(0.369)$ & $0.449(0.083)$ \\
\hline Industry $Q_{2}$ & $1.007(0.015)$ & $0.357(0.245)$ & $1.080(0.034)$ & $1.062(0.041)$ & $0.847(0.489)$ & $0.458(0.143)$ \\
\hline Industry $Q_{3}$ & $1.014(0.016)$ & $0.438(0.251)$ & $1.087(0.045)$ & $1.080(0.043)$ & $0.997(0.563)$ & $0.499(0.171)$ \\
\hline $\begin{array}{l}\text { Regime } R=I C-E B \\
{[13 \% \text { of industries, } 19 \% \text { of firms }]}\end{array}$ & $\widehat{\lambda}_{j}$ & $\widehat{\psi}_{j}$ & $\widehat{\mu}_{j}$ & $\left(\frac{\widehat{\mu}}{\widehat{\lambda}}\right)_{j}$ & $\widehat{\gamma}_{j}$ & $\widehat{\phi}_{j}$ \\
\hline Industry mean & $1.021(0.013)$ & $0.455(0.166)$ & $1.177(0.033)$ & $1.153(0.040)$ & $0.869(0.306)$ & $0.459(0.086)$ \\
\hline Industry $Q_{1}$ & $1.014(0.011)$ & $0.437(0.138)$ & $1.162(0.025)$ & $1.146(0.030)$ & $0.681(0.223)$ & $0.405(0.069)$ \\
\hline Industry $Q_{2}$ & $1.024(0.014)$ & $0.446(0.171)$ & $1.177(0.032)$ & $1.152(0.038)$ & $0.827(0.256)$ & $0.450(0.091)$ \\
\hline Industry $Q_{3}$ & $1.028(0.015)$ & $0.474(0.194)$ & $1.193(0.041)$ & $1.161(0.050)$ & $1.057(0.388)$ & $0.513(0.103)$ \\
\hline
\end{tabular}


Table 6 (ctd): Industry-specific scale elasticity parameter $\widehat{\lambda}_{j}$, joint market imperfections parameter $\widehat{\psi}_{j}$, and corresponding price-cost mark-up $\widehat{\mu}_{j}$ and absolute extent of rent sharing $\widehat{\phi}_{j}$ or labor supply elasticity $\left(\widehat{\varepsilon}_{w}^{N}\right)_{j}$ by country

\begin{tabular}{|c|c|c|c|c|c|c|}
\hline \multicolumn{7}{|c|}{ THE NETHERLANDS } \\
\hline $\begin{array}{l}\text { Regime } R=I C-P R \\
{[\mathbf{3 0 \%} \text { of industries, } \mathbf{3 7 \%} \text { of firms] }}\end{array}$ & $\widehat{\lambda}_{j}$ & $\widehat{\psi}_{j}$ & $\widehat{\mu}_{j}$ & $\left(\frac{\widehat{\mu}}{\hat{\lambda}}\right)_{j}$ & & \\
\hline Industry mean & $1.026(0.026)$ & $0.083(0.274)$ & $1.342(0.078)$ & $1.308(0.086)$ & & \\
\hline Industry $Q_{1}$ & $1.014(0.015)$ & $-0.010(0.155)$ & $1.309(0.056)$ & $1.281(0.059)$ & & \\
\hline Industry $Q_{2}$ & $1.024(0.017)$ & $0.173(0.235)$ & $1.339(0.064)$ & $1.308(0.076)$ & & \\
\hline Industry $Q_{3}$ & $1.033(0.029)$ & $0.189(0.270)$ & $1.368(0.073)$ & $1.335(0.089)$ & & \\
\hline $\begin{array}{l}\text { Regime } R=I C-E B \\
{[\mathbf{3 3 \%} \text { of industries, } \mathbf{3 6 \%} \text { of firms }]}\end{array}$ & $\widehat{\lambda}_{j}$ & $\widehat{\psi}_{j}$ & $\widehat{\mu}_{j}$ & $\left(\frac{\widehat{\mu}}{\hat{\lambda}}\right)_{j}$ & $\widehat{\gamma}_{j}$ & $\widehat{\phi}_{j}$ \\
\hline Industry mean & $1.013(0.034)$ & $0.513(0.320)$ & $1.415(0.092)$ & $1.398(0.111)$ & $0.773(0.153)$ & $0.430(0.047)$ \\
\hline Industry $Q_{1}$ & $0.983(0.014)$ & $0.422(0.172)$ & $1.364(0.053)$ & $1.328(0.066)$ & $0.636(0.097)$ & $0.389(0.031)$ \\
\hline Industry $Q_{2}$ & $1.011(0.027)$ & $0.498(0.227)$ & $1.400(0.081)$ & $1.401(0.101)$ & $0.773(0.120)$ & $0.436(0.036)$ \\
\hline Industry $Q_{3}$ & $1.046(0.050)$ & $0.571(0.338)$ & $1.506(0.121)$ & $1.476(0.153)$ & $0.922(0.154)$ & $0.480(0.053)$ \\
\hline $\begin{array}{l}\text { Regime } R=I C-M O \\
{[27 \% \text { of industries, } 22 \% \text { of firms }]}\end{array}$ & $\widehat{\lambda}_{j}$ & $\widehat{\psi}_{j}$ & $\widehat{\mu}_{j}$ & $\left(\frac{\widehat{\mu}}{\widehat{\lambda}}\right)_{j}$ & $\widehat{\beta}_{j}$ & $\left(\widehat{\varepsilon}_{w}^{N}\right)_{j}$ \\
\hline Industry mean & $1.070(0.051)$ & $-0.814(0.700)$ & $1.262(0.193)$ & $1.180(0.195)$ & $0.651(0.221)$ & $2.271(2.396)$ \\
\hline Industry $Q_{1}$ & $1.020(0.018)$ & $-0.819(0.261)$ & $1.159(0.069)$ & $1.058(0.072)$ & $0.606(0.114)$ & $1.556(1.023)$ \\
\hline Industry $Q_{2}$ & $1.047(0.039)$ & $-0.574(0513)$ & $1.229(0.172)$ & $1.204(0.174)$ & $0.687(0.177)$ & $2.220(1.943)$ \\
\hline Industry $Q_{3}$ & $1.130(0.089)$ & $-0.415(1.114)$ & $1.336(0.285)$ & $1.285(0.284)$ & $0.754(0.304)$ & $3.115(3.098)$ \\
\hline
\end{tabular}

Note: Robust standard errors in parentheses. 


\section{Appendix A : Details of the theoretical framework and the estimation method}

\section{A.1 Theoretical framework}

\section{A.1.1 IC and perfectly comp. labor market/right-to-manage bargaining (IC-PR) \\ $I C$ and perfectly competitive labor market}

Let us start from the following specification of the production function: $q_{i t}=\left(\varepsilon_{N}^{Q}\right)_{i t} n_{i t}+\left(\varepsilon_{M}^{Q}\right)_{i t} m_{i t}+$ $\left(\varepsilon_{K}^{Q}\right)_{i t} k_{i t}+\theta_{i t}$ (Eq. (1) in the main text). Firms operate under imperfect competition in the product market $(I C)$ and act as price takers in the input markets. Assuming that material input and labor are variable input factors, short-run profit maximization implies the following two first-order conditions:

$$
\begin{aligned}
& \left(\varepsilon_{M}^{Q}\right)_{i t}=\mu_{i t}\left(\alpha_{M}\right)_{i t} \\
& \left(\varepsilon_{N}^{Q}\right)_{i t}=\mu_{i t}\left(\alpha_{N}\right)_{i t}
\end{aligned}
$$

Eqs. (A.1) and (A.2) equal Eqs. (2) and (3) in the main text.

Assuming that the elasticity of scale, $\lambda_{i t}=\left(\varepsilon_{N}^{Q}\right)_{i t}+\left(\varepsilon_{M}^{Q}\right)_{i t}+\left(\varepsilon_{K}^{Q}\right)_{i t}$, is known, the capital elasticity can be expressed as:

$$
\left(\varepsilon_{K}^{Q}\right)_{i t}=\lambda_{i t}-\left(\varepsilon_{N}^{Q}\right)_{i t}-\left(\varepsilon_{M}^{Q}\right)_{i t}
$$

Inserting Eqs. (A.1), (A.2) and (A.3) in the production function and rearranging terms yields:

$$
q_{i t}=\mu_{i t}\left[\left(\alpha_{N}\right)_{i t}\left(n_{i t}-k_{i t}\right)+\left(\alpha_{M}\right)_{i t}\left(m_{i t}-k_{i t}\right)\right]+\lambda_{i t} k_{i t}+\nu_{i t}
$$

\section{IC and right-to-manage (RTM) bargaining}

Let us abstain from the assumption that labor is priced competitively. We assume that the workers and the firm bargain over wages $(w)$ but that the firm retains the right to set employment $(N)$ unilaterally afterwards (right-to-manage bargaining; Nickell and Andrews, 1983). Since, as in the perfectly competitive labor market case, material input and labor are unilaterally determined by the firm from profit maximization [see Eqs. (A.1) and (A.2) respectively], the mark-up of price over marginal cost $(\mu)$ that follows from Eq. (A.4) is not only consistent with the assumption that the labor market is perfectly competitive but also with the less restrictive right-to-manage bargaining assumption.

\section{A.1.2 IC and efficient bargaining $(I C-E B)$}

Firms operate under imperfect competition in the product market $(I C)$. On the labor side, we assume that the workers and the firm bargain over wages $(w)$ and employment $(N)$ (efficient bargaining; McDonald and Solow, 1981). It is the objective of the workers to maximize $U\left(w_{i t}, N_{i t}\right)=N_{i t} w_{i t}+\left(\bar{N}_{i t}-N_{i t}\right) \bar{w}_{i t}$, where $\bar{N}_{i t}$ is the competitive employment level $\left(0<N_{i t} \leq \bar{N}_{i t}\right)$ and $\bar{w}_{i t} \leq w_{i t}$ the reservation wage. Consistent with capital 
quasi-fixity, it is the firm's objective to maximize its short-run profit function: $\pi_{i t}=R_{i t}-w_{i t} N_{i t}-j_{i t} M_{i t}$, where $R_{i t}=P_{i t} Q_{i t}$ stands for total revenue. The outcome of the bargaining is the generalized Nash solution to:

$$
\max _{w_{i t}, N_{i t}, M_{i t}}\left\{N_{i t} w_{i t}+\left(\bar{N}_{i t}-N_{i t}\right) \bar{w}_{i t}-\bar{N}_{i t} \bar{w}_{i t}\right\}^{\phi_{i t}}\left\{R_{i t}-w_{i t} N_{i t}-j_{i t} M_{i t}\right\}^{1-\phi_{i t}}
$$

where $\phi_{i t} \in[0,1]$ represents the absolute extent of rent sharing.

Material input is unilaterally determined by the firm from profit maximization, which directly leads to Eq. (A.1).

Maximization with respect to the wage rate and labor respectively gives the following first-order conditions:

$$
\begin{gathered}
w_{i t}=\bar{w}_{i t}+\gamma_{i t}\left[\frac{R_{i t}-w_{i t} N_{i t}-j_{i t} M_{i t}}{N_{i t}}\right] \\
w_{i t}=\left(R_{N}\right)_{i t}+\phi_{i t}\left[\frac{R_{i t}-\left(R_{N}\right)_{i t} N_{i t}-j_{i t} M_{i t}}{N_{i t}}\right]
\end{gathered}
$$

with $\gamma_{i t}=\frac{\phi_{i t}}{1-\phi_{i t}}$ the relative extent of rent sharing and $\left(R_{N}\right)_{i t}$ the marginal revenue of labor.

Solving simultaneously Eqs. (A.6) and (A.7) leads to the following expression for the contract curve:

$$
\left(R_{N}\right)_{i t}=\bar{w}_{i t}
$$

Eq. (A.8) shows that under risk neutrality, the firm's decision about employment equals the one of a (nonbargaining) neoclassical firm that maximizes its short-run profit at the reservation wage.

Denote the marginal revenue by $\left(R_{Q}\right)_{i t}$ and the marginal product of labor by $\left(Q_{N}\right)_{i t}$. Given that $\mu_{i t}=\frac{P_{i t}}{\left(R_{Q}\right)_{i t}}$ in equilibrium, we can express the marginal revenue of labor as $\left(R_{N}\right)_{i t}=\left(R_{Q}\right)_{i t}\left(Q_{N}\right)_{i t}=\left(R_{Q}\right)_{i t}\left(\varepsilon_{N}^{Q}\right)_{i t} \frac{Q_{i t}}{N_{i t}}=$ $\frac{P_{i t}\left(Q_{N}\right)_{i t}}{\mu_{i t}}$. Using this expression together with Eq. (A.8), the elasticity of output with respect to labor can be written as:

$$
\left(\varepsilon_{N}^{Q}\right)_{i t}=\mu_{i t}\left(\frac{\bar{w}_{i t} N_{i t}}{P_{i t} Q_{i t}}\right)=\mu_{i t}\left(\bar{\alpha}_{N}\right)_{i t}
$$

Given that we can rewrite Eq. (A.6) as $\left(\alpha_{N}\right)_{i t}=\left(\bar{\alpha}_{N}\right)_{i t}+\gamma_{i t}\left[1-\left(\alpha_{N}\right)_{i t}-\left(\alpha_{M}\right)_{i t}\right]$, Eq. (A.9) is equivalent to Eq. (4) in the main text:

$$
\left(\varepsilon_{N}^{Q}\right)_{i t}=\mu_{i t}\left(\alpha_{N}\right)_{i t}-\mu_{i t} \gamma_{i t}\left[1-\left(\alpha_{N}\right)_{i t}-\left(\alpha_{M}\right)_{i t}\right]
$$

\section{A.1.3 IC and monopsony $(I C-M O)$}

So far, we have assumed that there is a potentially infinite supply of employees wanting a job in the firm. A small wage cut by the employer will result in the immediate resignation of all existing workers. However, there are a number of reasons why labor supply might be less than perfectly elastic, creating rents to jobs. Paramount among these are the absence of perfect information on alternative possible jobs (Burdett and Mortensen, 1998), moving costs (Boal and Ransom, 1997) and heterogeneous worker preferences for job 
characteristics (Bhaskar and To, 1999; Bhaskar et al., 2002) on the supply side, and efficiency wages with diseconomies of scale in monitoring (Boal and Ransom, 1997) and entry costs on the part of competing firms on the demand side. All these factors give employers non-negligible market power over their workers.

Consider a firm that operates under imperfect competition in the product market $(I C)$ and faces a labor supply $N_{i t}\left(w_{i t}\right)$, which is an increasing function of the wage $w_{i t}$. Both $N_{i t}\left(w_{i t}\right)$ and the inverse of this relationship $w_{i t}\left(N_{i t}\right)$ are referred to as the labor supply curve of the individual firm. The monopsonist firm's objective is to maximize its short-run profit function, taking the labor supply curve as given:

$$
\max _{N_{i t}, M_{i t}} \pi\left(w_{i t}, N_{i t}, M_{i t}\right)=R_{i t}\left(N_{i t}, M_{i t}\right)-w_{i t}\left(N_{i t}\right) N_{i t}-j_{i t} M_{i t}
$$

Maximization with respect to material input directly leads to Eq. (A.1).

Maximization with respect to labor gives the following first-order condition:

$$
w_{i t}=\beta_{i t}\left(R_{N}\right)_{i t}
$$

where $\beta_{i t}=\frac{\left(\varepsilon_{w}^{N}\right)_{i t}}{1+\left(\varepsilon_{w}^{N}\right)_{i t}}$ and $\left(\varepsilon_{w}^{N}\right)_{i t} \in \Re_{+}$represents the wage elasticity of the labor supply. Rewriting Eq. (A.12) gives the following expression for the elasticity of output with respect to labor (Eq. (5) in the main text):

$$
\left(\varepsilon_{N}^{Q}\right)_{i t}=\mu_{i t}\left(\alpha_{N}\right)_{i t}\left(1+\frac{1}{\left(\varepsilon_{w}^{N}\right)_{i t}}\right)
$$

\section{A.2 Consistent estimation of microeconomic production functions: Alternative estimators}

The recent literature on production function estimation is dominated by two econometric approaches that differ in handling endogeneity of inputs and unobserved productivity in models linear in parameters. Intuitively, both approaches differ in the way they put assumptions on the economic environment that allow econometricians to exploit lagged input decisions as instruments for current input choices. The parametric generalized method of moments $(G M M)$ approach relies on instrumental variables $(I V)$. The semiparametric structural control function $(C F)$ approach uses observed variables and economic theory to invert out productivity nonparametrically and hence to obtain an observable expression for productivity. ${ }^{1}$ In the main text, we provide details on the $G M M$ approach and its application in our framework. This section discusses $(i)$ the $I V$ approach and $(i i)$ the $C F$ approach on which the Wooldridge-Levinsohn-Petrin estimator is based.

Following most of the literature, we are interested in estimating average production coefficients of the production function:

$$
q_{i t}=\varepsilon_{N}^{Q} n_{i t}+\varepsilon_{M}^{Q} m_{i t}+\varepsilon_{K}^{Q} k_{i t}+u_{t}+\zeta_{i t}
$$

\footnotetext{
${ }^{1}$ Eberhardt and Helmers (2010) survey the most popular parametric and semiparametric estimators dealing with the transmission bias for Cobb-Douglas production functions while Del Gatto et al. (2011) survey methodologies for measuring productivity. Van Biesebroeck (2007) compares the robustness of five commonly used techniques to estimating total factor productivity -index numbers, data envelop analysis, stochastic frontiers, GMM and the Levinsohn-Petrin estimator-to the presence of measurement error and to differences in production technology.
} 
with $\zeta_{i t}=\omega_{i t}+\epsilon_{i t}$. Of the error components, $\omega_{i t}$ represents unobserved productivity to the econometrician but possible observed by the firm at $t$ when input decisions are made (transmitted productivity shock), while $\epsilon_{i t}$ captures all other sources of error or productivity that is not observed by the firm before making input choices at $t . u_{t}$ is a year-specific intercept.

\section{A.2.1 Instrumental variables approach}

The most straightforward solution to the endogeneity problem when estimating Eq. (A.14) is to use instrumental variables that are correlated with the inputs but uncorrelated with productivity $\left(\omega_{i t}\right.$ and $\left.\epsilon_{i t}\right)$. Potential instruments might be input prices, output prices and output demand/input supply shifters. Only the latter set of instruments would be valid irrespective of the type of competition in output and input markets. In practice, finding valid instruments has proven to be very hard in production function estimations. ${ }^{2}$

\section{A.2.2 Control function approach}

Fundamental to the $C F$ approach is to use firm decisions to find proxy variables for the transmitted productivity shock $\left(\omega_{i t}\right)$ and use information in these proxy variables to invert out $\omega_{i t}$ from the residual. Olley and Pakes (1996) (OP for short) use the investment decision to proxy for unobserved productivity. To obtain consistent estimates, their dynamic model of firm behavior assumes that the only unobserved state variable is productivity (scalar unobservable assumption) which evolves as a first-order Markov process and that the investment demand function is strictly monotonic in $\omega_{i t}$ to ensure invertibility of the investment demand function. Levinsohn and Petrin (2003) ( $L P$ for short) cast doubt on the validity of the strict monotonicity assumption because investment is very lumpy and hence the investment proxy might not smoothly respond to the productivity shock and because the proportion of firms reporting zero investment might be large in many datasets. They use an intermediate input demand function to invert out unobserved productivity. Both the $O P / L P$ procedure consists of two steps. In a first step, semiparametric methods are used to identify the coefficients on the variable input factors and the joint effect of all state variables on output. ${ }^{3}$ In a second step, the coefficients of the observable state variables are estimated under assumptions on the dynamics of the productivity process. Ackerberg et al. (2006) propose an alternative estimation procedure that draws on aspects of both the $O P$ and $L P$ procedures. ${ }^{4}$

\footnotetext{
${ }^{2}$ Exceptions are Eslava et al. (2004) and Syverson (2004) who follow Shea (1993) and use demand shifters in geographically differentiated industries as instruments. As discussed in Ackerberg et al. (2007), using input prices as instruments has not been successful in practice.

${ }^{3}$ Obviously, the nonparametric treatment of the inverse of the investment function -approximated by a high-order polynomial in its arguments- prevents identification of the capital coefficient due to collinearity.

${ }^{4}$ Other recent extensions include Doraszelski and Jaumandreu (2013) and Gandhi et al. (2013). Doraszelski and Jaumandreu (2013) develop an estimable model of endogenous productivity that integrates the capital model of R\&D within the $O P / L P$ productivity estimator. Gandhi et al. (2013) relax the scalar unobservable assumption in investment or other input demand functions, which rules out measurement or optimization error in these variables. They propose a nonparametric estimation strategy which is based on a transformation of the firm's first-order conditions for flexible inputs.
} 


\section{Appendix B : Statistical annex}

\section{B.1 Measurement of the cost of capital in the Japanese data}

The capital stock is constructed from tangible fixed assets. In the BSJBSA, tangible fixed assets include land that is reported at nominal book values except for 1995 and 1996. In other words, the information on land is available only in 1995 and 1996. To construct the capital stock, we first exclude land from tangible fixed assets, multiplying by ( 1 - the land ratio):

$$
\left(\widetilde{B}_{K}\right)_{i t}=(1-\varkappa)\left(B_{K}\right)_{i t}
$$

where $\left(\widetilde{B}_{K}\right)_{i t}$ and $\left(B_{K}\right)_{i t}$ are the book value of tangible fixed assets that excludes land and includes land respectively and $\varkappa$ is the land ratio. Following Fukao and Kwon (2006), the land ratio is proxied by the industry-average ratio of land to tangible fixed assets in 1995 and $1996 .{ }^{1}$

The book value of tangible assets (excluding land) is then converted to the current value of tangible assets (or nominal tangible assets). The conversion rate is constructed from the Financial Statements Statistics of Corporations by Industry published by the Ministry of Finance. The value of nominal tangible assets is then deflated by the investment goods deflator:

$$
\widetilde{K}_{i t}=\frac{\rho_{t}\left(\widetilde{B}_{K}\right)_{i t}}{\left(P_{I}\right)_{t}}
$$

where $\widetilde{K}_{i t}$ denotes real tangible assets for firm $i$ in year $t$ (2000 constant prices), $\rho_{t}$ is the conversion rate ${ }^{2}$ and $\left(P_{I}\right)_{t}$ is the investment goods deflator, which is defined as industry-specific nominal investment flows divided by industry-specific real investment flows. The latter is obtained from the JIP 2009 database. The real value of tangible assets in the initial year $\tau$ is defined as the initial capital stock $\left(\widetilde{K}_{i \tau}\right)$, where $\tau$ equals 1994 or the first year that a firm appears in the BSJBSA. The perpetual inventory method is then used to construct the real capital stock:

$$
K_{i t}=\left(1-\delta_{t}\right) K_{i t-1}+\frac{I_{i t}}{\left(P_{I}\right)_{t}}
$$

where $K_{i t}$ is the capital stock for firm $i$ in year $t, \delta_{t}$ the depreciation rate defined as the weighted average of various assets in an industry and $I_{i t}$ investment. ${ }^{3} \delta_{t}$ is obtained from the JIP 2009 database.

The cost of capital is the user cost of capital multiplied by the real capital stock. The user cost of capital is obtained from the JIP 2009 database and defined as the industry-specific nominal capital cost divided by the industry-specific real capital stock.

\footnotetext{
${ }^{1}$ Therefore, the land ratio is constant throughout the period.

${ }^{2}$ For more details on the conversion rate, see Tokui et al. (2008).

${ }^{3}$ We consider firms that did not report investment as firms with zero investment.
} 
Table B.1: Panel structure: Number of participations by country

\begin{tabular}{|c|c|c|c|c|c|c|c|c|c|c|c|c|}
\hline \multirow[b]{2}{*}{ \# of participations ${ }^{a)}$} & \multicolumn{4}{|c|}{ FRANCE } & \multicolumn{4}{|c|}{ JAPAN } & \multicolumn{4}{|c|}{ THE NETHERLANDS } \\
\hline & \# obs & $\%$ & \# firms & $\%$ & \# obs & $\%$ & \# firms & $\%$ & \# obs & $\%$ & \# firms & $\%$ \\
\hline 4 & 2,568 & 1.47 & 642 & 3.64 & 2,220 & 2.66 & 555 & 6.36 & 4,100 & 5.60 & 1,025 & 13.09 \\
\hline 5 & 4,910 & 2.81 & 982 & 5.56 & 3,200 & 3.84 & 640 & 7.33 & 3,065 & 4.19 & 613 & 7.83 \\
\hline 6 & 12,162 & 6.97 & 2,027 & 11.48 & 3,594 & 4.31 & 599 & 6.86 & 3,960 & 5.41 & 660 & 8.43 \\
\hline 7 & 13,972 & 8.00 & 1,996 & 11.31 & 4,620 & 5.54 & 660 & 7.56 & 4,634 & 6.34 & 662 & 8.46 \\
\hline 8 & 14,128 & 8.09 & 1,766 & 10.00 & 5,344 & 6.41 & 668 & 7.65 & 4,504 & 6.16 & 563 & 7.19 \\
\hline 9 & 14,346 & 8.22 & 1,594 & 9.03 & 6,660 & 7.99 & 740 & 8.48 & 5,310 & 7.26 & 590 & 7.54 \\
\hline 10 & 15,650 & 8.96 & 1,565 & 8.87 & 8,090 & 9.71 & 809 & 9.27 & 5,940 & 8.12 & 594 & 7.59 \\
\hline 11 & 13,926 & 7.98 & 1,266 & 7.17 & 10,043 & 12.05 & 913 & 10.46 & 6,292 & 8.60 & 572 & 7.31 \\
\hline 12 & 14,856 & 8.51 & 1,238 & 7.01 & 15,852 & 19.02 & 1,321 & 15.14 & 6,768 & 9.25 & 564 & 7.20 \\
\hline 13 & 13,000 & 7.45 & 1,000 & 5.66 & 23,699 & 28.44 & 1,823 & 20.89 & 6,929 & 9.47 & 533 & 6.81 \\
\hline 14 & 10,892 & 6.24 & 778 & 4.41 & & & & & 8,638 & 11.81 & 617 & 7.88 \\
\hline 15 & 8,910 & 5.10 & 594 & 3.36 & & & & & 5,265 & 7.20 & 351 & 4.48 \\
\hline 16 & 35,280 & 20.21 & 2,205 & 12.49 & & & & & 7,744 & 10.59 & 484 & 6.18 \\
\hline Total & 174,600 & 100.0 & 17,653 & 100.0 & 83,322 & 100.0 & 8,728 & 100.0 & 73,149 & 100.0 & 7,828 & 100.0 \\
\hline
\end{tabular}


Table B.2: Manufacturing-level estimates of output elasticities and market imperfection parameters by country

\begin{tabular}{|c|c|c|c|c|c|c|c|c|c|c|c|c|}
\hline & \multicolumn{4}{|c|}{$\overline{F F R}$} & \multicolumn{4}{|c|}{$\overline{J P}$} & \multicolumn{4}{|c|}{$\bar{N} N L$} \\
\hline & $O L S$ & $F E$ & $S Y S-G M M$ & $W-L P$ & $O L S$ & $F E$ & $S Y S-G M M$ & $W-L P$ & $O L S$ & $F E$ & $S Y S-G M M$ & $W-L P$ \\
\hline$\widehat{\varepsilon}_{N}^{Q}$ & $\begin{array}{c}0.343 \\
(0.004)\end{array}$ & $\begin{array}{c}0.304 \\
(0.002)\end{array}$ & $\begin{array}{c}0.181 \\
(0.021)\end{array}$ & $\begin{array}{c}0.287 \\
(0.004)\end{array}$ & $\begin{array}{c}0.178 \\
(0.004)\end{array}$ & $\begin{array}{c}0.128 \\
(0.002)\end{array}$ & $\begin{array}{c}0.055 \\
(0.032)\end{array}$ & $\begin{array}{c}0.159 \\
(0.003)\end{array}$ & $\begin{array}{c}0.353 \\
(0.007)\end{array}$ & $\begin{array}{c}0.322 \\
(0.003)\end{array}$ & $\begin{array}{c}0.323 \\
(0.006)\end{array}$ & $\begin{array}{c}0.306 \\
(0.006)\end{array}$ \\
\hline$\widehat{\varepsilon}_{M}^{Q}$ & $\begin{array}{c}0.597 \\
(0.003)\end{array}$ & $\begin{array}{c}0.573 \\
(0.001)\end{array}$ & $\begin{array}{c}0.617 \\
(0.020)\end{array}$ & $\begin{array}{c}0.580 \\
(0.024)\end{array}$ & $\begin{array}{c}0.781 \\
(0.003)\end{array}$ & $\begin{array}{c}0.809 \\
(0.001)\end{array}$ & $\begin{array}{c}0.845 \\
(0.017)\end{array}$ & $\begin{array}{c}0.710 \\
(0.025)\end{array}$ & $\begin{array}{c}0.562 \\
(0.007)\end{array}$ & $\begin{array}{c}0.518 \\
(0.001)\end{array}$ & $\begin{array}{c}0.572 \\
(0.004)\end{array}$ & $\begin{array}{c}0.442 \\
(0.027)\end{array}$ \\
\hline$\widehat{\varepsilon}_{K}^{Q}$ & $\begin{array}{c}0.061 \\
(0.006)\end{array}$ & $\begin{array}{c}0.070 \\
(0.002)\end{array}$ & $\begin{array}{c}0.065 \\
(0.037)\end{array}$ & $\begin{array}{c}0.163 \\
(0.030)\end{array}$ & $\begin{array}{c}0.051 \\
(0.006)\end{array}$ & $\begin{array}{c}0.047 \\
(0.003)\end{array}$ & $\begin{array}{c}0.078 \\
(0.020)\end{array}$ & $\begin{array}{c}0.277 \\
(0.031)\end{array}$ & $\begin{array}{c}0.113 \\
(0.013)\end{array}$ & $\begin{array}{c}0.080 \\
(0.003)\end{array}$ & $\begin{array}{c}0.115 \\
(0.005)\end{array}$ & $\begin{array}{c}0.393 \\
(0.035)\end{array}$ \\
\hline$\widehat{\lambda}$ & $\begin{array}{c}1.001 \\
(0.001) \\
\end{array}$ & $\begin{array}{c}0.947 \\
(0.001) \\
\end{array}$ & $\begin{array}{c}0.863 \\
(0.018) \\
\end{array}$ & $\begin{array}{c}1.030 \\
(0.006) \\
\end{array}$ & $\begin{array}{c}1.009 \\
(0.001)\end{array}$ & $\begin{array}{c}0.985 \\
(0.002) \\
\end{array}$ & $\begin{array}{c}0.978 \\
(0.032) \\
\end{array}$ & $\begin{array}{c}1.146 \\
(0.009) \\
\end{array}$ & $\begin{array}{c}1.028 \\
(0.003) \\
\end{array}$ & $\begin{array}{c}0.920 \\
(0.002) \\
\end{array}$ & $\begin{array}{c}1.009 \\
(0.006) \\
\end{array}$ & $\begin{array}{c}1.141 \\
(0.007) \\
\end{array}$ \\
\hline$\widehat{\psi}$ & $\begin{array}{c}0.079 \\
(0.017) \\
\end{array}$ & $\begin{array}{c}0.159 \\
(0.007) \\
\end{array}$ & $\begin{array}{c}0.643 \\
(0.100) \\
\end{array}$ & $\begin{array}{c}0.208 \\
(0.051) \\
\end{array}$ & $\begin{array}{c}0.202 \\
(0.021) \\
\end{array}$ & $\begin{array}{c}0.490 \\
(0.011) \\
\end{array}$ & $\begin{array}{c}0.908 \\
(0.163) \\
\end{array}$ & $\begin{array}{c}0.192 \\
(0.042) \\
\end{array}$ & $\begin{array}{l}-0.030 \\
(0.039) \\
\end{array}$ & $\begin{array}{l}-0.012 \\
(0.011) \\
\end{array}$ & $\begin{array}{c}0.104 \\
(0.025) \\
\end{array}$ & $\begin{array}{l}-0.186 \\
(0.067) \\
\end{array}$ \\
\hline$\widehat{\mu}$ & $\begin{array}{c}1.189 \\
(0.007)\end{array}$ & $\begin{array}{c}1.141 \\
(0.002)\end{array}$ & $\begin{array}{c}1.229 \\
(0.040)\end{array}$ & $\begin{array}{c}1.137 \\
(0.048)\end{array}$ & $\begin{array}{c}1.094 \\
(0.004)\end{array}$ & $\begin{array}{c}1.133 \\
(0.002)\end{array}$ & $\begin{array}{c}1.184 \\
(0.024)\end{array}$ & $\begin{array}{c}0.996 \\
(0.034)\end{array}$ & $\begin{array}{l}1.255 \\
(0.015)\end{array}$ & $\begin{array}{c}1.158 \\
(0.003)\end{array}$ & $\begin{array}{c}1.277 \\
(0.008)\end{array}$ & $\begin{array}{c}0.967 \\
(0.059)\end{array}$ \\
\hline$\widehat{\gamma}$ & $\begin{array}{c}0.736 \\
(0.017)\end{array}$ & $\begin{array}{c}0.856 \\
(0.007)\end{array}$ & $\begin{array}{l}1.485 \\
(0.079)\end{array}$ & $\begin{array}{c}0.911 \\
(0.047)\end{array}$ & $\begin{array}{c}0.708 \\
(0.039)\end{array}$ & $\begin{array}{c}1.277 \\
(0.020)\end{array}$ & $\begin{array}{c}2.046 \\
(0.276)\end{array}$ & $\begin{array}{c}0.676 \\
(0.071)\end{array}$ & & & $\begin{array}{c}2.254 \\
(0.006)\end{array}$ & \\
\hline$\widehat{\phi}$ & $\begin{array}{c}0.424 \\
(0.005)\end{array}$ & $\begin{array}{c}0.461 \\
(0.002)\end{array}$ & $\begin{array}{c}0.598 \\
(0.013)\end{array}$ & $\begin{array}{c}0.477 \\
(0.013)\end{array}$ & $\begin{array}{c}0.414 \\
(0.013)\end{array}$ & $\begin{array}{c}0.561 \\
(0.004)\end{array}$ & $\begin{array}{c}0.672 \\
(0.030)\end{array}$ & $\begin{array}{c}0.403 \\
(0.025)\end{array}$ & & & $\begin{array}{c}0.693 \\
(0.001)\end{array}$ & \\
\hline $\begin{array}{c}\widehat{\beta} \\
\widehat{\varepsilon}_{w}^{N}\end{array}$ & & & & & & & & & & & & $\begin{array}{c}0.839 \\
(0.057) \\
5.210 \\
(2.199) \\
\end{array}$ \\
\hline$\frac{\widehat{\mu}}{\lambda}$ & $\begin{array}{c}1.187 \\
(0.007) \\
\end{array}$ & $\begin{array}{c}1.205 \\
(0.003) \\
\end{array}$ & $\begin{array}{c}1.423 \\
(0.046) \\
\end{array}$ & $\begin{array}{c}1.104 \\
(0.052) \\
\end{array}$ & $\begin{array}{c}1.084 \\
(0.004) \\
\end{array}$ & $\begin{array}{c}1.151 \\
(0.003) \\
\end{array}$ & $\begin{array}{c}1.210 \\
(0.039) \\
\end{array}$ & $\begin{array}{c}0.869 \\
(0.034) \\
\end{array}$ & $\begin{array}{c}1.221 \\
(0.016) \\
\end{array}$ & $\begin{array}{c}1.158 \\
(0.003) \\
\end{array}$ & $\begin{array}{c}1.266 \\
(0.009) \\
\end{array}$ & $\begin{array}{c}0.848 \\
(0.056) \\
\end{array}$ \\
\hline $\begin{array}{c}\text { Time dummies } \\
\text { Industry dummies }\end{array}$ & $\begin{array}{l}\text { yes } \\
\text { yes }\end{array}$ & $\begin{array}{l}\text { yes } \\
\text { no }\end{array}$ & $\begin{array}{l}\text { yes } \\
\text { yes }\end{array}$ & $\begin{array}{l}\text { yes } \\
\text { yes }\end{array}$ & $\begin{array}{l}\text { yes } \\
\text { yes }\end{array}$ & $\begin{array}{l}\text { yes } \\
\text { no }\end{array}$ & $\begin{array}{l}\text { yes } \\
\text { yes }\end{array}$ & $\begin{array}{l}\text { yes } \\
\text { yes }\end{array}$ & $\begin{array}{l}\text { yes } \\
\text { yes }\end{array}$ & $\begin{array}{l}\text { yes } \\
\text { no }\end{array}$ & $\begin{array}{l}\text { yes } \\
\text { yes }\end{array}$ & $\begin{array}{l}\text { yes } \\
\text { yes }\end{array}$ \\
\hline $\begin{array}{c}\text { \# obs. } \\
R^{2}\end{array}$ & $\begin{array}{c}174,600 \\
0.922\end{array}$ & 174,600 & 174,600 & $\begin{array}{c}111,423 \\
0.981\end{array}$ & $\begin{array}{c}83,322 \\
0.976\end{array}$ & 83,322 & 83,322 & $\begin{array}{c}49,599 \\
0.994\end{array}$ & $\begin{array}{c}72,057 \\
0.925\end{array}$ & 72,057 & 72,057 & $\begin{array}{c}36,615 \\
0.982\end{array}$ \\
\hline $\begin{array}{c}R M S E \\
R_{w i t h i n}^{2} \\
\quad \rho\end{array}$ & 0.659 & $\begin{array}{l}0.861 \\
0.780\end{array}$ & & 0.181 & 0.371 & $\begin{array}{l}0.915 \\
0.650\end{array}$ & & 0.108 & 0.661 & $\begin{array}{l}0.903 \\
0.790\end{array}$ & & 0.177 \\
\hline Sargan & & & 0.000 & & & & 0.000 & & & & 0.000 & \\
\hline Hansen & & & 0.000 & 0.015 & & & 0.000 & 0.000 & & & 0.002 & 0.135 \\
\hline $\begin{array}{c}\text { Dif-Hansen (lev) } \\
\text { Dif-Hansen (L2-dif) }\end{array}$ & & & $\begin{array}{l}0.015 \\
0.000\end{array}$ & & & & $\begin{array}{l}1.000 \\
0.000\end{array}$ & & & & $\begin{array}{l}0.042 \\
0.250\end{array}$ & \\
\hline Dif-Hansen (L3-dif) & & & 0.000 & & & & 0.000 & & & & 0.221 & \\
\hline$m 1$ & & & -36.92 & & & & -19.85 & & & & -28.11 & \\
\hline$m^{2}$ & & & -7.68 & & & & -5.37 & & & & -8.97 & \\
\hline
\end{tabular}

Notes: Sargan, Hansen, Dif-Hansen: tests of overidentifying restrictions, asymptotically distributed as $\chi_{d f}^{2} \cdot p$-values

are reported. Dif-Hansen (lev) tests the validity of the 1-year lag of the first-differenced inputs as instruments in the levels equation while Dif-Hansen (L2-dif)/(L3-dif) test the validity of the 2-/3-year lags of the inputs as instruments in the first-differenced equation. $m 1$ and $m 2$ : tests for first-order and second-order serial correlation in the first-differenced residuals, asymptotically distributed as $N(0,1)$. 
Table B.3: Industry repartition by country

\begin{tabular}{|c|c|c|c|c|c|c|c|}
\hline \multirow[b]{2}{*}{ Industry $j$} & \multirow[b]{2}{*}{ Name } & \multicolumn{2}{|c|}{ FRANCE } & \multicolumn{2}{|c|}{ JAPAN } & \multicolumn{2}{|c|}{ THE NETHERLANDS } \\
\hline & & Code - NES $114^{a}$ ) & $\begin{array}{l}\text { \# Firms } \\
(\# \text { Obs.) }\end{array}$ & Code - BSJBSA ${ }^{b)}$ & $\begin{array}{l}\text { \# Firms } \\
(\# \text { Obs.) }\end{array}$ & Code $-\mathrm{SBI}^{c)}$ & $\begin{array}{l}\text { \# Firms } \\
\text { (\# Obs.) }\end{array}$ \\
\hline 1 & Livestock, seafood and flour products & B01 & $520(4,794)$ & $91-93$ & $276(2,551)$ & $151-152,156$ & $283(2,688)$ \\
\hline 2 & Miscellaneous food and related products & В02, В04-B06 & $1,381(13,636)$ & 99,102 & $566(5,488)$ & $153-155,157-158$ & $867(7,649)$ \\
\hline 3 & Beverages and tobacco & B03 & $182(1,854)$ & 101 & $130(1,277)$ & 159,160 & $37(430)$ \\
\hline 4 & Textiles & F21-F23 & $881(8,398)$ & 111-113, 119 & $207(1,901)$ & $171-177$ & $208(2,051)$ \\
\hline 5 & Clothing and skin goods & $\mathrm{C} 11-\mathrm{C} 12$ & $1,267(11,105)$ & $121-122$ & $144(1,134)$ & $181-183$ & $76(610)$ \\
\hline 6 & Wooden products & F31 & $840(9,197)$ & 131,139 & $82(721)$ & $201-205$ & $270(2,606)$ \\
\hline 7 & Furniture & $\mathrm{C} 41$ & $586(5,723)$ & 140 & $88(759)$ & 361 & $413(3,680)$ \\
\hline 8 & Pulp, paper and paper products & F32-F33 & $546(6,005)$ & $151-152$ & $294(2,892)$ & $211-212$ & $229(2,572)$ \\
\hline 9 & Publishing, (re)printing & $\mathrm{C} 31$ & $1,391(12,973)$ & $160,413-414$ & $561(5,399)$ & $221-222$ & $865(7,222)$ \\
\hline 10 & Chemicals & $\mathrm{F} 41, \mathrm{~F} 43$ & $372(4,003)$ & $171,181,189,201,209$ & $229(2,407)$ & $231-233,251$ & $49(495)$ \\
\hline 11 & Organic chemical products & F 42 & $100(1,046)$ & $172-173$ & $154(1,570)$ & $241-243,247$ & $205(2,040)$ \\
\hline 12 & Pharmaceuticals & $\mathrm{C} 31$ & $205(2,041)$ & 175 & $181(1,936)$ & 244 & $39(373)$ \\
\hline 13 & Miscellaneous chemical products & $\mathrm{C} 32$ & $189(1,968)$ & 174,179 & $293(3,104)$ & $245-246$ & $96(949)$ \\
\hline 14 & Plastics & F 45-F46 & $1,206(12,572)$ & 190 & $470(4,542)$ & 252 & $388(3,928)$ \\
\hline 15 & Ceramic, stone and clay products & F13-F14 & $830(8,474)$ & 221-222, 229 & $408(3,804)$ & $261-267$ & $309(2,963)$ \\
\hline 16 & Steel & F51, F53 & $326(3,581)$ & 231-232 & $280(2,733)$ & $271-273,2751-2752$ & $48(520)$ \\
\hline 17 & Metals & $\mathrm{E} 22, \mathrm{~F} 52, \mathrm{~F} 55$ & $1,376(14,268)$ & $241-242$ & $218(2,204)$ & $274,2753-2754,282-283$ & $134(1,415)$ \\
\hline 18 & Architectural metal products & $\mathrm{E} 21$ & $256(2,336)$ & 251 & $198(1,762)$ & 281 & $619(5,783)$ \\
\hline 19 & Other metal products & F54 & $1,747(18,426)$ & 259 & $487(4,741)$ & $284-287$ & $689(6,452)$ \\
\hline 20 & Special industrial machinery & E25, E27-E28 & $556(5,278)$ & 262 & $252(2,371)$ & $291,293,295$ & $555(5,423)$ \\
\hline 21 & General industrial machinery & E24 & $410(3,647)$ & 261,263 & $262(2,439)$ & 292 & $475(4,557)$ \\
\hline 22 & Miscellaneous machinery & E23, E26 & $344(3,498)$ & 269 & $506(4,813)$ & 294 & $34(342)$ \\
\hline 23 & Industrial apparatus & E32 & $85(675)$ & 271 & $246(2,208)$ & 311 & $42(394)$ \\
\hline 24 & Household electrical appliances & $\mathrm{C} 44-\mathrm{C} 46$ & $204(2,011)$ & 272 & $73(630)$ & $223,297,334-335$ & $64(627)$ \\
\hline 25 & Other electrical machinery & E31, E33 & $120(882)$ & $273,281-282$ & $404(3,578)$ & $300,322-323$ & $44(347)$ \\
\hline 26 & Electronic parts and components & F61-F62 & $533(4,825)$ & 290 & $505(4,657)$ & $314-316,321$ & $138(1,109)$ \\
\hline 27 & Motor vehicles & D01 & $219(2,104)$ & 301 & $673(6,799)$ & $341-343$ & $204(1,984)$ \\
\hline 28 & Other transport equipment & D02, E11-E14 & $345(3,443)$ & 309 & $131(1,214)$ & $351-355$ & $148(1,329)$ \\
\hline 29 & Precision instruments & E34-E35 & $310(2,541)$ & 311-313, 319 & $237(2,133)$ & $331-333$ & $227(1,920)$ \\
\hline 30 & Miscellaneous manufacturing products & $\mathrm{C} 42-\mathrm{C} 43$ & $326(3,296)$ & 310,320 & $173(1,555)$ & $362-366$ & $73(691)$ \\
\hline Total & & & $17,653(174,600)$ & & $8,728(83,322)$ & & $7,828(73,149)$ \\
\hline
\end{tabular}

Notes: a) NES 114: French industrial classification, "Nomenclature Economique de Synthèse - Niveau 3",

b) BSJBSA: Basic Survey of Japanse Business Structure and Activities,

c) SBI: Dutch industrial classification, "Standaard Bedrijfsindeling". 
Table B.4: Underpinnings of common threshold of $|0.30|$ for $\psi_{j}$ by country

\begin{tabular}{c|ccc}
\hline \hline & $F R$ & $J P$ & $N L$ \\
\hline$\left(\alpha_{N}\right)_{j}$ & $0.294[0.302]$ & $0.196[0.198]$ & $0.263[0.269]$ \\
$\left(\alpha_{M}\right)_{j}$ & $0.510[0.516]$ & $0.719[0.723]$ & $0.454[0.459]$ \\
$\left(\alpha_{K}\right)_{j}$ & $0.196[0.190]$ & $0.085[0.083]$ & $0.283[0.285]$ \\
$\left(\widehat{\varepsilon}_{N}^{Q}\right)_{j}$ & $0.304[0.295]$ & $0.192[0.185]$ & $0.355[0.325]$ \\
$\left(\widehat{\varepsilon}_{M}^{Q}\right)_{j}$ & $0.635[0.651]$ & $0.795[0.791]$ & $0.592[0.592]$ \\
$\left(\widehat{\varepsilon}_{K}^{Q}\right)_{j}$ & $0.045[0.041]$ & $0.044[0.046]$ & $0.088[0.087]$ \\
\hline$\widehat{\gamma}_{j}$ & $0.362[0.379]$ & $0.625[0.656]$ & $0.214[0.219]$ \\
$\widehat{\phi}_{j}$ & $0.266[0.275]$ & $0.385[0.396]$ & $0.176[0.180]$ \\
$\widehat{\beta}_{j}$ & $0.806[0.808]$ & $0.786[0.785]$ & $0.813[0.811]$ \\
$\left(\widehat{\varepsilon}_{w}^{N}\right)_{j}$ & $4.149[4.204]$ & $3.684[3.646]$ & $4.347[4.299]$ \\
\hline \hline
\end{tabular}

Notes: This table shows that when we choose a common threshold of $|0.30|$ for $\left|\psi_{j 0}\right|$, the average and median values (in square brackets) of industry-specific labor market imperfection parameters are economically meaningful for the three countries. E.g. the average value for $\widehat{\gamma}_{j}$ in $F R$ is computed as: $\widehat{\gamma}_{j}=0.30 \frac{\left(\alpha_{M}\right)_{j}}{\left(\widehat{\varepsilon}_{M}^{Q}\right)_{j}} \frac{\left(\alpha_{N}\right)_{j}}{\left(\alpha_{K}\right)_{j}}=0.362$. 
Table B.5: Details on industry classification $1 \& 2$ by country

\begin{tabular}{|c|c|c|c|c|c|c|c|c|c|c|c|c|c|}
\hline \multirow[b]{3}{*}{ Industry $j$} & \multirow[b]{3}{*}{ Name } & \multicolumn{3}{|c|}{ Classification 1} & \multicolumn{9}{|c|}{ Classification 2} \\
\hline & & \multicolumn{3}{|c|}{ Regime $R$} & \multicolumn{3}{|c|}{$P M S$} & \multicolumn{3}{|c|}{$\angle M S$} & \multicolumn{3}{|c|}{ Regime $R$} \\
\hline & & $F R$ & $J P$ & $N L$ & $F R$ & $J P$ & $N L$ & $F R$ & $J P$ & $N L$ & $F R$ & $J P$ & $N L$ \\
\hline 1 & Livestock, seafood and flour products & $P C-P R$ & $P C-E B$ & $I C-M O$ & $P C^{*}$ & $P C^{*}$ & mover & mover & $P R^{*}$ & $P R^{*}$ & $P C^{*}-P R^{*}$ & & \\
\hline 2 & Miscellaneous food and related products & $I C-E B$ & $P C-E B$ & $I C-E B$ & $I C^{*}$ & mover & $I C^{*}$ & mover & mover & mover & $I C^{*}-E B^{*}$ & & \\
\hline 3 & Beverages and tobacco & $I C-M O$ & $P C-E B$ & $I C-M O$ & mover & $P C^{*}$ & mover & $E B^{*}$ & $P R^{*}$ & $P R^{*}$ & & $P C^{*}-E B^{*}$ & \\
\hline 4 & Textiles & $I C-E B$ & $I C-P R$ & $I C-P R$ & $I C^{*}$ & mover & $I C^{*}$ & mover & mover & mover & $I C^{*}-E B^{*}$ & & \\
\hline 5 & Clothing and skin goods & $I C-E B$ & $P C-P R$ & $P C-M O$ & $I C^{*}$ & $P C^{*}$ & $P C^{*}$ & $P R^{*}$ & $P R^{*}$ & $P R^{*}$ & $I C^{*}-E B^{*}$ & $P C^{*}-P R^{*}$ & $P C^{*}-P R^{*}$ \\
\hline 6 & Wooden products & $I C-E B$ & $P C-E B$ & $I C-E B$ & $I C^{*}$ & mover & $I C^{*}$ & mover & mover & mover & $I C^{*}-E B^{*}$ & & \\
\hline 7 & Furniture & $I C-E B$ & $I C-P R$ & $I C-E B$ & $I C^{*}$ & mover & $I C^{*}$ & $P R^{*}$ & mover & mover & & & \\
\hline 8 & Pulp, paper and paper products & $I C-E B$ & $P C-P R$ & $P C-M O$ & $I C^{*}$ & $P C^{*}$ & mover & $P R^{*}$ & $P R^{*}$ & $P R^{*}$ & & & \\
\hline 9 & Publishing, (re)printing & $I C-E B$ & $P C-P R$ & $I C-M O$ & $I C^{*}$ & mover & $I C^{*}$ & $P R^{*}$ & $P R^{*}$ & $P R^{*}$ & $I C^{*}-E B^{*}$ & & $I C^{*}-P R^{*}$ \\
\hline 10 & Chemicals & $I C-P R$ & $I C-E B$ & $I C-E B$ & $I C^{*}$ & $I C^{*}$ & $I C^{*}$ & mover & mover & mover & & & \\
\hline 11 & Organic chemical products & $P C-M O$ & $I C-P R$ & $I C-P R$ & mover & $I C^{*}$ & $I C^{*}$ & mover & $E B^{*}$ & mover & & & \\
\hline 12 & Pharmaceuticals & $I C-M O$ & $I C-P R$ & $I C-M O$ & $I C^{*}$ & $I C^{*}$ & $I C^{*}$ & mover & mover & mover & $I C^{*}-P R^{*}$ & & \\
\hline 13 & Miscellaneous chemical products & $I C-P R$ & $I C-P R$ & $P C-P R$ & $I C^{*}$ & mover & mover & $P R^{*}$ & mover & mover & & & \\
\hline 14 & Plastics & $I C-P R$ & $P C-P R$ & $I C-P R$ & $I C^{*}$ & $P C^{*}$ & $I C^{*}$ & $P R^{*}$ & mover & mover & & $P C^{*}-P R^{*}$ & \\
\hline 15 & Ceramic, stone and clay products & $I C-E B$ & $P C-P R$ & $I C-M O$ & $I C^{*}$ & mover & $I C^{*}$ & $P R^{*}$ & $P R^{*}$ & $P R^{*}$ & $I C^{*}-E B^{*}$ & & $I C^{*}-P R^{*}$ \\
\hline 16 & Steel & $I C-E B$ & $P C-P R$ & $I C-E B$ & $I C^{*}$ & mover & $I C^{*}$ & mover & $P R^{*}$ & mover & $I C^{*}-E B^{*}$ & & \\
\hline 17 & Metals & $I C-E B$ & $I C-P R$ & $I C-P R$ & $I C^{*}$ & mover & $I C^{*}$ & $P R^{*}$ & $E B^{*}$ & mover & $I C^{*}-E B^{*}$ & & \\
\hline 18 & Architectural metal products & $I C-P R$ & $P C-E B$ & $I C-E B$ & mover & mover & $I C^{*}$ & mover & mover & $E B^{*}$ & & & $I C^{*}-E B^{*}$ \\
\hline 19 & Other metal products & $I C-E B$ & $I C-P R$ & $I C-P R$ & $I C^{*}$ & mover & $I C^{*}$ & $P R^{*}$ & $P R^{*}$ & $P R^{*}$ & $I C^{*}-E B^{*}$ & & $I C^{*}-P R^{*}$ \\
\hline 20 & Special industrial machinery & $I C-E B$ & $P C-P R$ & $I C-P R$ & $I C^{*}$ & mover & $I C^{*}$ & mover & $P R^{*}$ & $P R^{*}$ & & & $I C^{*}-P R^{*}$ \\
\hline 21 & General industrial machinery & $I C-P R$ & $P C-P R$ & $I C-P R$ & mover & $P C^{*}$ & $I C^{*}$ & $P R^{*}$ & mover & mover & & $P C^{*}-P R^{*}$ & \\
\hline 22 & Miscellaneous machinery & $I C-M O$ & $P C-P R$ & $I C-M O$ & mover & mover & mover & $P R^{*}$ & $P R^{*}$ & mover & & & \\
\hline 23 & Industrial apparatus & $P C-P R$ & $I C-E B$ & $I C-E B$ & $P C^{*}$ & $I C^{*}$ & $I C^{*}$ & mover & mover & mover & $P C^{*}-P R^{*}$ & & \\
\hline 24 & Household electrical appliances & $I C-P R$ & $P C-P R$ & $I C-M O$ & $I C^{*}$ & mover & mover & mover & $P R^{*}$ & mover & $I C^{*}-P R^{*}$ & & \\
\hline 25 & Other electrical machinery & $I C-P R$ & $P C-P R$ & $I C-P R$ & mover & mover & $I C^{*}$ & $P R^{*}$ & mover & mover & & & \\
\hline 26 & Electronic parts and components & $I C-P R$ & $I C-E B$ & $I C-E B$ & mover & $I C^{*}$ & $I C^{*}$ & mover & mover & mover & & & \\
\hline 27 & Motor vehicles & $P C-P R$ & $I C-E B$ & $I C-P R$ & mover & $I C^{*}$ & $I C^{*}$ & mover & mover & mover & & $I C^{*}-E B^{*}$ & \\
\hline 28 & Other transport equipment & $I C-E B$ & $I C-P R$ & $I C-E B$ & $I C^{*}$ & mover & $I C^{*}$ & mover & $E B^{*}$ & mover & & & \\
\hline 29 & Precision instruments & $I C-P R$ & $I C-P R$ & $I C-E B$ & $I C^{*}$ & mover & $I C^{*}$ & $P R^{*}$ & mover & mover & & & \\
\hline 30 & Miscellaneous manufacturing products & $I C-P R$ & $I C-P R$ & $I C-M O$ & $I C^{*}$ & $I C^{*}$ & mover & $E B^{*}$ & $P R^{*}$ & $P R^{*}$ & & & \\
\hline Total & & $I C-E B$ & $I C-E B$ & $I C-E B$ & & & & & & & & & \\
\hline
\end{tabular}


Table B.6: Industry-specific input shares $\left(\alpha_{J}\right)_{j}(J=N, M, K)$, output elasticities $\left(\widehat{\varepsilon}_{J}^{Q}\right)_{j}$, scale elasticity $\widehat{\lambda}_{j}$, joint market imperfections parameter $\widehat{\psi}_{j}$, and corresponding price-cost mark-up $\widehat{\mu}_{j}$ and absolute extent of rent sharing $\widehat{\phi}_{j}$ or labor supply elasticity $\left(\widehat{\varepsilon}_{w}^{N}\right)_{j}$ by country

\begin{tabular}{|c|c|c|c|c|c|c|c|c|c|c|c|c|c|c|c|c|c|c|}
\hline \multicolumn{19}{|c|}{ FRANCE } \\
\hline \multicolumn{19}{|c|}{ Regime $R=I C-E B \quad[43 \%$ of industries, $68 \%$ of firms $]$} \\
\hline Ind. $j$ & $\left(\alpha_{N}\right) j$ & $\left(\alpha_{M}\right)_{j}$ & $\left(\alpha_{K}\right)_{j}$ & $\left(\widehat{\varepsilon}_{N}^{Q}\right)_{j}$ & $\left(\widehat{\varepsilon}_{M}^{Q}\right)_{j}$ & $\left(\widehat{\varepsilon}_{K}^{Q}\right)_{j}$ & $\widehat{\lambda}_{j}$ & $\widehat{\psi}_{j}$ & $\widehat{\mu}_{j}$ & $\widehat{\gamma}_{j}$ & $\widehat{\phi}_{j}$ & Sargan & Hansen & $\begin{array}{c}\text { Dif- } \\
\text { Hansen } \\
\text { (lev) }\end{array}$ & $\begin{array}{c}\text { Dif- } \\
\text { Hansen } \\
\text { (L2-dif) }\end{array}$ & $\begin{array}{c}\text { Dif- } \\
\text { Hansen } \\
\text { (L3-dif) }\end{array}$ & $m 1$ & $m 2$ \\
\hline 7 & 0.310 & 0.524 & 0.166 & $0.296(0.037)$ & $0.671(0.027)$ & $0.014(0.054)$ & $0.980(0.021)$ & $0.326(0.156)$ & $1.280(0.052)$ & $0.476(0.213)$ & $0.322(0.098)$ & 0.000 & 0.000 & 0.001 & 0.211 & 0.422 & -9.48 & -1.97 \\
\hline 8 & 0.243 & 0.548 & 0.209 & $0.169(0.048)$ & $0.668(0.049)$ & $0.098(0.089)$ & $0.935(0.020)$ & $0.523(0.272)$ & $1.219(0.090)$ & $0.500(0.228)$ & $0.333(0.101)$ & 0.000 & 0.000 & 0.172 & 0.398 & 0.587 & -7.68 & -3.78 \\
\hline 6 & 0.259 & 0.549 & 0.192 & $0.201(0.030)$ & $0.730(0.020)$ & $0.061(0.038)$ & $0.993(0.020)$ & $0.551(0.138)$ & $1.330(0.036)$ & $0.558(0.130)$ & $0.358(0.054)$ & 0.000 & 0.000 & 0.000 & 0.050 & 0.119 & -11.27 & -0.13 \\
\hline 15 & 0.290 & 0.485 & 0.225 & $0.217(0.030)$ & $0.675(0.025)$ & $0.101(0.043)$ & $0.994(0.020)$ & $0.642(0.137)$ & $1.391(0.052)$ & $0.595(0.111)$ & $0.373(0.044)$ & 0.000 & 0.000 & 0.000 & 0.260 & 0.534 & -11.32 & -1.57 \\
\hline 28 & 0.293 & 0.521 & 0.185 & $0.245(0.049)$ & $0.717(0.030)$ & $0.041(0.069)$ & $1.003(0.020)$ & $0.539(0.212)$ & $1.375(0.058)$ & $0.619(0.223)$ & $0.383(0.085)$ & 0.000 & 0.006 & 0.305 & 0.469 & 0.795 & -6.92 & -0.94 \\
\hline 17 & 0.343 & 0.466 & 0.192 & $0.318(0.031)$ & $0.686(0.024)$ & $0.025(0.042)$ & $1.029(0.019)$ & $0.545(0.124)$ & $1.473(0.051)$ & $0.662(0.134)$ & $0.398(0.049)$ & 0.000 & 0.000 & 0.000 & 0.000 & 0.584 & -14.53 & -4.88 \\
\hline 2 & 0.245 & 0.568 & 0.188 & $0.134(0.028)$ & $0.731(0.021)$ & $0.081(0.043)$ & $0.945(0.016)$ & $0.739(0.141)$ & $1.287(0.036)$ & $0.750(0.127)$ & $0.428(0.041)$ & 0.000 & 0.000 & 0.003 & 0.036 & 0.899 & -9.70 & -2.35 \\
\hline 9 & 0.337 & 0.474 & 0.189 & $0.261(0.027)$ & $0.635(0.020)$ & $0.059(0.036)$ & $0.955(0.020)$ & $0.566(0.108)$ & $1.339(0.042)$ & $0.755(0.126)$ & $0.430(0.041)$ & 0.000 & 0.000 & 0.000 & 0.133 & 0.454 & -11.50 & -1.38 \\
\hline 20 & 0.345 & 0.490 & 0.165 & $0.274(0.048)$ & $0.641(0.029)$ & $0.077(0.067)$ & $0.992(0.024)$ & $0.513(0.186)$ & $1.308(0.059)$ & $0.819(0.267)$ & $0.450(0.081)$ & 0.000 & 0.003 & 0.012 & 0.733 & 0.071 & -10.62 & 1.18 \\
\hline 4 & 0.336 & 0.492 & 0.172 & $0.246(0.036)$ & $0.652(0.024)$ & $0.021(0.043)$ & $0.919(0.031)$ & $0.592(0.133)$ & $1.324(0.049)$ & $0.872(0.176)$ & $0.466(0.050)$ & 0.000 & 0.000 & 0.000 & 0.460 & 0.378 & -10.53 & -1.98 \\
\hline 16 & 0.297 & 0.531 & 0.172 & $0.189(0.034)$ & $0.737(0.022)$ & $0.021(0.044)$ & $0.947(0.017)$ & $0.753(0.139)$ & $1.390(0.042)$ & $0.934(0.155)$ & $0.483(0.041)$ & 0.000 & 0.009 & 0.213 & 0.739 & 0.960 & -7.17 & -0.56 \\
\hline 19 & 0.382 & 0.442 & 0.176 & $0.295(0.023)$ & $0.602(0.014)$ & $0.048(0.031)$ & $0.944(0.015)$ & $0.588(0.085)$ & $1.361(0.032)$ & $0.936(0.118)$ & $0.483(0.031)$ & 0.000 & 0.000 & 0.000 & 0.049 & 0.051 & -19.02 & -2.30 \\
\hline 5 & 0.407 & 0.420 & 0.173 & $0.239(0.038)$ & $0.628(0.019)$ & $0.033(0.040)$ & \begin{tabular}{|l}
$0.901(0.029)$ \\
\end{tabular} & $0.908(0.118)$ & $1.496(0.044)$ & $1.429(0.160)$ & $0.588(0.027)$ & 0.000 & 0.000 & 0.000 & 0.142 & 0.790 & -11.66 & -1.40 \\
\hline \multicolumn{19}{|c|}{ Regime $R=I C-P R \quad[33 \%$ of industries, $22 \%$ of firms] } \\
\hline Ind. $j$ & $\left(\alpha_{N}\right)_{j}$ & $\left(\alpha_{M}\right)_{j}$ & $\left(\alpha_{K}\right) j$ & $\left(\widehat{\varepsilon}_{N}^{Q}\right)_{j}$ & $\left(\widehat{\varepsilon}_{M}^{Q}\right)_{j}$ & $\left(\widehat{\varepsilon}_{K}^{Q}\right)_{j}$ & $\widehat{\lambda}_{j}$ & $\widehat{\psi}_{j}$ & $\widehat{\mu}_{j}$ & & & Sargan & Hansen & $\begin{array}{c}\text { Dif- } \\
\text { Hansen } \\
\text { (lev) }\end{array}$ & $\begin{array}{c}\text { Dif- } \\
\text { Hansen } \\
\text { (L2-dif) }\end{array}$ & $\begin{array}{c}\text { Dif- } \\
\text { Hansen } \\
\text { (L3-dif) }\end{array}$ & $m 1$ & $m^{2}$ \\
\hline 26 & 0.317 & 0.491 & 0.191 & $0.296(0.057)$ & $0.556(0.029)$ & $0.130(0.058)$ & $0.981(0.036)$ & $0.201(0.208)$ & $1.132(0.059)$ & & & 0.000 & 0.000 & 0.002 & 0.059 & 0.263 & -6.84 & -1.67 \\
\hline 18 & 0.273 & 0.580 & 0.147 & $0.256(0.053)$ & $0.669(0.038)$ & $0.021(0.064)$ & $0.945(0.042)$ & $0.217(0.226)$ & $1.153(0.066)$ & & & 0.000 & 0.370 & 0.903 & 0.455 & 0.690 & -7.00 & -2.08 \\
\hline 21 & 0.308 & 0.511 & 0.182 & $0.306(0.059)$ & $0.598(0.049)$ & $0.031(0.095)$ & $0.935(0.031)$ & $0.178(0.268)$ & $1.171(0.096)$ & & & 0.000 & 0.036 & 0.078 & 0.367 & 0.626 & -7.99 & 0.40 \\
\hline 25 & 0.329 & 0.404 & 0.267 & $0.430(0.066)$ & $0.492(0.051)$ & $0.096(0.082)$ & $1.017(0.029)$ & $-0.093(0.266)$ & $1.216(0.125)$ & & & 0.000 & 1.000 & 1.000 & 1.000 & 1.000 & -2.23 & -1.09 \\
\hline 24 & 0.324 & 0.492 & 0.184 & $0.461(0.061)$ & $0.600(0.042)$ & $-0.034(0.088)$ & $1.027(0.031)$ & $-0.205(0.253)$ & $1.219(0.085)$ & & & 0.000 & 0.175 & 0.186 & 0.433 & 0.569 & -5.67 & -0.24 \\
\hline 14 & 0.275 & 0.542 & 0.183 & $0.271(0.023)$ & $0.667(0.018)$ & $0.067(0.032)$ & $1.005(0.016)$ & $0.244(0.105)$ & $1.230(0.033)$ & & & 0.000 & 0.000 & 0.000 & 0.026 & 0.804 & -14.05 & -2.06 \\
\hline 10 & 0.225 & 0.554 & 0.221 & $0.261(0.047)$ & $0.685(0.042)$ & $0.062(0.070)$ & $1.008(0.023)$ & $0.073(0.257)$ & $1.236(0.076)$ & & & 0.000 & 0.007 & 0.471 & 0.669 & 0.663 & -7.54 & -1.87 \\
\hline 13 & 0.255 & 0.543 & 0.203 & $0.350(0.062)$ & $0.690(0.039)$ & $-0.024(0.090)$ & $1.016(0.026)$ & $-0.101(0.302)$ & $1.272(0.071)$ & & & 0.000 & 0.353 & 0.441 & 0.410 & 0.784 & -4.72 & -0.96 \\
\hline 30 & 0.328 & 0.474 & 0.198 & $0.391(0.049)$ & $0.607(0.031)$ & $0.005(0.063)$ & $1.004(0.027)$ & $0.090(0.191)$ & $1.281(0.065)$ & & & 0.000 & 0.139 & 0.001 & 0.965 & 0.653 & -7.89 & 1.30 \\
\hline 29 & 0.358 & 0.391 & 0.251 & $0.429(0.067)$ & $0.553(0.043)$ & $0.028(0.091)$ & $1.010(0.034)$ & $0.216(0.262)$ & $1.415(0.110)$ & & & 0.000 & 0.001 & 0.143 & 0.167 & 0.666 & -7.34 & -0.36 \\
\hline \multicolumn{19}{|c|}{ Regime $R=I C-M O \quad[\mathbf{1 0 \%}$ of industries, $4 \%$ of firms $]$} \\
\hline Ind. $j$ & $\left(\alpha_{N}\right)_{j}$ & $\left(\alpha_{M}\right)_{j}$ & $\left(\alpha_{K}\right) j$ & $\left(\widehat{\varepsilon}_{N}^{Q}\right)_{j}$ & $\left(\widehat{\varepsilon}_{M}^{Q}\right) j$ & $\left(\widehat{\varepsilon}_{K}^{Q}\right)_{j}$ & $\widehat{\lambda}_{j}$ & $\widehat{\psi}_{j}$ & $\widehat{\mu}_{j}$ & $\widehat{\beta}_{j}$ & $\left(\widehat{\varepsilon}_{w}^{N}\right)_{j}$ & Sargan & Hansen & $\begin{array}{c}\text { Dif- } \\
\text { Hansen } \\
\text { (lev) } \\
\end{array}$ & $\begin{array}{c}\text { Dif- } \\
\text { Hansen } \\
\text { (L2-dif) } \\
\end{array}$ & $\begin{array}{c}\text { Dif- } \\
\text { Hansen } \\
\text { (L3-dif) }\end{array}$ & $m 1$ & $m^{2}$ \\
\hline 3 & 0.181 & 0.590 & 0.229 & $0.325(0.044)$ & $0.694(0.036)$ & $0.040(0.063)$ & $1.059(0.021)$ & $-0.624(0.276)$ & $1.176(0.062)$ & $0.653(0.108)$ & $1.883(0.900)$ & 0.000 & 0.372 & 0.640 & 0.582 & 0.969 & -4.83 & -1.87 \\
\hline 12 & 0.230 & 0.545 & 0.225 & $0.402(0.072)$ & $0.658(0.045)$ & $-0.046(0.106)$ & $1.015(0.022)$ & $-0.542(0.379)$ & $1.207(0.083)$ & $0.690(0.162)$ & $2.226(1.690)$ & 0.000 & 0.166 & 0.044 & 0.582 & 0.352 & -4.34 & -0.39 \\
\hline 22 & 0.326 & 0.482 & 0.182 & $0.505(0.075)$ & $0.544(0.050)$ & $-0.004(0.116)$ & $1.045(0.028)$ & $-0.419(0.321)$ & $1.130(0.104)$ & $0.730(0.168)$ & $2.700(2.302)$ & 0.000 & 0.008 & 0.003 & 0.754 & 0.810 & -8.94 & -0.79 \\
\hline
\end{tabular}


Table B.6 (ctd): Industry-specific input shares $\left(\alpha_{J}\right)_{j}(J=N, M, K)$, output elasticities $\left(\widehat{\varepsilon}_{J}^{Q}\right)_{j}$, scale elasticity $\widehat{\lambda}_{j}$, joint market imperfections parameter $\widehat{\psi}_{j}$, and corresponding price-cost mark-up $\widehat{\mu}_{j}$ and absolute extent of rent sharing $\widehat{\phi}_{j}$ or labor supply elasticity $\left(\widehat{\varepsilon}_{w}^{N}\right)_{j}$ by country

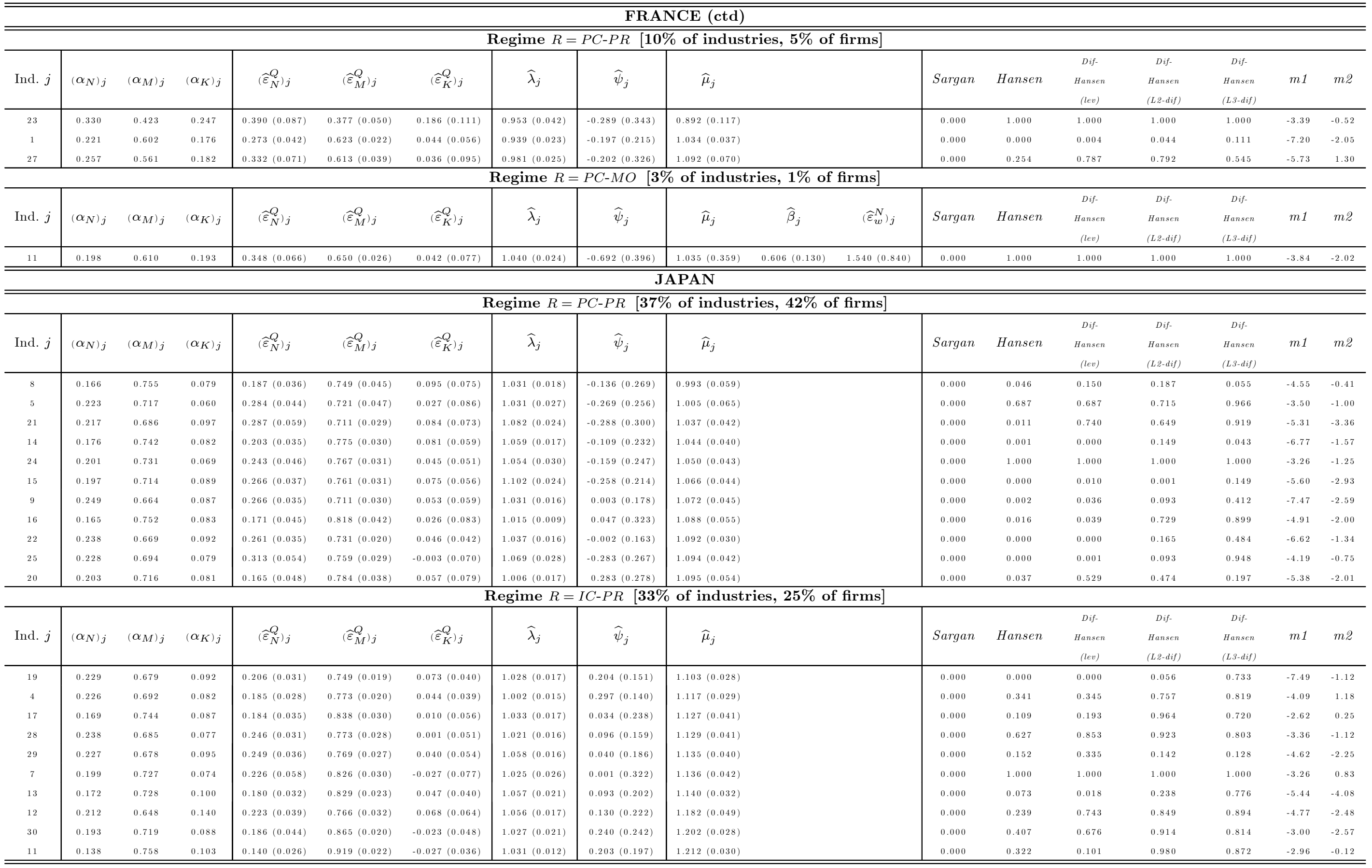


Table B.6 (ctd): Industry-specific input shares $\left(\alpha_{J}\right)_{j}(J=N, M, K)$, output elasticities $\left(\widehat{\varepsilon}_{J}^{Q}\right)_{j}$, scale elasticity $\widehat{\lambda}_{j}$, joint market imperfections parameter $\widehat{\psi}_{j}$, and corresponding price-cost mark-up $\widehat{\mu}_{j}$ and absolute extent of rent sharing $\widehat{\phi}_{j}$ or labor supply elasticity $\left(\widehat{\varepsilon}_{w}^{N}\right)_{j}$ by country

JAPAN (ctd)

\begin{tabular}{|c|c|c|c|c|c|c|c|c|c|c|c|c|c|c|c|c|c|c|}
\hline \multicolumn{19}{|c|}{ JAPAN (ctd) } \\
\hline \multicolumn{19}{|c|}{ Regime $R=P C-E B \quad[\mathbf{1 7 \%}$ of industries, $\mathbf{1 4 \%}$ of firms $]$} \\
\hline Ind. $j$ & $\left(\alpha_{N}\right)_{j}$ & $\left(\alpha_{M}\right)_{j}$ & $\left(\alpha_{K}\right)_{j}$ & $\left(\widehat{\varepsilon}_{N}^{Q}\right)_{j}$ & $\left(\widehat{\varepsilon}_{M}^{Q}\right)_{j}$ & $\left(\widehat{\varepsilon}_{K}^{Q}\right) j$ & $\widehat{\lambda}_{j}$ & $\widehat{\psi}_{j}$ & $\widehat{\mu}_{j}$ & $\widehat{\gamma}_{j}$ & $\widehat{\phi}_{j}$ & Sargan & Hansen & $\begin{array}{c}\text { Dif- } \\
\text { Hansen } \\
\text { (lev) }\end{array}$ & $\begin{array}{c}\text { Dif- } \\
\text { Hansen } \\
\text { (L2-dif) }\end{array}$ & $\begin{array}{c}\text { Dif- } \\
\text { Hansen } \\
\text { (Ls-dif) }\end{array}$ & $m 1$ & $m 2$ \\
\hline 18 & 0.189 & 0.744 & 0.067 & $0.150(0.040)$ & $0.815(0.038)$ & $0.049(0.073)$ & $1.014(0.015)$ & $0.300(0.257)$ & $1.096(0.051)$ & $0.769(0.626)$ & $0.435(0.200)$ & 0.000 & 0.466 & 0.742 & 0.885 & 0.828 & -3.68 & -1.21 \\
\hline 6 & 0.155 & 0.784 & 0.061 & $0.115(0.036)$ & $0.852(0.018)$ & $0.036(0.045)$ & $1.003(0.014)$ & $0.347(0.245)$ & $1.087(0.023)$ & $0.815(0.563)$ & $0.449(0.171)$ & 0.000 & 1.000 & 1.000 & 1.000 & 1.000 & -4.00 & -1.15 \\
\hline 1 & 0.150 & 0.790 & 0.060 & $0.107(0.030)$ & $0.843(0.019)$ & $0.058(0.028)$ & $1.007(0.024)$ & $0.357(0.208)$ & $1.067(0.024)$ & $0.847(0.489)$ & $0.458(0.143)$ & 0.000 & 0.032 & 0.853 & 0.138 & 0.675 & -4.44 & -1.81 \\
\hline 2 & 0.186 & 0.738 & 0.076 & $0.119(0.022)$ & $0.798(0.025)$ & $0.100(0.041)$ & $1.017(0.016)$ & $0.438(0.142)$ & $1.080(0.034)$ & $0.997(0.299)$ & $0.499(0.075)$ & 0.000 & 0.000 & 0.000 & 0.024 & 0.119 & -5.90 & -1.54 \\
\hline 3 & 0.129 & 0.786 & 0.086 & $0.035(0.033)$ & $0.805(0.035)$ & $0.134(0.032)$ & $0.974(0.015)$ & $0.756(0.251)$ & $1.025(0.045)$ & $1.110(0.369)$ & $0.526(0.083)$ & 0.000 & 0.775 & 1.000 & 1.000 & 0.998 & -3.21 & 0.21 \\
\hline \multicolumn{19}{|c|}{ Regime $R=I C-E B \quad[\mathbf{1 3 \%}$ of industries, $\mathbf{1 9 \%}$ of firms $]$} \\
\hline Ind. $j$ & $\left(\alpha_{N}\right)_{j}$ & $\left(\alpha_{M}\right)_{j}$ & $\left(\alpha_{K}\right)_{j}$ & $\left(\widehat{\varepsilon}_{N}^{Q}\right)_{j}$ & $\left(\widehat{\varepsilon}_{M}^{Q}\right)_{j}$ & $\left(\widehat{\varepsilon}_{K}^{Q}\right)_{j}$ & $\widehat{\lambda}_{j}$ & $\widehat{\psi}_{j}$ & $\widehat{\mu}_{j}$ & $\widehat{\gamma}_{j}$ & $\widehat{\phi}_{j}$ & Sargan & Hansen & $\begin{array}{c}\text { Dif- } \\
\text { Hansen } \\
\text { (lev) }\end{array}$ & $\begin{array}{c}\text { Dif- } \\
\text { Hansen } \\
\text { (L2-dif) }\end{array}$ & $\begin{array}{c}\text { Dif- } \\
\text { Hansen } \\
\text { (Ls-dif) }\end{array}$ & $m 1$ & $m 2$ \\
\hline 10 & 0.171 & 0.730 & 0.099 & $0.120(0.026)$ & $0.845(0.021)$ & $0.041(0.033)$ & $1.006(0.014)$ & $0.452(0.160)$ & $1.157(0.029)$ & $0.673(0.231)$ & $0.402(0.083)$ & 0.000 & 0.004 & 0.105 & 0.814 & 0.847 & -5.61 & -3.39 \\
\hline 26 & 0.210 & 0.681 & 0.110 & $0.160(0.035)$ & $0.816(0.024)$ & $0.051(0.044)$ & $1.027(0.014)$ & $0.433(0.183)$ & $1.199(0.035)$ & $0.688(0.281)$ & $0.408(0.099)$ & 0.000 & 0.000 & 0.000 & 0.063 & 0.527 & -6.81 & -2.00 \\
\hline 27 & 0.187 & 0.731 & 0.082 & $0.125(0.019)$ & $0.853(0.015)$ & $0.043(0.029)$ & $1.021(0.008)$ & $0.496(0.116)$ & $1.167(0.020)$ & $0.966(0.215)$ & $0.491(0.056)$ & 0.000 & 0.000 & 0.000 & 0.247 & 0.841 & -7.35 & -4.32 \\
\hline 23 & 0.225 & 0.702 & 0.073 & $0.168(0.037)$ & $0.833(0.032)$ & $0.027(0.066)$ & $1.028(0.016)$ & $0.441(0.204)$ & $1.186(0.046)$ & $1.148(0.495)$ & $0.534(0.107)$ & 0.000 & 0.144 & 0.326 & 0.819 & 0.307 & -5.49 & -2.92 \\
\hline
\end{tabular}


Table B.6 (ctd): Industry-specific input shares $\left(\alpha_{J}\right)_{j}(J=N, M, K)$, output elasticities $\left(\widehat{\varepsilon}_{J}^{Q}\right)_{j}$, scale elasticity $\widehat{\lambda}_{j}$, joint market imperfections parameter $\widehat{\psi}_{j}$,

and corresponding price-cost mark-up $\widehat{\mu}_{j}$ and absolute extent of rent sharing $\widehat{\phi}_{j}$ or labor supply elasticity $\left(\widehat{\varepsilon}_{w}^{N}\right)_{j}$ by country

\section{THE NETHERLANDS}

\begin{tabular}{|c|c|c|c|c|c|c|c|c|c|c|c|c|c|c|c|c|c|c|}
\hline \multicolumn{19}{|c|}{ THE NETHERLANDS } \\
\hline \multicolumn{19}{|c|}{ Regime $R=I C-P R \quad[30 \%$ of industries, $37 \%$ of firms] } \\
\hline Ind. $j$ & $\left(\alpha_{N}\right)_{j}$ & $\left(\alpha_{M}\right)_{j}$ & $\left(\alpha_{K}\right)_{j}$ & $\left(\widehat{\varepsilon}_{N}^{Q}\right)_{j}$ & $\left(\widehat{\varepsilon}_{M}^{Q}\right)_{j}$ & $\left(\widehat{\varepsilon}_{K}^{Q}\right)^{\prime} j$ & $\widehat{\lambda}_{j}$ & $\widehat{\psi}_{j}$ & $\widehat{\mu}_{j}$ & & & Sargan & Hansen & $\begin{array}{c}\text { Dif- } \\
\text { Hansen } \\
(l e v) \\
\end{array}$ & $\begin{array}{c}\text { Dif- } \\
\text { Hansen } \\
\text { (L2-dif) }\end{array}$ & $\begin{array}{c}\text { Dif- } \\
\text { Hansen } \\
\text { (L3-dif) }\end{array}$ & $m 1$ & m2 \\
\hline 4 & 0.268 & 0.461 & 0.271 & $0.328(0.057)$ & $0.592(0.035)$ & $0.094(0.077)$ & $1.015(0.029)$ & $0.063(0.270)$ & $1.285(0.076)$ & & & 0.000 & 0.357 & 0.211 & 0.660 & 0.653 & -4.59 & -1.32 \\
\hline 27 & 0.247 & 0.545 & 0.208 & $0.278(0.049)$ & $0.708(0.031)$ & $0.027(0.075)$ & $1.014(0.014)$ & $0.173(0.247)$ & $1.299(0.057)$ & & & 0.000 & 0.118 & 0.140 & 0.901 & 0.546 & -4.89 & -2.53 \\
\hline 17 & 0.269 & 0.466 & 0.266 & $0.304(0.052)$ & $0.610(0.034)$ & $0.088(0.067)$ & $1.001(0.029)$ & $0.179(0.235)$ & $1.310(0.073)$ & & & 0.000 & 0.378 & 0.754 & 0.047 & 0.424 & -4.69 & -0.49 \\
\hline 19 & 0.323 & 0.357 & 0.320 & $0.474(0.032)$ & $0.478(0.023)$ & $0.082(0.052)$ & $1.033(0.017)$ & $-0.131(0.155)$ & $1.336(0.064)$ & & & 0.000 & 0.109 & 0.235 & 0.189 & 0.346 & -10.88 & -3.61 \\
\hline 14 & 0.240 & 0.451 & 0.310 & $0.276(0.031)$ & $0.604(0.022)$ & $0.111(0.040)$ & $0.990(0.017)$ & $0.189(0.156)$ & $1.340(0.048)$ & & & 0.000 & 0.180 & 0.430 & 0.286 & 0.155 & -7.39 & -0.53 \\
\hline 20 & 0.307 & 0.432 & 0.261 & $0.417(0.031)$ & $0.581(0.024)$ & $0.078(0.051)$ & $1.076(0.015)$ & $-0.010(0.147)$ & $1.345(0.056)$ & & & 0.000 & 0.169 & 0.319 & 0.263 & 0.347 & -9.34 & -2.34 \\
\hline 21 & 0.313 & 0.429 & 0.257 & $0.352(0.030)$ & $0.587(0.022)$ & $0.086(0.049)$ & $1.025(0.013)$ & $0.245(0.138)$ & $1.368(0.051)$ & & & 0.000 & 0.158 & 0.116 & 0.622 & 0.412 & -8.23 & -2.45 \\
\hline 11 & 0.171 & 0.505 & 0.324 & $0.203(0.063)$ & $0.705(0.033)$ & $0.121(0.068)$ & $1.028(0.030)$ & $0.213(0.397)$ & $1.397(0.066)$ & & & 0.000 & 0.757 & 0.193 & 0.998 & 0.995 & -4.53 & -2.48 \\
\hline 25 & 0.266 & 0.472 & 0.262 & $0.419(0.171)$ & $0.660(0.101)$ & $-0.023(0.180)$ & $1.056(0.069)$ & $-0.173(0.724)$ & $1.399(0.215)$ & & & 0.000 & 1.000 & 1.000 & 1.000 & 1.000 & -1.85 & 0.81 \\
\hline \multicolumn{19}{|c|}{ Regime $R=I C-E B \quad[33 \%$ of industries, $36 \%$ of firms] } \\
\hline Ind. $j$ & $\left(\alpha_{N}\right)_{j}$ & $\left(\alpha_{M}\right)_{j}$ & $\left(\alpha_{K}\right)_{j}$ & $\left(\widehat{\varepsilon}_{N}^{Q}\right)_{j}$ & $\left(\widehat{\varepsilon}_{M}^{Q}\right)_{j}$ & $\left(\widehat{\varepsilon}_{K}^{Q}\right)_{j}$ & $\widehat{\lambda}_{j}$ & $\widehat{\psi}_{j}$ & $\widehat{\mu}_{j}$ & $\widehat{\gamma}_{j}$ & $\widehat{\phi}_{j}$ & Sargan & Hansen & $\begin{array}{c}\text { Dif- } \\
\text { Hansen } \\
\text { (lev) } \\
\end{array}$ & $\begin{array}{c}\text { Dif- } \\
\text { Hansen } \\
\text { (L2-dif) }\end{array}$ & $\begin{array}{c}\text { Dif- } \\
\text { Hansen } \\
\text { (L3-dif) }\end{array}$ & $m 1$ & $m 2$ \\
\hline 7 & 0.299 & 0.450 & 0.251 & $0.322(0.024)$ & $0.625(0.019)$ & $0.100(0.035)$ & $1.046(0.009)$ & $0.314(0.106)$ & $1.390(0.043)$ & $0.478(0.072)$ & $0.327(0.032)$ & 0.000 & 0.251 & 0.651 & 0.165 & 0.383 & -6.02 & -1.89 \\
\hline 2 & 0.242 & 0.488 & 0.270 & $0.267(0.019)$ & $0.712(0.014)$ & $0.068(0.028)$ & $1.047(0.009)$ & $0.353(0.097)$ & $1.458(0.028)$ & $0.582(0.040)$ & $0.368(0.016)$ & 0.000 & 0.021 & 0.032 & 0.378 & 0.320 & -8.05 & -3.29 \\
\hline 16 & 0.271 & 0.441 & 0.288 & $0.273(0.068)$ & $0.674(0.055)$ & $0.036(0.113)$ & $0.983(0.051)$ & $0.520(0.339)$ & $1.528(0.126)$ & $0.636(0.141)$ & $0.389(0.053)$ & 0.000 & 1.000 & 1.000 & 1.000 & 1.000 & -2.52 & 1.74 \\
\hline 10 & 0.224 & 0.478 & 0.298 & $0.181(0.168)$ & $0.627(0.058)$ & $0.250(0.134)$ & $1.057(0.077)$ & $0.504(0.779)$ & $1.311(0.121)$ & $0.644(0.297)$ & $0.392(0.110)$ & 0.000 & 1.000 & 1.000 & 1.000 & 1.000 & -1.27 & -1.02 \\
\hline 26 & 0.286 & 0.429 & 0.285 & $0.264(0.071)$ & $0.590(0.049)$ & $0.121(0.103)$ & $0.957(0.030)$ & $0.453(0.334)$ & $1.375(0.115)$ & $0.764(0.155)$ & $0.433(0.050)$ & 0.000 & 0.968 & 0.949 & 0.840 & 0.977 & -3.96 & -1.42 \\
\hline 6 & 0.271 & 0.494 & 0.235 & $0.233(0.036)$ & $0.634(0.030)$ & $0.113(0.059)$ & $0.980(0.021)$ & $0.423(0.179)$ & $1.284(0.061)$ & $0.783(0.108)$ & $0.439(0.034)$ & 0.000 & 0.310 & 0.419 & 0.296 & 0.856 & -7.15 & -1.63 \\
\hline 29 & 0.359 & 0.344 & 0.297 & $0.371(0.058)$ & $0.524(0.034)$ & $0.122(0.080)$ & $1.017(0.027)$ & $0.493(0.239)$ & $1.524(0.100)$ & $0.813(0.125)$ & $0.449(0.038)$ & 0.000 & 0.291 & 0.895 & 0.766 & 0.652 & -5.05 & -1.15 \\
\hline 28 & 0.270 & 0.488 & 0.242 & $0.214(0.048)$ & $0.666(0.026)$ & $0.127(0.064)$ & $1.006(0.027)$ & $0.571(0.214)$ & $1.364(0.053)$ & $0.922(0.115)$ & $0.480(0.031)$ & 0.000 & 0.820 & 0.602 & 0.782 & 0.786 & -4.46 & -1.30 \\
\hline 18 & 0.292 & 0.474 & 0.234 & $0.239(0.037)$ & $0.669(0.025)$ & $0.089(0.058)$ & $0.997(0.014)$ & $0.591(0.172)$ & $1.411(0.053)$ & $0.996(0.097)$ & $0.499(0.024)$ & 0.000 & 0.001 & 0.207 & 0.074 & 0.109 & -9.74 & -2.20 \\
\hline 23 & 0.288 & 0.466 & 0.246 & $0.173(0.175)$ & $0.701(0.103)$ & $0.146(0.213)$ & $1.020(0.077)$ & $0.907(0.743)$ & $1.506(0.222)$ & $1.102(0.380)$ & $0.524(0.086)$ & 0.000 & 1.000 & 1.000 & 1.000 & 1.000 & -1.45 & 1.54 \\
\hline
\end{tabular}


Table B.6 (ctd): Industry-specific input shares $\left(\alpha_{J}\right)_{j}(J=N, M, K)$, output elasticities $\left(\widehat{\varepsilon}_{J}^{Q}\right)_{j}$, scale elasticity $\widehat{\lambda}_{j}$, joint market imperfections parameter $\widehat{\psi}_{j}$,

and corresponding price-cost mark-up $\widehat{\mu}_{j}$ and absolute extent of rent sharing $\widehat{\phi}_{j}$ or labor supply elasticity $\left(\widehat{\varepsilon}_{w}^{N}\right)_{j}$ by country

\begin{tabular}{|c|c|c|c|c|c|c|c|c|c|c|c|c|c|c|c|c|c|c|}
\hline \multicolumn{19}{|c|}{ THE NETHERLANDS (ctd) } \\
\hline \multicolumn{19}{|c|}{ Regime $R=I C-M O \quad[27 \%$ of industries, $22 \%$ of firms $]$} \\
\hline Ind. $j$ & $\left(\alpha_{N}\right) j$ & $\left(\alpha_{M}\right) j$ & $\left(\alpha_{K}\right) j$ & $\left(\widehat{\varepsilon}_{N}^{Q}\right)_{j}$ & $\left(\widehat{\varepsilon}_{M}^{Q}\right)_{j}$ & $\left(\widehat{\varepsilon}_{K}^{Q}\right)_{j}$ & $\widehat{\lambda}_{j}$ & $\widehat{\psi}_{j}$ & $\widehat{\mu}_{j}$ & $\widehat{\beta}_{j}$ & $\left(\widehat{\varepsilon}_{w}^{N}\right)_{j}$ & Sargan & Hansen & $\begin{array}{c}\text { Dif- } \\
\text { Hansen } \\
\text { (lev) } \\
\end{array}$ & $\begin{array}{c}\text { Dif- } \\
\text { Hansen } \\
\text { (L2-dif) }\end{array}$ & $\begin{array}{c}\text { Dif- } \\
\text { Hansen } \\
\text { (L3-dif) }\end{array}$ & $m 1$ & $m 2$ \\
\hline 3 & 0.148 & 0.458 & 0.394 & $0.555(0.219)$ & $0.540(0.112)$ & $0.041(0.290)$ & $1.135(0.083)$ & $-2.570(1.663)$ & $1.179(0.245)$ & $0.315(0.176)$ & $0.459(0.376)$ & 0.000 & 1.000 & 1.000 & 1.000 & 1.000 & -2.29 & -0.90 \\
\hline 30 & 0.305 & 0.407 & 0.288 & $0.607(0.098)$ & $0.466(0.075)$ & $0.052(0.162)$ & $1.126(0.029)$ & $-0.844(0.484)$ & $1.145(0.184)$ & $0.576(0.177)$ & $1.358(0.986)$ & 0.000 & 1.000 & 1.000 & 1.000 & 1.000 & -3.01 & -1.30 \\
\hline 1 & 0.146 & 0.646 & 0.208 & $0.252(0.046)$ & $0.712(0.036)$ & $0.058(0.072)$ & $1.022(0.018)$ & $-0.628(0.354)$ & $1.102(0.056)$ & $0.637(0.140)$ & $1.755(1.059)$ & 0.000 & 0.318 & 0.223 & 0.267 & 0.224 & -4.42 & -3.50 \\
\hline 12 & 0.231 & 0.383 & 0.386 & $0.541(0.196)$ & $0.592(0.125)$ & $0.031(0.276)$ & $1.163(0.096)$ & $-0.795(1.092)$ & $1.547(0.326)$ & $0.660(0.347)$ & $1.945(3.014)$ & 0.000 & 1.000 & 1.000 & 1.000 & 1.000 & -0.38 & -0.86 \\
\hline 24 & 0.264 & 0.409 & 0.327 & $0.433(0.108)$ & $0.480(0.065)$ & $0.087(0.155)$ & $1.000(0.050)$ & $-0.470(0.543)$ & $1.173(0.160)$ & $0.714(0.261)$ & $2.496(3.183)$ & 0.000 & 1.000 & 1.000 & 1.000 & 1.000 & -2.64 & 0.69 \\
\hline 22 & 0.288 & 0.416 & 0.296 & $0.550(0.211)$ & $0.577(0.182)$ & $-0.072(0.375)$ & $1.055(0.102)$ & $-0.520(1.137)$ & $1.388(0.439)$ & $0.728(0.494)$ & $2.672(6.661)$ & 0.000 & 1.000 & 1.000 & 1.000 & 1.000 & -2.53 & -1.42 \\
\hline 9 & 0.322 & 0.370 & 0.309 & $0.529(0.035)$ & $0.474(0.025)$ & $0.036(0.056)$ & $1.040(0.015)$ & $-0.361(0.168)$ & $1.284(0.068)$ & $0.781(0.088)$ & $3.560(1.830)$ & 0.000 & 0.080 & 0.234 & 0.459 & 0.447 & -8.25 & -1.34 \\
\hline 15 & 0.250 & 0.415 & 0.335 & $0.401(0.030)$ & $0.531(0.029)$ & $0.088(0.046)$ & $1.019(0.017)$ & $-0.326(0.158)$ & $1.280(0.070)$ & $0.797(0.085)$ & $3.928(2.057)$ & 0.000 & 0.179 & 0.125 & 0.275 & 0.518 & -6.69 & -0.97 \\
\hline \multicolumn{19}{|c|}{ Regime $R=P C-M O \quad[\mathbf{7 \%}$ of industries, $4 \%$ of firms $]$} \\
\hline Ind. $j$ & $\left(\alpha_{N}\right) j$ & $\left(\alpha_{M}\right) j$ & $\left(\alpha_{K}\right) j$ & $\left(\widehat{\varepsilon}_{N}^{Q}\right)_{j}$ & $\left(\widehat{\varepsilon}_{M}^{Q}\right)_{j}$ & $\left(\widehat{\varepsilon}_{K}^{Q}\right)_{j}$ & $\widehat{\lambda}_{j}$ & $\widehat{\psi}_{j}$ & $\widehat{\mu}_{j}$ & $\widehat{\beta}_{j}$ & $\left(\widehat{\varepsilon}_{w}^{N}\right)_{j}$ & Sargan & Hansen & $\begin{array}{c}\text { Dif- } \\
\text { Hansen } \\
(l e v) \\
\end{array}$ & $\begin{array}{c}\text { Dif- } \\
\text { Hansen } \\
\text { (L2-dif) }\end{array}$ & $\begin{array}{c}\text { Dif- } \\
\text { Hansen } \\
\text { (L3-dif) }\end{array}$ & $m 1$ & $m^{2}$ \\
\hline 8 & 0.240 & 0.475 & 0.285 & $0.500(0.051)$ & $0.465(0.051)$ & $0.128(0.090)$ & $1.093(0.021)$ & $-1.103(0.293)$ & $0.979(0.107)$ & $0.470(0.090)$ & $0.887(0.320)$ & 0.000 & 0.218 & 0.026 & 0.183 & 0.304 & -6.17 & $2-2.54$ \\
\hline 5 & 0.287 & 0.497 & 0.216 & $0.441(0.115)$ & $0.468(0.059)$ & $0.110(0.095)$ & $1.020(0.057)$ & $-0.595(0.424)$ & $0.943(0.119)$ & $0.613(0.181)$ & $1.584(1.212)$ & 0.000 & 1.000 & 1.000 & 1.000 & 1.000 & -2.06 & -0.83 \\
\hline \multicolumn{19}{|c|}{ Regime $R=P C-P R[\mathbf{3 \%}$ of industries, $\mathbf{1 \%}$ of firms $]$} \\
\hline Ind. $j$ & $\left(\alpha_{N}\right) j$ & $\left(\alpha_{M}\right) j$ & $\left(\alpha_{K}\right)_{j}$ & $\left(\widehat{\varepsilon}_{N}^{Q}\right)_{j}$ & $\left(\widehat{\varepsilon}_{M}^{Q}\right)_{j}$ & $\left(\widehat{\varepsilon}_{K}^{Q}\right)_{j}$ & $\widehat{\lambda}_{j}$ & $\widehat{\psi}_{j}$ & $\widehat{\mu}_{j}$ & & & Sargan & Hansen & $\begin{array}{c}\text { Dif- } \\
\text { Hansen } \\
\text { (lev) } \\
\end{array}$ & $\begin{array}{c}\text { Dif- } \\
\text { Hansen } \\
\text { (L2-dif) }\end{array}$ & $\begin{array}{c}\text { Dif- } \\
\text { Hansen } \\
\text { (L3-dif) }\end{array}$ & $m 1$ & $m^{2}$ \\
\hline 13 & 0.198 & 0.482 & 0.320 & $0.266(0.072)$ & $0.520(0.055)$ & $0.251(0.105)$ & $1.037(0.042)$ & $-0.263(0.442)$ & $1.079(0.114)$ & & & 0.000 & 0.905 & 0.999 & 0.995 & 1.000 & -3.06 & -1.07 \\
\hline
\end{tabular}

Notes: Robust standard errors in parentheses. Time dummies are included but not reported. Sargan, Hansen, Dif-Hansen: tests of overidentifying restrictions, asymptotically distributed as $\chi_{d f}^{2}$. $p$-values are reported. Dif-Hansen (lev) tests the validity of the 1-year lag of the first-differenced

inputs as instruments in the levels equation while Dif-Hansen (L2-dif)/(L3-dif) test the validity of the 2-/3-year lags of the inputs as instruments in

the first-differenced equation. $m 1$ and $m 2$ : tests for first-order and second-order serial correlation in the first-differenced residuals, asymptotically

distributed as $N(0,1)$. Industries within $R=P C$ - $P R$ and $R=I C-P R$ are ranked according to $\widehat{\mu}_{j}$, industries within $R=P C$ - $E B$ and $R=I C$ - $E B$ are ranked according to $\widehat{\phi}_{j}$ and industries within $R=P C-M O$ and $R=I C-M O$ are ranked according to $\widehat{\beta}_{j}$. 